\title{
SAMBA: Stochastic Analytical Model with a Bayesian Approach*
}

\author{
Marcos R. de Castro** \\ Solange N. Gouvea ${ }^{* * *}$ \\ André Minella**** \\ Rafael C. Santos ${ }^{* * * * *}$ \\ Nelson F. Souza-Sobrinho
}

\begin{abstract}
We develop and estimate a DSGE model for the Brazilian economy as part of the macroeconomic modeling framework of the Central Bank of Brazil. The model combines the building blocks of standard DSGE models (e.g., price and wage rigidities and adjustment costs) with the following features that better describe the Brazilian economy: (i) a fiscal authority pursuing an explicit target for the primary surplus; (ii) administered or regulated prices as part of the consumer price index; (iii) external finance for imports, which amplifies the effects of changes in external financial conditions on the economy; and (iv) imported goods used in the production of intermediate goods. It also includes the presence of financially constrained households. We estimate the model with Bayesian techniques, using data since 1999, when inflation targeting was implemented in Brazil. Evaluation based on impulse response functions, moment conditions, variance error decomposition, and initial forecasting exercises suggests that the model can be a useful tool for policy analysis and forecasting.
\end{abstract}

Keywords: DSGE model, Bayesian estimation, inflation targeting, Brazil.

JEL Codes: E17, E30, E52.

\footnotetext{
${ }^{*}$ Submitted in Dec 2014. Revised in Jan 2016. This project has benefited from the visits of Jaromir Benes, Larry Christiano, Stephen Murchison, and Alessandro Rebucci, courses given by Fabio Canova, Kai Christoffel, Michel Juillard, Tommaso Monacelli, Roberto Motto, and Carl Walsh, and a visit to the Central Bank of Chile, to which we are very grateful. We are also grateful to Tomiê Sugahara and José R. da Costa e Silva for their participation in early stages of the project, and Angelo Fasolo for his comments and suggestions.

${ }^{* *}$ Banco Central do Brasil, Brazil. E-mail: marcos.castro@bcb.gov.br

${ }^{* * *}$ Banco Central do Brasil, Brazil. E-mail: solange.gouvea@bcb.gov.br

**** Banco Central do Brasil, Brazil. E-mail: andre.minella@bcb.gov.br

***** Banco Central do Brasil, Brazil. E-mail: rafael.santos@bcb.gov.br, rafael.santos@fgv.br

****** Banco Central do Brasil, Brazil. E-mail: nelson.souza@bcb.gov.br, nsobrinho@imf.org
}

Brazilian Review of Econometrics

v. SAMBA, n 1, pp. 103-170 November 2015 


\section{Introduction}

Many central banks have put great effort into developing applied dynamic stochastic general equilibrium (DSGE) models. ${ }^{1}$ In this paper, we build and estimate a DSGE model for the Brazilian economy, which we call SAMBA — Stochastic Analytical Model with a Bayesian Approach. The model was developed to be part of the macroeconomic modeling framework of the Central Bank of Brazil (BCB), providing support for policy analysis and forecasting.

The model embeds prominent features of the Brazilian economy, such as

(i) the fiscal authority pursues an explicit target for the primary surplus-to-GDP ratio, in accordance with the fiscal regime in place since 1999; and

(ii) significant part of consumer prices is regulated by the government (administered or regulated prices), following contract rules or other non-market based procedures.

The model also includes two other features that are less usual in standard DSGE models, but relevant in the case of the Brazilian economy. First, as in many other countries with relatively large manufacturing sectors, most of Brazilian imports are inputs in the production function rather than final consumption goods. Hence, following McCALLUM and NELSON (2000) and MURCHISON and RENNISON (2006), we treat imports as inputs that are used to produce differentiated sectoral goods. As a result, the local-currency price of imports is a key component of the marginal cost of domestic firms that face price rigidity. Second, as in the data, we assume that a fraction of imports is financed abroad. Hence, shocks to external financial conditions have an extra channel of transmission to the domestic economy. In particular, an increase in the country risk premium raises the relative cost of investment goods - more intensive in the use of imported inputs - thus negatively affecting aggregate investment.

In developing the building blocks of our model, we have borrowed many insights from ADOLFSON et al. (2007, 2008), CHRISTIANO et al. (2005), CHRISTOFFEL et al. (2008), MEDINA and SOTO (2007), MURCHISON and RENNISON (2006), and SMETS and WOUTERS (2003, 2007). The features of our small open economy model include wage and sectoral price rigidities, as well as real frictions in the form of habit persistence in consumption and adjustment costs in investment, exports and imports. The model also includes both monetary and fiscal authorities, whose behavior is modeled according to the actual institutional arrangements, that is, targets for inflation and for the primary fiscal balance. We also assume that a fraction of households is financially constrained, which breaks up Ricardian equivalence, and is consistent with the fact that a large proportion

\footnotetext{
${ }^{1}$ For instance, the central banks of Canada (ToTEM), Chile (MAS), Colombia (PATACON), England (BEQM), Euro Area (NAWM), New Zealand (KITT), Norway (NEMO), Peru (MEGAD), and Sweden (RAMSES).
} 
of Brazilians have no or limited access to credit. Furthermore, the country risk premium responds not only to domestic fundamentals (net external debt-to-GDP ratio) but also to shifts in foreign investors' preference for risk.

We estimated the model using Bayesian techniques, which are more suitable for the estimation of this class of models. DSGE models often have a large number of parameters - many of which are weakly identified - and the sample size is usually small. This is particularly relevant for our estimation, whose sample starts in 1999, when inflation targeting was implemented in Brazil, and ends in 2010. Furthermore, Bayesian techniques formally incorporate expert's knowledge in the form of priors, which not only complement the information available in the data but also help to estimate otherwise weakly identifiable parameters. Judgment is put into practice by including beliefs to which some level of accuracy is attached. This procedure is implemented in a coherent and clear-cut way in the Bayesian estimation. Moreover, the resulting posterior distributions of the parameters are used in the construction of credible intervals for different exercises.

We assess the performance of the model by examining the behavior of the underlying impulse response functions, moment conditions, variance error decomposition, and forecasting exercises. Overall, the performance is quite satisfactory, allowing the use of the model as a tool for policy analysis and forecasting. In particular, it can assess the impact of different shocks to the economy. The impulse response functions generated by the model, even considering the whole set of shocks, are, in general, consistent with the theory and results for other countries, as well as with the empirical evidence available for Brazil. The forecasting exercises are also encouraging, enabling the use of the model as part of a well-defined forecasting framework.

The current BCB macroeconomic modeling framework comprises a suite of models, including small and medium-size semi-structural models, vector autoregression (VAR) models and auxiliary structures that are used to answer specific policy issues. The DSGE model is an important additional tool to that framework. It provides a theoretically consistent device to deal with a broad range of issues.

Section 2 describes the model and equilibrium conditions. Section 3 provides the data and estimation details. Section 4 presents the main results, and Section 5 concludes. $^{2}$

\section{Model Overview}

SAMBA is a small open economy model that combines what are now standard features of DSGE models — such as wage and price rigidities, habit persistence in consumption and capital adjustment costs — with specific features of the Brazilian economy, such as firms subject to regulated prices, imports in the production

\footnotetext{
${ }^{2}$ Extra material, including the equilibrium conditions along the balanced growth path, and the steady state and log-linear version of the model, can be found in the working paper version of this paper (http://www.bcb.gov.br/pec/wps/ingl/wps239.pdf).
} 
process, external finance of imports, and a country-specific fiscal rule.

In the model, there are several types of agents: households, domestic producers, importing firms, and government. There are two types of households. Both have the same endowment of time, which is allocated between labor and leisure, but differ with respect to their participation in capital, asset and labor markets. The first type - optimizing households - owns the capital stock and all shares of the firms and are able to accumulate financial assets. The second type - ruleof-thumb households - is financially constrained. They do not have access to financial markets and simply consume whatever labor income they earn.

Domestic producers are classified into three groups: domestic input producers, intermediate good producers, and final good assemblers. Producers of intermediate goods are grouped into four different sectors, according to the final good supplied: private consumption goods, government consumption goods, investment goods, and exported goods. We assume different technologies for producing each good, and the production process in each sector is carried out in three stages. In the first stage, a representative firm produces a non-tradable domestic input using capital and labor. Still in the first stage, importing firms buy differentiated goods from abroad and sell them to assemblers that transform those goods into a homogeneous input to be used in the production process. In the second stage, a large number of intermediate good producers combine domestic and imported inputs and produce differentiated varieties. The share of domestic and imported inputs varies across sectors. In the third and final stage, sectoral assemblers combine the intermediate varieties into sectoral homogeneous goods, which are sold domestically and abroad.

Physical capital, domestic input and all final goods are traded in competitive markets. On the other hand, workers, importers and domestic intermediate good producers are monopolistic competitors, facing wage or price rigidity à la CALVO (1983). Therefore, there are two layers of nominal rigidity in the model. The first layer comprises stickiness of input prices - wages and import prices. The second layer involves stickiness in the prices of the intermediate varieties used to produce the four final goods. As in CHRISTIANO et al. (2007), all prices are set in the currency of the buyer ("pricing to market"), including exports.

The government in the model is represented by fiscal and monetary authorities. The fiscal authority levies lump-sum taxes on optimizing households, makes transfers to firms, and demands government goods. It also levies a tax on rule-ofthumbers' income, which can be understood as net of government transfers. Most of the transfers in Brazil are directed to lower income people, who usually have less access to financial and credit markets. For reasons of parsimony, we have kept the tax structure in the model as simple as possible. Government also issues domestic bonds, which are held by optimizing households. Decisions regarding government spending are subject to an empirical fiscal rule, which is meant to describe the actual behavior of the fiscal authority, whereby it targets the primary surplus-toGDP ratio. The monetary authority, in turn, targets the CPI inflation by setting 
the interest rate according to a forward-looking Taylor-type rule, in line with the inflation targeting framework.

Agents in the domestic economy take as given the prices and allocations of the world economy. For simplicity, we treat the variables describing the rest of the world as exogenous stochastic processes. However, in the background and whenever necessary we treat domestic and foreign economies as having analogous features, i.e., similar type of agents and production structure. For instance, Brazil's imports are inputs to the domestic production, and exports are inputs to the production of foreign firms. The main linkages between the domestic and the world economy arise from international trade in goods, asset markets and loans. Domestic households issue foreign-currency bonds abroad — external bonds for short - and domestic firms borrow from abroad through foreign-currency loans to finance imports - external finance or loans for short. We assume that asset markets are incomplete and the law of one price does not hold, so the model features imperfect risk sharing and partial exchange rate pass-through in the short run.

In the following subsections we describe in detail the problems and constraints faced by each economic agent, and derive the associated equilibrium conditions. For ease of exposition, we adopt the following conventions. We express the level of growing (non-stationary) variables by upper-case letters, say $X_{t}$, and the level of detrended (stationary) variables by adding tilde, $\tilde{X}_{t}$. The long-run (steady state) levels of detrended or stationary variables are expressed without subscript $t, \tilde{X}$, and the linear or log-linear deviations from the steady state are represented by lower-case letters without tilde, $x_{t}$. We use the letter $Z_{t}^{S}$ to denote the level of the shock process $S$, and $z_{t}^{S}$ to denote its linear version. Innovations to the shock processes are represented by $\varepsilon_{t}^{S}$. Additionally, we use $Q_{t}^{H}$ to denote the price of good $H$ relative to the price of consumption goods, which is used as numéraire in the model. We index foreign variables by an asterisk '*', say $X_{t}^{*}$, nominal variables by the superscript ${ }^{~} n, X_{t}^{n}$, and optimally chosen prices by a lowercase ${ }^{\circ}, X_{t}^{o}$. In our timing convention, flow variables decided in period $t$ are indexed by $t$, whereas stock variables (e.g., capital and bond holdings) chosen at $t$ are index by $t+1$. Whenever required, we use subscript $j$ to identify economic agents and the subscript $i$ to denote time window. In the model, time is equivalent to a calendar quarter and is indexed by $t=0,1,2, \ldots$ We ignore population growth.

\section{$2.1 \quad$ Households}

The economy is populated by a mass one of households indexed by $j \in[0,1]$. Optimizing households $(O)$ account for a fraction $1-\varpi_{R T}$ of the population, and rule-of-thumb households $(R T)$ account for the remaining share. As mentioned before, optimizing households are not financially constrained and choose their consumption, savings and investment in a forward-looking manner. These households use three different assets or savings instruments — physical capital, non-contingent 
one-period government bonds and non-contingent one-period bonds issued abroad - to smooth their consumption over time. On the other hand, rule-of-thumb households have no access to credit, capital and asset markets and do not earn firm dividends. They simply spend their entire labor income on consumption goods. We also assume that both types of households supply differentiated labor services, setting their wages in a monopolistically competitive labor market, subject to Calvo-type contracts.

\subsubsection{Optimizing Households}

Each optimizing household, indexed by $j \in O$, chooses consumption, physical capital and financial assets to maximize the expected discounted flow of utility,

$$
\max _{\left\{C_{j, t}, B_{j, t+1}, B_{j, t+1}^{*}, K_{j, t+1}, I_{j, t}\right\}} E_{0} \sum_{t=0}^{\infty} \beta^{t} u\left(C_{j, t}, N_{j, t}\right),
$$

subject to the flow budget constraint

$$
\begin{aligned}
& P_{t}^{C} C_{j, t}+P_{t}^{I} I_{j, t}+\frac{B_{j, t+1}}{R_{t} S_{t}^{B}}+\frac{S_{t} B_{j, t+1}^{*}}{R_{t}^{*} S_{t}^{B *}} \leq \\
& W_{j, t}^{n} N_{j, t}+R_{t}^{K, n} K_{j, t}+B_{j, t}+S_{t} B_{j, t}^{*}+D_{j, t}^{n}-T_{j, t}^{O, n}+\Xi_{j, t}^{n}, \forall j \in O,
\end{aligned}
$$

and to the law of motion of capital

$$
K_{j, t+1}=(1-\delta) K_{j, t}+\left[1-S\left(\frac{I_{j, t}}{Z_{t}^{I} I_{j, t-1}}\right)\right] I_{j, t}
$$

where $E_{0}$ is the expectations operator, $\beta \in(0,1)$ is the time discount factor, $C_{j, t}$ is the consumption level, and $N_{j, t}$ is differentiated labor. In the budget constraint, $P_{t}^{C}$ is the price of consumption goods, $I_{j, t}$ is investment, $P_{t}^{I}$ is the price of investment goods, $B_{j, t}$ denotes one-period government domestic bonds, $R_{t}$ is the domestic gross interest rate, $S_{t}^{B}$ is the domestic risk premium, $S_{t}$ is the exchange rate (defined as units of domestic currency per units of foreign currency), $B_{j, t}^{*}$ represents one-period foreign-currency bonds issued abroad, $R_{t}^{*}$ is the external gross interest rate, $S_{t}^{B^{*}}$ is the country risk premium, $W_{j, t}^{n}$ is the household-specific nominal wage rate, $R_{t}^{K, n}$ is the net nominal rental rate of capital, $K_{j, t}$ is physical capital, $D_{j, t}^{n}$ denotes nominal dividends received from the firms, $T_{j, t}^{O, n}$ is lump-sum nominal net taxes, and $\Xi_{j, t}^{n}$ are nominal state-contingent securities. We adopt the convention that $B_{j, t}$ and $B_{j, t}^{*}$ represent nominal bonds issued in $t-1$ and maturing in $t$, and $K_{j, t}$ are capital holdings from $t-1$. So $B_{j, t+1}, B_{j, t+1}^{*}$ and $K_{j, t+1}$ are decided in $t$. In the law of motion of capital, $\delta$ is the depreciation rate of capital, $S($.$) is a convex adjustment cost, and Z_{t}^{I}$ is an investment-specific technology shock. The function $S($.$) satisfies S\left(Z^{Z}\right)=S^{\prime}\left(Z^{Z}\right)=0$ and $S^{\prime \prime}\left(Z^{Z}\right) \equiv \vartheta_{I}>0$, 
where $Z^{Z}$ is the steady-state growth rate of the technology process $Z_{t}$, which we define in more details below.

We assume the following functional form for the instantaneous utility function, augmented by external habit persistence:

$$
u\left(C_{j, t}, N_{j, t}\right)=Z_{t}^{C}\left[\frac{\left(C_{j, t}-\kappa C_{t-1}^{O}\right)^{1-\sigma}}{1-\sigma}-Z_{t}^{1-\sigma} \frac{\psi}{1+\eta}\left(N_{j, t}\right)^{1+\eta}\right],
$$

where $C_{t}^{O}$ is the average consumption of optimizing households, $Z_{t}^{C}$ is a shock to the household's intertemporal preference, $Z_{t}$ is the level of technology, $\sigma$ is the inverse of the intertemporal elasticity of substitution, $\psi>0$ is a weight parameter, $\kappa \in[0,1)$ is a parameter governing the external habit persistence, and $\eta$ is the inverse of labor supply elasticity. As in ERCEG et al. (2006), we assume that preferences over leisure shift with the level of technology so that the model is consistent with balanced growth path, even when preferences over consumption are not logarithmic.

The household purchases consumption goods $C_{j, t}$ at the price level $P_{t}^{C}$, investment goods $I_{j, t}$ at the price $P_{t}^{I}$, buys or sells discounted values of one-period government bonds $B_{j, t+1}$, and buys or sells one-period foreign-currency bonds $B_{j, t}^{*}$ issued abroad. Government bonds pay the risk-free interest rate $R_{t}$ (in gross terms), which is also the interest rate controlled by the monetary authority. However, the effective return received by households also includes an exogenous financial intermediation premium, denoted by $S_{t}^{B}$, which we interpret as a domestic risk premium (see SMETS and WOUTERS (2007) and CHRISTOFFEL et al. (2008)). It represents a wedge between the interest paid by the government and the interest received by the household. This premium is rebated in a lump-sum way to optimizing households, being included in $T_{j, t}^{O, n}$. In practice, it can also be used as capturing changes in financial conditions that affect both consumption and investment at the same direction. In fact, a positive shock to $S_{t}^{B}$ reduces both consumption and investment, generating a positive co-movement between those two aggregate demand components, in contrast to the intertemporal preference shock, which generates a negative relationship.

The value in domestic currency of bonds issued abroad is given by $S_{t} B_{j, t+1}^{*}$. The effective return on these bonds depends on an external premium over the riskless international interest rate (hereafter, country risk premium), denoted by $S_{t}^{B^{*}}$. For simplicity, we assume that households do not internalize the fact that their demand for foreign bonds may shift the country risk premium.

Optimizing households have four sources of income. The first is labor income, which depends on the household-specific nominal wage rate $W_{j, t}^{n}$ and the amount $N_{j, t}$ of differentiated labor services provided to firms. The second is capital income, from renting physical capital $K_{j, t}$ at the competitive net nominal rental rate of capital $R_{t}^{K, n}$. The third source of income is the return accrued from bond holdings, and the last one is dividends $D_{j, t}^{n}$ received from firms. There are two 
remaining factors that also affect the nominal income of optimizing households: a net lump-sum nominal tax $T_{t}^{O, n}$ levied by the government, which is the same across optimizing households, and nominal state-contingent securities $\Xi_{j, t}^{n}$. These securities are traded amongst optimizing households and provide full insurance against labor income risk. They are just a technical device to make aggregation tractable under wage rigidity. ${ }^{3}$

We assume that capital accumulation is costly and subject to investmentspecific innovations. As usual, the adjustment cost given by the function $S($.) helps to replicate the hump-shaped response of investment to monetary policy shocks.

For convenience, we split households' decisions into two steps. In the first step, they take the labor income as given and choose the optimal allocations of consumption, investment and assets, and in the second stage they choose their desired wage. The first-order conditions associated with the choices of $C_{j, t}, B_{j, t+1}$, $B_{j, t+1}^{*}, K_{j, t+1}$ and $I_{j, t}$ are, respectively:

$$
\begin{gathered}
\Lambda_{j, t}=Z_{t}^{C}\left(C_{j, t}-\kappa C_{t-1}^{O}\right)^{-\sigma}, \\
\Lambda_{j, t}=\beta E_{t}\left(\Lambda_{j, t+1} \frac{P_{t}^{C}}{P_{t+1}^{C}} R_{t} S_{t}^{B}\right), \\
\Lambda_{j, t}=\beta E_{t}\left(\Lambda_{j, t+1} \frac{P_{t}^{C}}{P_{t+1}^{C}} \frac{S_{t+1}}{S_{t}} R_{t}^{*} S_{t}^{B^{*}}\right), \\
\Lambda_{j, t} Q_{j, t}^{K}=\beta E_{t} \Lambda_{j, t+1}\left(\frac{R_{t+1}^{K, n}}{\left.P_{t+1}^{C}+Q_{j, t+1}^{K}(1-\delta)\right),}\right. \\
\Lambda_{j, t} \frac{P_{t}^{I}}{P_{t}^{C}}=\beta E_{t}\left[\Lambda_{j, t+1} Q_{j, t+1}^{K} S^{\prime}\left(\frac{I_{j, t+1}}{Z_{t+1}^{I} I_{j, t}}\right)\left(\frac{I_{j, t+1}}{Z_{t+1}^{I} I_{j, t}}\right)^{2} Z_{t+1}^{I}\right] \\
+\Lambda_{j, t} Q_{t}^{K}\left[1-S\left(\frac{I_{j, t}}{Z_{t}^{I} I_{j, t-1}}\right)-S^{\prime}\left(\frac{I_{j, t}}{Z_{t}^{I} I_{j, t-1}}\right) \frac{I_{j, t}}{Z_{t}^{I} I_{j, t-1}}\right],
\end{gathered}
$$

where $\Lambda_{j, t}$ is the Lagrange multiplier associated with $j$ th household's real budget constraint, and $Q_{j, t}^{K}$ is the Lagrange multiplier associated with the law of motion of capital. The former is the real shadow price of the consumption good, whereas the latter is the real shadow value of capital.

\footnotetext{
${ }^{3}$ In particular, they ensure that the equilibrium consumption of all optimizing households is the same, regardless of their labor income. Otherwise, we would have to keep track of the wealth distribution arising from agent heterogeneity. To simplify the model even further, we assume that physical and financial wealth is equally distributed across optimizing households at the beginning of time and that dividends received from firms in each period are also equally distributed across optimizing households.
} 
Along the symmetric equilibrium, all optimizing households make identical choices, thus we can drop the subscript $j$ from the equations above. With this in mind, the per capita consumption of optimizing households, $C_{t}^{O}$, implied by conditions (4) and (5) is given by the following consumption Euler equation:

$$
Z_{t}^{C}\left(C_{t}^{O}-\kappa C_{t-1}^{O}\right)^{-\sigma}=\beta E_{t}\left[Z_{t+1}^{C}\left(C_{t+1}^{O}-\kappa C_{t}^{O}\right)^{-\sigma} \frac{R_{t} S_{t}^{B}}{\Pi_{t+1}^{C}}\right],
$$

where $\Pi_{t+1}^{C}=P_{t+1}^{C} / P_{t}^{C}$ is the gross CPI inflation rate between periods $t$ and $t+1$.

Combining (5) and (6) yields the uncovered interest rate parity (UIP) condition:

$$
E_{t}\left(\frac{R_{t} S_{t}^{B}}{\Pi_{t+1}^{C}} \Lambda_{t+1}\right)=E_{t}\left(\frac{S_{t+1}}{S_{t}} \frac{R_{t}^{*} S_{t}^{B^{*}}}{\Pi_{t+1}^{C}} \Lambda_{t+1}\right) .
$$

We define the consumption-based real exchange rate as the price of the foreign consumption good $P_{t}^{C^{*}}$, expressed in local currency $S_{t} P_{t}^{C^{*}}$, relative to the price of the domestic consumption good as

$$
Q_{t} \equiv \frac{S_{t} P_{t}^{C^{*}}}{P_{t}^{C}}
$$

and plug it into the UIP condition in order to obtain a convenient expression for the real exchange rate in terms of the real interest rate differential (UIP in real terms):

$$
E_{t}\left(\frac{R_{t} S_{t}^{B}}{\Pi_{t+1}^{C}} \Lambda_{t+1}\right)=E_{t}\left(\frac{Q_{t+1}}{Q_{t}} \frac{R_{t}^{*} S_{t}^{B^{*}}}{\Pi_{t+1}^{C *}} \Lambda_{t+1}\right),
$$

where $\Pi_{t}^{C^{*}}=P_{t}^{C^{*}} / P_{t-1}^{C^{*}}$. We assume that $S_{t}^{B^{*}}$ depends only on aggregate variables describing both domestic and external fundamentals as follows:

$$
S_{t}^{B^{*}}=S^{B^{*}}\left\{\exp \left[-\varphi_{B}^{*}\left(B_{t+1}^{*^{y}}-B^{*^{y}}\right)+\varphi_{V}^{*}\left(V_{t}^{*}-V\right)\right]\right\} Z_{t}^{B^{*}},
$$

where $\varphi_{B}^{*}$ and $\varphi_{V}^{*}$ are positive parameters, $B_{t+1}^{*^{y}}$ is net foreign assets-to-GDP ratio, $V_{t}^{*}$ describes foreign investors' risk aversion, and $Z_{t}^{B^{*}}$ is a shock that captures movements in the country risk premium associated with domestic exogenous factors, such as political uncertainty and others. The variables $S^{B^{*}}, \tilde{B}^{*^{y}}$ and $V$ are the corresponding steady-state values. Net foreign assets-to-GDP ratio is defined as $B_{t+1}^{* y} \equiv \frac{S_{t} B_{t+1}^{*}}{P_{t}^{Y} Y_{t}}$, where $P_{t}^{Y}$ is the GDP deflator and $Y_{t}$ is real GDP. The equation describes what the literature calls pull and push factors, corresponding respectively to domestic and external factors. The external debt-elastic country risk premium usually enters small open economy models as a technical device to render net foreign assets stationary. Moreover, there is empirical evidence that the country risk premium of emerging-market economies like Brazil reacts to the 
net foreign assets position (pull factor). By the same token, the evidence suggests that movements in foreign investors' attitude towards risk also shift the country risk premium (push factor). On the other hand, we assume that the domestic risk premium follows an autoregressive process of order one - $\operatorname{AR}(1)$ :

$$
S_{t}^{B}=\left(S^{B}\right)^{1-\rho_{B}}\left(S_{t-1}^{B}\right)^{\rho_{B}} \exp \left\{\varepsilon_{t}^{B}\right\} .
$$

Turning to the wage setting, we can think of an "employment agency" that aggregates the differentiated labor services provided by each household into a homogeneous labor input $N_{t}$, which is then supplied to domestic firms in competitive input markets (ERCEG et al., 2000). We assume that the employment agency combines the differentiated labor services through a Dixit-Stiglitz aggregator:

$$
N_{t}=\left(\int_{0}^{1}\left(N_{j, t}\right)^{\frac{\epsilon_{t}^{W}-1}{\epsilon_{t}^{W}}} d j\right)^{\frac{\epsilon_{t}^{W}}{\epsilon_{t}^{W}-1}},
$$

where $\epsilon_{t}^{W}>1, \forall t$, is a time-varying elasticity of substitution that may shift the wage markup. The optimization problem of the employment agency is given by:

$$
\max _{N_{j, t}}\left\{W_{t}^{n}\left(\int_{0}^{1}\left(N_{j, t}\right)^{\frac{\epsilon_{t}^{W}-1}{\epsilon_{t}^{W}}} d j\right)^{\frac{\epsilon_{t}^{W}}{\epsilon_{t}^{W}-1}}-\int_{0}^{1} W_{j, t}^{n} N_{j, t} d j\right\},
$$

where $W_{t}^{n}$ is the aggregate nominal wage rate.

We assume that the employment agency makes deals with firms on behalf of all households - optimizers and rule-of-thumbers. The solution to the problem faced by the employment agency implies the following demand for the differentiated labor service of the $j$ th household:

$$
N_{j, t}=\left(\frac{W_{j, t}^{n}}{W_{t}^{n}}\right)^{-\epsilon_{t}^{W}} N_{t}, \quad \forall j \in[0,1] .
$$

The break-even condition for the competitive employment agency pins down the aggregate wage index:

$$
W_{t}^{n}=\left(\int_{0}^{1}\left(W_{j, t}^{n}\right)^{1-\epsilon_{t}^{W}} d j\right)^{\frac{1}{1-\epsilon_{t}^{W}}} .
$$

We assume that optimizing households face Calvo lottery for wages. In each period, with probability $1-\theta_{W}$, household $j \in O$ may be able to renegotiate its nominal wage contract with the employment agency. With probability $\theta_{W}$, household $j \in O$ is unable to optimally change its nominal wage, but it is permitted 
to updated the wage contract taking into account past wage inflation, CPI inflation and productivity gains, according to the following indexation rule:

$$
W_{j, t}^{n}=\Upsilon_{t}^{W} W_{j, t-1}^{n}, \forall j \in O
$$

where $\Upsilon_{t}^{W}$ is the indexation factor, given by:

$$
\Upsilon_{t}^{W}=\left(\Pi_{t-1}^{W}\right)^{\omega_{W}}\left(Z_{t-1}^{Z} \Pi_{t-1}^{C}\right)^{1-\omega_{W}}
$$

where $\omega_{W} \in[0,1]$ is an indexation parameter, $\Pi_{t}^{W} \equiv W_{t}^{n} / W_{t-1}^{n}$ is the gross inflation rate of nominal wages, and $Z_{t}^{Z}=Z_{t} / Z_{t-1}$ is the stochastic and timevarying gross growth rate of technology (proxy for labor productivity growth). Since nominal wages embody productivity growth, this indexation rule ensures that in steady state all nominal wages grow at the rate $Z^{Z} \Pi^{C}$. The rule considers the fact that workers try to keep the purchasing power of their wages and, at the same time, take into account the behavior of aggregate wage, as an indicator of labor market conditions or due to relative wage concerns.

Each optimizing household who is able to renegotiate optimally its wage contract evaluates the disutility of labor relative to the utility arising from the real labor income. The optimal wage-setting problem is the following:

$$
\max _{\left\{W_{j, t}^{n}\right\}} E_{t} \sum_{i=0}^{\infty}\left(\theta_{W} \beta\right)^{i}\left[-Z_{t}^{C} Z_{t+i}^{1-\sigma} \frac{\psi}{1+\eta}\left(N_{j, t+i}\right)^{1+\eta}+\Lambda_{t+i}\left(\frac{W_{j, t}^{n}}{P_{t+i}^{C}} N_{j, t+i}\right)\right], \quad \forall j \in O,
$$

subject to the wage demand equation (15) and the wage indexation rule (17). The first-order condition describing the optimal wage-setting decision is the following in the symmetric equilibrium:

$$
\begin{gathered}
E_{t} \sum_{i=0}^{\infty}\left(\theta_{W} \beta\right)^{i}\left[\Lambda_{t+i}\left(\epsilon_{t+i}^{W}-1\right)\left(W_{t}^{n, o}\right)^{-\epsilon_{t+i}^{W}}\left(\frac{\Upsilon_{t, t+i}^{W}}{W_{t+i}^{n}}\right)^{1-\epsilon_{t+i}^{W}} \frac{W_{t+i}^{n}}{P_{t+i}^{C}} N_{t+i}\right]= \\
E_{t} \sum_{i=0}^{\infty}\left(\theta_{W} \beta\right)^{i} \\
{\left[Z_{t+i}^{C} Z_{t+i}^{1-\sigma} \epsilon_{t+i}^{W} \psi\left(W_{t}^{n, o}\right)^{-\epsilon_{t+i}^{W}(1+\eta)-1}\left(\frac{\Upsilon_{t, t+i}^{W}}{W_{t+i}^{n}}\right)^{-\epsilon_{t+i}^{W}(1+\eta)} N_{t+i}^{1+\eta}\right]}
\end{gathered}
$$

where

$$
\Upsilon_{t, t+i}^{W}=\left\{\begin{array}{cc}
1, & i=0 \\
\prod_{k=1}^{i}\left(\Pi_{t-1+k}^{W}\right)^{\omega_{W}}\left(Z_{t-1+k}^{Z} \Pi_{t-1+k}^{C}\right)^{1-\omega_{W}}, i \geq 1
\end{array}\right.
$$

is the wage indexation factor, accumulated between $t$ and $t+i$, and $W_{t}^{n, o}$ is the optimal wage. 
Using equations (16) and (17) and the fact that the optimal wage is the same across optimizing households, we obtain the law of motion for the wage rate of optimizing households

$$
W_{t}^{O, n}=\left[\theta_{W}\left(\Upsilon_{t}^{W} W_{t-1}^{n}\right)^{1-\epsilon_{t}^{W}}+\left(1-\theta_{W}\right)\left(W_{t}^{n^{o}}\right)^{1-\epsilon_{t}^{W}}\right]^{\frac{1}{1-\epsilon_{t}^{W}}} .
$$

Thus, equilibrium conditions for optimizing households can be described by equations (4), (7), (8), (9), (11), (18), (19), and (20), plus the law of motion of capital (2).

\subsubsection{Rule-of-Thumb Households}

Rule-of-thumb households just consume their disposable labor income as follows:

$$
P_{t}^{C} C_{j, t}=\left(1-T_{t}^{R T}\right) W_{j, t}^{n} N_{j, t}, \quad \forall j \in R T,
$$

where $T_{t}^{R T}$ is the marginal net tax rate (out of transfers) levied by the government on the labor income of rule-of-thumbers. As in MEDINA and SOTO (2007), we assume that each rule-of-thumber sets its wage equal to the average wage rate of optimizing households, that is, $W_{j, t}^{R T, n}=W_{t}^{O, n}$. Since both types of households face the same labor demand schedule (15), labor services provided by a typical ruleof-thumber are equal to the average provided by optimizing households, $N_{j, t}^{R T}=$ $N_{t}^{O}$. Therefore, wages and labor services of rule-of-thumbers are equal to their average in the economy. As a result, we can write the consumption of a typical rule-of-thumb household $C_{t}^{R T}$ as follows:

$$
C_{t}^{R T}=\left(1-T_{t}^{R T}\right) W_{t} N_{t},
$$

where $W_{t} \equiv W_{t}^{n} / P_{t}^{C}$ is the real wage rate.

\section{$2.2 \quad$ Firms}

As mentioned before, the production of sectoral goods in the SAMBA model is carried out in three stages. In the first stage, there are domestic input producers and importers. The representative domestic producer operates a standard constant returns-to-scale technology that provides the combined services of capital and labor to sectoral intermediate good producers. In parallel, importers buy differentiated inputs abroad and resell them to an assembler of imported goods. In turn, the assembler transforms the differentiated goods into a homogeneous imported input, which is sold to the sectoral intermediate good producers.

In the second stage, there is a continuum of intermediate good producers indexed by $j \in[0,1]$ in each sector - private consumption goods, government consumption goods, investment goods, and exports - that operate constant returnsto-scale technologies that transform the imported input and the bundle of capital 
and labor into sectoral differentiated goods. Lastly, in the third stage, sectoral assemblers combine the differentiated goods into corresponding sectoral homogeneous goods.

The production in the second stage also requires the use of financial services. In particular, intermediate good producers must finance a fraction of their imported inputs with working capital borrowed from abroad. These working capital requirements capture the fact that a sizeable fraction of Brazilian imports is financed by foreign banks and suppliers. The requirements also help to account for the fact that financial crises may disrupt trade credit and trade flows.

\subsubsection{Sectoral Assemblers}

For convenience, we start describing the behavior of home firms operating in the third stage of production. In this stage, perfectly competitive sectoral goods assemblers combine the sectoral intermediate varieties into a sectoral homogenous good through a standard Dixit-Stiglitz aggregator:

$$
Y_{t}^{H}=\left(\int_{0}^{1}\left(Y_{j, t}^{H}\right)^{\frac{\epsilon_{H, t}^{P}-1}{\epsilon_{H, t}^{P}}} d j\right)^{\frac{\epsilon_{H, t}^{P}}{\epsilon_{H, t^{P}}^{P}}}
$$

where $H=C, I, G, X$ denotes the corresponding sector (private consumption, investment, government consumption, and exports, respectively), $Y_{t}^{H}$ is the sectoral output and $Y_{j, t}^{H}$ is the differentiated variety produced by intermediate good firm j. $\epsilon_{H, t}^{P}>1$ is a time-varying elasticity of substitution between the differentiated varieties. This time-dependent elasticity will imply a time-varying markup in the goods market. We will interpret a shift in the markup as a "cost-push" shock to sectoral inflation Phillips curves.

Sectoral goods assemblers choose the optimal amounts of each variety and break even in equilibrium. The problem solved by the assembler in sector $H$ is given by:

$$
\max _{\left\{Y_{j, t}^{H}\right\}}\left\{P_{t}^{H} Y_{t}^{H}-\int_{0}^{1} P_{j, t}^{H} Y_{j, t}^{H} d j\right\}, \forall H, \forall j \in H,
$$

subject to equation (22), where $P_{t}^{H}$ is the aggregate price of home good $H$, and $P_{j, t}^{H}$ is the price of intermediate variety $j$. The assumption of pricing to market means that $P_{t}^{H}$ and $P_{j, t}^{H}$, for $j=X$, is expressed in foreign currency. The problem solution yields the following optimal demand for the $j$ th variety:

$$
Y_{j, t}^{H}=\left(\frac{P_{j, t}^{H}}{P_{t}^{H}}\right)^{-\epsilon_{H, t}^{P}} Y_{t}^{H}, \forall H, \forall j \in H
$$


The break-even condition for the sectoral good assembler implies the following sectoral price index:

$$
P_{t}^{H}=\left(\int_{0}^{1}\left(P_{j, t}^{H}\right)^{1-\epsilon_{H, t}^{P}} d j\right)^{\frac{1}{1-\epsilon_{H, t}^{P}}}, \forall H
$$

\subsubsection{Domestic Input Producers}

We now turn to the first production stage, starting with the representative domestic input producer. This firm operates in perfectly competitive markets and produces the domestic input $Y_{t}^{D}$ through a standard Cobb-Douglas technology using capital and labor:

$$
Y_{t}^{D}=Z_{t}^{D} K_{t}^{\alpha}\left(Z_{t}\left(N_{t}-\bar{N}\right)\right)^{1-\alpha},
$$

where $K_{t}$ is physical capital, $N_{t}$ is total labor input, $\bar{N}$ is overhead labor, which we assume constant over time, $Z_{t}^{D}$ is a domestic transitory technology shock, and $Z_{t}$ is a stochastic trend embodying permanent shifts in technology. The overhead labor helps to smooth the rate of change of total labor input over the business cycle. The temporary technology shock evolves according to an $\mathrm{AR}(1)$ process:

$$
\log \left(Z_{t}^{D}\right)=\rho_{D} \log \left(Z_{t-1}^{D}\right)+\varepsilon_{t}^{D},
$$

where $\varepsilon_{t}^{D}$ is the innovation. The growth rate of the stochastic trend is defined as $Z_{t}^{Z}=Z_{t} / Z_{t-1}$, which follows:

$$
\log \left(Z_{t}^{Z}\right)=\left(1-\rho_{Z}\right) Z^{Z}+\rho_{Z} \log \left(Z_{t-1}^{Z}\right)+\varepsilon_{t}^{Z},
$$

where $Z^{Z}$ is the long-run growth rate of technology, in gross terms, and $\varepsilon_{t}^{Z}$ is the innovation.

The domestic input producer takes all prices as given and chooses the optimal amounts of capital and labor services as to minimize total input costs, subject to the technology constraint (25):

$$
\min _{\left\{K_{t}, N_{t}\right\}}\left\{R_{t}^{K, n} K_{t}+W_{t}^{n} N_{t}-T_{t}^{D, n}+P_{t}^{D}\left(Y_{t}^{D}-Z_{t}^{D} K_{t}^{\alpha}\left(Z_{t}\left(N_{t}-\bar{N}\right)\right)^{1-\alpha}\right)\right\},
$$

where $T_{t}^{D, n}$ is a lump-sum transfer from the government, which is equal to the overhead labor cost. The transfer is simply a technical device that ensures a welldefined solution to the problem above. $P_{t}^{D}$ is the Lagrange multiplier associated with the technology constraint, which in equilibrium will be equal to the nominal marginal cost of the domestic input producer. Cost minimization implies the following optimal demands for capital and labor, respectively:

$$
R_{t}^{K, n}=\alpha P_{t}^{D} \frac{Y_{t}^{D}}{K_{t}},
$$




$$
W_{t}^{n}=(1-\alpha) P_{t}^{D} \frac{Y_{t}^{D}}{N_{t}-\bar{N}} .
$$

Substituting (28) and (29) into the technology constraint (25) yields the following expression for the unit cost associated with the choice of domestic inputs:

$$
P_{t}^{D}=\left(\frac{1}{\alpha} R_{t}^{K, n}\right)^{\alpha}\left(\frac{1}{1-\alpha} \frac{W_{t}^{n}}{Z_{t}}\right)^{1-\alpha} \frac{1}{Z_{t}^{D}} .
$$

\subsubsection{Importers}

Now we look at the behavior of importing firms. We assume that there is a continuum of importing firms indexed by $j \in[0,1]$ that buy differentiated goods from the rest of the world. Each importing firm buys a distinct variety which is then sold in a monopolistically competitive market to an assembler of imported goods. The assembler transforms the differentiated inputs into a homogenous good, which is finally sold to domestic intermediate good producers. Similar to the sectoral assemblers described above, the assembler of imported goods also bundles the differentiated varieties through a Dixit-Stiglitz aggregator:

$$
M_{t}=\left(\int_{0}^{1}\left(M_{j, t}\right)^{\frac{\epsilon_{M}-1}{\epsilon_{M}}} d j\right)^{\frac{\epsilon_{M}}{\epsilon_{M}-1}}, \epsilon_{M}>1,
$$

where $M_{t}$ is the homogenous imported good, $M_{j, t}$ is the imported variety $j$, and $\epsilon_{M}$ is the elasticity of substitution across varieties. The problem of the imported goods assembler is analogous to the home good assembler's problem, that is,

$$
\max _{\left\{M_{j, t}\right\}}\left\{P_{t}^{M} M_{t}-\int_{0}^{1} P_{j, t}^{M} M_{j, t} d j\right\},
$$

subject to (31), where $P_{j, t}^{M}$ is the local-currency price charged by importing firm $j$, and $P_{t}^{M}$ is the local-currency aggregate import price. The first-order and zeroprofit conditions imply the following demand for the $j$ th imported good and aggregate import price index:

$$
\begin{gathered}
M_{j, t}=\left(\frac{P_{j, t}^{M}}{P_{t}^{M}}\right)^{-\epsilon_{M}} M_{t} \\
P_{t}^{M}=\left(\int_{0}^{1}\left(P_{j, t}^{M}\right)^{1-\epsilon_{M}} d j\right)^{\frac{1}{1-\epsilon_{M}}} .
\end{gathered}
$$

Monopolistic importing firms face price rigidity à la Calvo when setting their prices. The presence of price rigidity in the import sector helps to slow down the pass-through of the exchange rate to domestic prices. In each period, each 
importing firm $j$ faces a constant probability $1-\theta_{M}$ of resetting its prices according to market conditions. Otherwise, with probability $\theta_{M}$ it simply updates the price considering past inflation of imported goods and the CPI inflation target, according to the following indexation rule:

$$
P_{j, t}^{M}=\Upsilon_{t}^{M} P_{j, t-1}^{M},
$$

where $\Upsilon_{t}^{M}$ is the indexation factor, given by

$$
\Upsilon_{t}^{M}=\left(\Pi_{t-1}^{M}\right)^{\omega_{M}}\left(\bar{\Pi}_{t}^{C}\right)^{1-\omega_{M}}
$$

where $\omega^{M} \in[0,1]$ is an indexation parameter, $\bar{\Pi}_{t}^{C}$ is the CPI inflation target in gross terms, and $\Pi_{t-1}^{M}$ is the gross inflation rate of imported goods, defined as $\Pi_{t}^{M}=P_{t}^{M} / P_{t-1}^{M}$. In the long run, the imported goods inflation (in local currency) converges to the inflation target.

The value of importing firm profits is given by $P_{j, t}^{M} M_{j, t}-S_{t} P_{t}^{M^{*}} M_{j, t}$, where $P_{t}^{M^{*}}$ is the foreign-currency price of the $j$ th imported variety. The importing firm that receives the price signal in period $t$ maximizes the real value of the expected discounted flow of its profits along the paths over which its own price is not adjusted optimally:

$$
\max _{\left\{P_{j, t}^{M}\right\}} E_{t} \sum_{i=0}^{\infty}\left(\theta_{M} \beta\right)^{i} \Lambda_{t, t+i}\left(\Upsilon_{t, t+i}^{M} P_{j, t+i}^{M}-S_{t+i} P_{t+i}^{M^{*}}\right) M_{j, t+i},
$$

subject to the demand constraint (32) and the indexation rule (34), where $\Lambda_{t, t+i} \equiv$ $\Lambda_{t+i} /\left(\Lambda_{t} \Pi_{t, t+i}^{C}\right)$ is optimizing households' marginal rate of substitution between nominal income in periods $t$ and $t+i$, and $\Upsilon_{t, t+i}^{M}$ is the indexation factor accumulated between $t$ and $t+i$. Since all firms that are able to change their prices face the same import cost, they choose the same optimal price along the symmetric equilibrium $\left(P_{t}^{M^{o}}=P_{j, t}^{M}\right)$. Taking the first-order condition yields an expression for the optimal price analogous to the one presented in equation (42). From equation (33), we derive a law of motion for the imported good price index analogous to that recorded in equation (43). Therefore, the equations concerning the indexation rule (34), the indexation factor (35), the optimal price and the law of motion determine the behavior of the price of imported goods.

\subsubsection{Sectoral Intermediate Producers}

The decisions of inputs and prices made by intermediated good producers can be broken down into two problems.

Input Choices In the second production stage, there is a continuum of intermediate good producers indexed by $j \in[0,1]$ in each sector. These firms combine 
domestic and imported inputs through the following CES production function:

$$
Y_{j, t}^{H}=\left[\left(\varpi_{H}\right)^{\frac{1}{\epsilon_{H}}}\left(Y_{H, j, t}^{D}\right)^{\frac{\epsilon_{H}-1}{\epsilon_{H}}}+\left(1-\varpi_{H}\right)^{\frac{1}{\epsilon_{H}}}\left[\left(1-\Gamma_{H}^{M}\left(r_{j, t}^{H}\right)\right) M_{j, t}^{H}\right]^{\frac{\epsilon_{H}-1}{\epsilon_{H}}}\right]^{\frac{\epsilon_{H}}{\epsilon_{H}-1}}
$$

where as before $H=C, I, G, X, M_{j, t}^{H}$ is the imported input, $\Gamma_{H}^{M}\left(r_{j, t}^{H}\right)$ is an adjustment cost associated with the imported input, which is a function of the importsto-output ratio $r_{j, t}^{H} \equiv M_{j, t}^{H} / Y_{j, t}^{H}, \varpi_{H} \in[0,1]$ is the weight of the domestic input in the production function, and $\epsilon_{H}>0$ is the elasticity of substitution between the two inputs. We assume the following functional form for the adjustment cost:

$$
\Gamma_{H}^{M}\left(r_{j, t}^{H}\right)=\frac{\vartheta_{H}^{M}}{2}\left(\left(Z_{H, t}^{M}\right)^{-\frac{1}{\vartheta_{H}^{M}}} \frac{M_{j, t}^{H} / Y_{j, t}^{H}}{M_{t-1}^{H} / Y_{t-1}^{H}}-1\right)^{2}
$$

where $\vartheta_{H}^{M}>0$ and $Z_{H, t}^{M}$ is a shock to the adjustment cost that shifts the demand for imports. This formulation is based on BAYOUMI et al. (2004) and CHRISTOFFEL et al. (2008), and implies that it is costly for the firm to adjust its current imports-to-output ratio relative to past sectoral imports-to-output ratio. The above formulation satisfies $\Gamma_{H, t}^{M \prime}=\Gamma_{H}^{M}=0$ in the steady state, where $\Gamma_{H, t}^{M \prime}$ is the derivative of the adjustment cost function, and has two convenient properties. First, it helps to slow down the response of the import share to fluctuations in the relative price of imported inputs. Second, it allows imported inputs to respond quickly to shifts in the demand for the home good. In other words, imports respond more slowly to price movements induced by changes in the exchange rate or external prices than to domestic demand fluctuations. This feature is consistent with the empirical evidence for Brazil.

Each sectoral intermediate good producer takes as given the input prices and chooses the combination of inputs that minimizes its total cost

$$
\min _{\left\{Y_{j, t}^{D}, M_{j, t}^{H}\right\}}\left\{P_{t}^{D} Y_{H, j, t}^{D}+\left[1+\iota_{H}\left(R_{t}^{*} S_{t}^{B^{*}}-1\right)\right] P_{t}^{M} M_{j, t}^{H}\right\}, \quad \forall j \in H,
$$

subject to the technology constraint (36). The parameter $\iota_{H}$ is the fraction of the imported input that must be financed abroad through intra-period loans at the net interest rate $R_{t}^{*} S_{t}^{B^{*}}-1$. This working capital constraint captures some of the observed trade credit frictions and helps to replicate the negative co-movement between investment and the country risk premium. It amplifies the effect of shocks to the country risk premium on imports. ${ }^{4}$ Let $M C_{j, t}^{H, n}$ be the Lagrange multiplier (in nominal terms) associated with the technology constraint and define $P_{H, t}^{M} \equiv$

\footnotetext{
${ }^{4}$ Using the estimated model, we observe that, in the case of a shock to the country risk premium, the reduction in imports is around $30 \%$ higher (in the first two years) when compared to a model with $\iota_{H}=0$ (keeping all other parameters constant).
} 
$\left[1+\iota_{H}\left(R_{t}^{*} S_{t}^{B^{*}}-1\right)\right] P_{t}^{M}$ as the effective import cost in sector $H$. We assume that all firms in the same sector face the same technology and effective import cost and have adjustment costs that do not depend upon firm's history. Thus $r_{j, t}^{H}$ is the same across firms and so is the real marginal cost. Therefore, we can drop the subscript $j$ from $r_{j, t}^{H}$ and $M C_{j, t}^{H}$. Taking into account these properties, the first-order conditions characterizing the optimal choices of $Y_{j, t}^{D}$ and $M_{j, t}^{H}$ can be written respectively as:

$$
\begin{gathered}
Y_{H, j, t}^{D}=\varpi_{H}\left(\frac{P_{t}^{D}}{M C_{t}^{H}}\right)^{-\epsilon_{H}} Y_{j, t}^{H}, \\
M_{j, t}^{H}=\left(\frac{1-\varpi_{H}}{1-\Gamma_{H, t}^{M}}\right)\left(\frac{P_{H, t}^{M}}{\left(1-\Gamma_{H, t}^{M}-\Gamma_{H, t}^{M \dagger}\right) M C_{t}^{H, n}}\right)^{-\epsilon_{H}} Y_{j, t}^{H},
\end{gathered}
$$

where $\Gamma_{H}^{M \dagger}\left(r_{t}^{H}\right) \equiv \Gamma_{H}^{M \prime}\left(r_{t}^{H}\right) M_{t}^{H}$. Note that $\Gamma_{H}^{M}$ and $\Gamma_{H}^{M \dagger}$ are also the same across firms. Lastly, substituting the optimal input-output ratios into the technology constraint pins down the nominal marginal cost in sector $H$ :

$$
M C_{t}^{H, n}=\left[\varpi_{H}\left(P_{t}^{D}\right)^{1-\epsilon_{H}}+\left(1-\varpi_{H}\right)\left(\frac{P_{H, t}^{M}}{1-\Gamma_{H, t}^{M}-\Gamma_{H, t}^{M \dagger}}\right)^{1-\epsilon_{H}}\right]^{\frac{1}{1-\epsilon_{H}}}
$$

which is simply a weighted average of the costs of domestic and imported inputs. Note that the share of imports varies across sectors. In particular, we assume that the production of government goods does not use imported inputs, that is, $\varpi_{G}=1$. Thus government consumption is a purely non-tradable good whose nominal marginal cost of production is given by $M C_{t}^{G, n}=P_{t}^{D}$.

Price Setting in the Government Consumption and Investment Goods Sectors We now describe the price choices of the intermediate good producers in the sectors that produce government consumption and investment goods. As before, prices are set according to Calvo contracts. In each period $t$, with probability $1-\theta_{H}$, each intermediate good firm $j \in H$ - where in this subsection $H=G, I$ - sets its price optimally, and with probability $\theta_{H}$ it adjusts the price according to the following indexation rule:

$$
P_{j, t}^{H}=\Upsilon_{t}^{H} P_{j, t-1}^{H}, \quad j \in H=G, I,
$$

with the following indexation factor that weights past sectoral inflation and the inflation target:

$$
\Upsilon_{t}^{H}=\left(\Pi_{t-1}^{H}\right)^{\omega_{H}}\left(\bar{\Pi}_{t}^{C}\right)^{1-\omega_{H}},
$$


where $\omega_{H} \in[0,1]$ is sector $H$ indexation parameter, and the gross inflation rate in sector $H=G, I$ is given by $\Pi_{t}^{H}=P_{t}^{H} / P_{t-1}^{H}$.

Intermediate good producers, when setting prices optimally, maximize the value of the expected discounted flow of profits:

$$
\max _{\left\{P_{j, t}^{H}\right\}} E_{t} \sum_{i=0}^{\infty}\left(\theta_{H} \beta\right)^{i} \Lambda_{t, t+i}\left(\Upsilon_{t, t+i}^{H} P_{j, t}^{H}-M C_{t+i}^{H, n}\right) Y_{j, t+i}^{H}, \quad \forall j \in H=G, I,
$$

subject to the demand constraint (23) and indexation rule (40), where the nominal marginal cost $M C_{t+i}^{H, n}$ is given by equation (39), and $\Upsilon_{t, t+i}^{H}$ is the indexation factor accumulated between $t$ and $t+i$.

The first-order condition with respect to the optimal price $P_{t}^{H^{o}}=P_{j, t}^{H}$, along the symmetric equilibrium, is given by:

$$
\begin{aligned}
& E_{t} \sum_{i=0}^{\infty}\left(\theta_{H} \beta\right)^{i} \Lambda_{t, t+i}\left(\frac{\Upsilon_{t, t+i}^{H}}{P_{t+i}^{H}}\right)^{1-\epsilon_{H, t+i}^{P}}\left(P_{t}^{H^{o}}\right)^{-\epsilon_{H, t+i}^{P}} P_{t+i}^{H} Y_{t+i}^{H}\left(\epsilon_{H, t+i}^{P}-1\right)= \\
& E_{t} \sum_{i=0}^{\infty}\left(\theta_{H} \beta\right)^{i} \Lambda_{t, t+i}\left(\frac{\Upsilon_{t, t+i}^{H}}{P_{t+i}^{H}}\right)^{-\epsilon_{H, t+i}^{P}}\left(P_{t}^{H^{o}}\right)^{-\epsilon_{H, t+i}^{P}-1} M C_{t+i}^{H, n} Y_{t+i}^{H} \epsilon_{H, t+i}^{P} \cdot(42)
\end{aligned}
$$

Using equation (24), we derive the following law of motion for the sectoral price index $P_{t}^{H}$ in sector $H=G, I$ :

$$
P_{t}^{H}=\left[\theta_{H}\left(\Upsilon_{t}^{H} P_{t-1}^{H}\right)^{1-\epsilon_{H, t}^{P}}+\left(1-\theta_{H}\right)\left(P_{t}^{H^{o}}\right)^{1-\epsilon_{H, t}^{P}}\right]^{\frac{1}{1-\epsilon_{H, t}^{P}}} .
$$

Therefore, conditions (40)-(43) determine the behavior of the prices of government consumption and investment goods.

Price Setting in the Consumption Goods Sector We have two types of intermediate producers in the consumption goods sector. They have the same technology, solve the same cost minimization problem and face similar downwardsloping demand curve for their products. Nevertheless, they do differ with respect to their pricing policies. A fraction $1-\varpi_{A}$ of firms in the consumption goods sector choose their price in the same way the intermediate good producers of the other three sectors do. We call this group freely-set price firms, denoting this set by $F$. In each period a firm $j \in F$ faces a constant probability $1-\theta_{F}$ of choosing its price optimally and a probability $\theta_{F}$ of adjusting its price according to an indexation rule, which is similar to (41):

$$
P_{j, t}^{F}=\Upsilon_{t}^{F} P_{j, t-1}^{F}, \quad \forall j \in F,
$$


where the indexation factor is a weighted average of past overall CPI inflation and the inflation target:

$$
\Upsilon_{t}^{F}=\left(\Pi_{t-1}^{C}\right)^{\omega_{F}}\left(\bar{\Pi}_{t}^{C}\right)^{1-\omega_{F}}
$$

with weight $\omega_{F} \in[0,1]$. To be more consistent with actual informal price indexation schemes, the rule includes the inflation of the (overall) CPI instead of that of freely-set prices.

On the other hand, if the firm is allowed to choose its price optimally, it does so by solving the usual price optimization problem:

$$
\max _{\left\{P_{j, t}^{F}\right\}} E_{t} \sum_{i=0}^{\infty}\left(\theta_{F} \beta\right)^{i} \Lambda_{t, t+i}\left(\Upsilon_{t, t+i}^{F} P_{j, t}^{F}-M C_{t+i}^{C, n}\right) Y_{j, t+i}^{F}, \quad \forall j \in F
$$

subject to the demand constraint (23) and indexation rule (44), where $\Upsilon_{t, t+i}^{F}$ is the indexation factor accumulated between $t$ and $t+i$, and $M C_{t+i}^{C, n}$ is the nominal marginal cost incurred in the production of consumption goods, given by equation (39).

In the symmetric equilibrium, the optimal freely-set price $P_{t}^{F^{o}}$ is determined by the usual pricing condition, analogous to that presented in equation (42). Using equation (24), we can find the law of motion for the freely-set price index, analogous to the one in equation (43).

We now turn to the fraction $\varpi_{A}$ of consumption good producers. A firm indexed by $j \in\left[0, \varpi_{A}\right]$ is not free to choose its own price and must follow an exogenous pricing policy. Their prices are regulated or administered by the government. They include the prices of oil by-products, public utilities (electricity, water, telephone), bus fares, medications etc., and account for about a third of the overall CPI. ${ }^{5}$ Their prices are either set by the government or follow contracts settled with government agencies. Administered prices are less sensitive to demand conditions and are usually set in a backward-looking manner (MINELLA et al., 2003). We denote this set of firms by $A$, where $A \cup F=C$.

Let $P_{j, t}^{A}$ be the price of firm $j \in A$. We assume that, in each period $t$, a fraction $\theta_{A}$ of firms are drawn randomly from the set $A$ and are allowed to set their prices according to a pre-specified rule $\Upsilon_{t}^{A}$. The remaining fraction $1-\theta_{A}$ of firms that were not drawn by the rule simply update their prices according to the inflation

\footnotetext{
${ }^{5}$ To simplify the model we assume that all producers of consumption goods have identical technology and only differ in their pricing decisions. Modeling administered price firms as belonging to a different sector would add adittional undesired complexity. Our interest is in the differences in terms of price settting and not in the particular behavior of the production of those groups. See FREITAS and BUGARIN (2007) for a different approach, where they develop a multi-sector but simpler model to study the welfare and monetary policy implications of administered prices.
} 
target $\bar{\Pi}_{t}^{C} \cdot{ }^{6}$ Therefore,

$$
P_{j, t}^{A}=\left\{\begin{array}{l}
\Upsilon_{t}^{A} P_{j, t-1}^{A}, \text { with probability } \theta_{A} \\
\bar{\Pi}_{t}^{C} P_{j, t-1}^{A}, \text { with probability } 1-\theta_{A}
\end{array}\right.
$$

In practice, administered prices are usually allowed to change once a year. So we set $\theta_{A}=1 / 4$. Electricity and telephone rates explicitly follow contract-based rules, which mandate price adjustments according to the past four-quarter CPI inflation, the past four-quarter change in the General Price Index (IGP) - which is largely affected by the exchange rate $^{7}$ — and past changes in costs. Since the model does not have an equivalent to the IGP, the pricing rule will capture this factor through the CPI inflation and movements in the real exchange rate. The majority of the other items of administered prices, in practice, follow past fourquarter CPI inflation very closely. Taking this into account, we chose the following functional form for the indexation factor $\Upsilon_{t}^{A}$ :

$$
\Upsilon_{t}^{A}=\bar{\Upsilon}^{A}\left[\left(\prod_{j=1}^{4} \Pi_{t-j}^{C}\right)\left(\frac{Q_{t-1}}{Q_{t-5}}\right)^{v_{A}^{1}}\left(\frac{M C_{t-1}^{C}}{M C_{t-5}^{C}}\right)^{v_{A}^{2}}\right]^{\chi_{A}}\left(Q_{t}^{F}\right)^{\left(1-\chi_{A}\right)}\left(Z_{t}^{A}\right)^{\frac{1}{\theta_{A}}}
$$

where $\bar{\Upsilon}^{A} \equiv\left(\bar{\Pi}^{C}\right)^{1-4 \chi_{A}}$ is a constant ensuring that in steady state $\Upsilon^{A}$ is equal to the steady-state inflation target $\bar{\Pi}^{C}, M C_{t}^{C}=M C_{t}^{C, n} / P_{t}^{C}$ is the real marginal cost of the consumption goods sector, $v_{A}^{1}$ and $v_{A}^{2}$ are positive weights (total weight is given by $\left.1+v_{A}^{1}+v_{A}^{2}\right)$, and $Q_{t}^{F}=P_{t}^{F} / P_{t}^{C}$ is the relative freely-set price, raised to the exponent $\left(1-\chi_{A}\right)$, which ensures that freely-set and administered prices do not diverge permanently. The term $Z_{t}^{A}$ is an $\operatorname{AR}(1)$ process that captures shifts in the administered prices that are not modeled explicitly. Its exponent is just a convenient normalization. The rule captures key features of the behavior of administered prices in Brazil: i) backward-looking nature; ii) indexation has long lags (up to five quarters); and iii) key role played by the CPI inflation, but also allowing for the effects of changes in the exchange rate and production costs.

Because all administered price firms always update their prices randomly and since the rule $\Upsilon_{t}^{A}$ depends only upon aggregate variables, we can define the overall administered price index as follows:

$$
P_{t}^{A} \equiv\left(\frac{1}{\varpi_{A}} \int_{j \in A}\left(P_{j, t}^{C}\right)^{1-\epsilon_{C, t}^{P}} d j\right)^{\frac{1}{1-\epsilon_{C, t}^{P}}}
$$

\footnotetext{
${ }^{6}$ Since the long-run inflation rate is positive, this is simply a technical requirement in order to prevent permanent distortion in relative prices.

${ }^{7}$ IGP is comprised of the Broad Producer Price Index (60\%), Consumer Price Index (30\%), and Civil Construction Cost Index (10\%).
} 
Solving for the integral and simplifying further yields the law of motion for administered prices, which in turn implies the following equation for the administered price inflation:

$$
\Pi_{t}^{A}=\left[\theta_{A}\left(\Upsilon_{t}^{A}\right)^{1-\epsilon_{C, t}^{P}}+\left(1-\theta_{A}\right)\left(\bar{\Pi}_{t}^{C}\right) 1-\epsilon_{C, t}^{P}\right]^{\frac{1}{1-\epsilon_{C, t}^{P}}}
$$

where $\Pi_{t}^{A}=P_{t}^{A} / P_{t-1}^{A}$. Note that, in the long run, $\Upsilon^{A}=\bar{\Pi}^{C}$ and all administered price firms will adjust their prices according to the steady-state inflation target.

Starting from equation (24), the aggregate CPI can be expressed as a weighted average of the freely-set and administered price indices:

$$
P_{t}^{C}=\left[\varpi_{A}\left(P_{t}^{A}\right)^{1-\epsilon_{C, t}^{P}}+\left(1-\varpi_{A}\right)\left(P_{t}^{F}\right)^{1-\epsilon_{C, t}^{P}}\right]^{\frac{1}{1-\epsilon_{C, t}^{P}}} .
$$

We can then derive the (overall) CPI inflation, which is a weighted average of the inflation rates of administered and freely-set prices:

$$
\Pi_{t}^{C}=\left[\varpi_{A}\left(\Pi_{t}^{A} \frac{P_{t-1}^{A}}{P_{t-1}^{C}}\right)^{1-\epsilon_{C, t}^{P}}+\left(1-\varpi_{A}\right)\left(\Pi_{t}^{F} \frac{P_{t-1}^{F}}{P_{t-1}^{C}}\right)^{1-\epsilon_{C, t}^{P}}\right]^{\frac{1}{1-\epsilon_{C, t}^{P}}}
$$

where $\Pi_{t}^{F}=P_{t}^{F} / P_{t-1}^{F}$. As in the data, the CPI inflation in the model displays a slow-moving component with strong backward-looking dynamics $\left(\Pi_{t}^{A}\right)$, and a component that is more susceptible to forward-looking behavior $\left(\Pi_{t}^{F}\right)$, although also affected by backward-looking behavior (indexation parameter $\omega_{F}$ ). These features help to replicate the actual Brazilian inflation dynamics, which display relatively high persistence overtime and slow response to changes in the monetary policy stance.

Therefore, the behavior of consumer prices is described by the equations regarding the indexation rule (44), the indexation factor (45), the optimal price and the law of motion for freely-set prices, the law of motion for administered prices (47), and the behavior of the overall CPI (49).

Price Setting in the Exported Goods Sector The price setting in the exported goods sector is analogous to that in the previous subsection, except for the fact that exporting firms set their prices in foreign currency. Let $P_{j, t}^{X}$ be the foreign-currency price of the variety sold by the $j$ th intermediate producer of the exported good. In each period $t$, with probability $1-\theta_{X}$, each intermediate good firm $j \in X$ sets its price optimally, and with probability $\theta_{X}$ it adjusts the price according to the following indexation rule:

$$
P_{j, t}^{X}=\Upsilon_{t}^{X} P_{j, t-1}^{X},
$$


where the indexation factor combines past sectoral inflation in foreign currency and the CPI inflation abroad:

$$
\Upsilon_{t}^{X}=\left(\Pi_{t-1}^{X}\right)^{\omega_{X}}\left(\Pi_{t-1}^{*}\right)^{1-\omega_{X}},
$$

with indexation parameter $\omega_{X} \in[0,1]$, and the gross inflation rate in the export goods sector given by $\Pi_{t}^{X}=P_{t}^{X} / P_{t-1}^{X}$.

The producer of the intermediate exported good who sets its price optimally maximizes the real value of the expected discounted flow of profits in local currency as follows:

$$
\max _{\left\{P_{j, t}^{X}\right\}} E_{t} \sum_{i=0}^{\infty}\left(\theta_{X} \beta\right)^{i} \Lambda_{t, t+i}\left(\Upsilon_{t, t+i}^{X} S_{t+i} P_{j, t}^{X}-M C_{t+i}^{X, n}\right) Y_{j, t+i}^{X},
$$

subject to the demand constraint (23) and indexation rule (50), where $\Upsilon_{t, t+i}^{X}$ is the indexation factor accumulated between $t$ and $t+i$, and the nominal marginal cost is given by equation (39).

Along the symmetric equilibrium, $P_{j, t}^{X^{o}}=P_{t}^{X}$, the first-order condition with respect to $P_{j, t}^{X}$ is analogous to that presented in equation (42). In turn, the law of motion of the export price index $P_{t}^{X}$ is analogous to the one in equation (43).

Therefore, the behavior of export good prices can be described by equations (50), (51), and those concerning the optimal price and the law of motion.

\subsubsection{Foreign Importers}

We assume that exports $X_{t}$ from Brazil is a homogeneous good before it leaves the dock, but it is a differentiated good in the world market. By symmetry with the domestic economy, the Brazilian exported good is used as a production input in the rest of the world (ROW). The export assembler ships the Brazilian good abroad at the foreign-currency price $P_{t}^{X^{*}}$. In turn, foreign producers combine imports from Brazil, $M_{t}^{*}$, and inputs produced in the ROW, $Y_{t}^{D^{*}}$. By symmetry with the domestic economy, the foreign production function is the following:

$$
Y_{t}^{*}=\left[\left(\varpi^{*}\right)^{\frac{1}{\epsilon^{*}}}\left[\left(1-\Gamma_{t}^{M^{*}}\right) M_{t}^{*}\right]^{\frac{\epsilon^{*}-1}{\epsilon^{*}}}+\left(1-\varpi^{*}\right)^{\frac{1}{\epsilon^{*}}}\left(Y_{t}^{D^{*}}\right)^{\frac{\epsilon^{*}-1}{\epsilon^{*}}}\right]^{\frac{\epsilon^{*}}{\epsilon^{*}-1}},
$$

where, of course, $M_{t}^{*}=X_{t}, \epsilon^{*}>0$ is the elasticity of substitution between Brazilian exports and the inputs produced in the ROW, $\varpi^{*}$ is the share of Brazilian exports in the ROW output bundle, and $\Gamma_{t}^{M^{*}}$ is an import adjustment cost, given by:

$$
\Gamma_{t}^{M^{*}}=\frac{\vartheta^{M^{*}}}{2}\left(\left(Z_{t}^{M^{*}}\right)^{-\frac{1}{\vartheta^{*}}} \frac{X_{t} / Y_{t}^{*}}{X_{t-1} / Y_{t-1}^{*}}-1\right)^{2},
$$


with $\vartheta^{M^{*}} \geq 0$.

The foreign producer chooses the optimal combination of Brazilian and ROW inputs as to minimize its total cost:

$$
\min _{\left\{X_{t}, Y_{t}^{D^{*}}\right\}}\left\{P_{t}^{D^{*}} Y_{t}^{D^{*}}+P_{t}^{X^{*}} X_{t}\right\}
$$

subject to the technology constraint (52). The first-order condition with respect to $X_{t}$ generates the world demand for Brazilian exports:

$$
X_{t}=\left(\frac{\varpi^{*}}{1-\Gamma_{t}^{M^{*}}}\right)\left(\frac{Q_{t}^{X^{*}}}{\left(1-\Gamma_{t}^{M^{*}}-\Gamma_{t}^{M^{* \dagger}}\right)}\right)^{-\epsilon^{*}} Y_{t}^{*},
$$

where as before $\Gamma_{t}^{M^{* \dagger}}$ is the derivative of the adjustment cost function, $Q_{t}^{X^{*}} \equiv$ $P_{t}^{X^{*}} / P_{t}^{*}$ is the relative price of Brazilian exports in foreign currency, and $P_{t}^{*}$ is the Lagrange multiplier associated with the constraint. Since we are not modeling the ROW in a full way, we assume from now on that $P_{t}^{*}=P_{t}^{C^{*}}$, that is, the price of foreign final goods is equal to the price of foreign consumption goods.

\subsection{Government}

Government comprises monetary and fiscal authorities. They follow rules that are meant to describe in a concise way the modus operandi of the Brazilian monetary and fiscal policies, given by explicit targets for inflation and for the public sector primary surplus-to-GDP ratio.

\subsubsection{Monetary Policy}

The goal of the monetary authority is to stabilize CPI inflation around the inflation target, using as instrument the nominal interest rate, according to the following forward-looking Taylor-type rule:

$$
R_{t}=\left(R_{t-1}\right)^{\gamma_{R}}\left[\frac{\left(\bar{\Pi}_{t-3, t+1}^{C}\right)^{\frac{1}{4}}\left(Z^{Z}\right)^{\sigma}}{\beta}\left(\frac{\left(E_{t} \Pi_{t, t+4}^{C}\right)^{\frac{1}{4}}}{\left(\bar{\Pi}_{t, t+4}^{C}\right)^{\frac{1}{4}}}\right)^{\gamma_{\Pi}}\left(\frac{Y_{t}}{Z_{t} \tilde{Y}}\right)^{\gamma_{Y}}\right]^{1-\gamma_{R}} Z_{t}^{R}
$$

where $\gamma_{R} \in(0,1)$ is an interest-rate smoothing parameter, $\gamma_{\Pi}>1, \gamma_{Y}>0, Z_{t}^{R}$ captures monetary policy shocks, $\Pi_{t, t+4}^{C} \equiv \prod_{i=1}^{4} \Pi_{t+i}^{C}=P_{t+4}^{C} / P_{t}^{C}$ is the fourquarter inflation rate, and $\bar{\Pi}_{t, t+4}^{C} \equiv \prod_{i=1}^{4} \bar{\Pi}_{t+i}^{C}$ is the four-quarter inflation target. In Brazil, the actual target refers to the inflation in the calendar year. It is set in June for the calendar year that starts one year and a half later. Thus we assume 
the target is known by agents four quarters in advance in the model. We use a fourquarter horizon for inflation in order to capture the forward-looking nature of the conduct of monetary policy. The term $\left(\bar{\Pi}_{t-3, t+1}^{C}\right)^{\frac{1}{4}}\left(Z^{Z}\right)^{\sigma} / \beta$ is the equilibrium nominal interest rate (or the nominal natural rate of interest).

The rule also allows for a direct role played by the output gap, which is defined as $Y_{t} / Z_{t} \tilde{Y}$, where $Z_{t} \tilde{Y}$ is the output level along the balanced-growth path. In other words, the output gap is the deviation of the actual output from the output in the balanced-growth path. Our measure of the output gap is similar to those by ADOLFSON et al. (2007), CHRISTOFFEL et al. (2008), and DEL NEGRO et al. (2007). ${ }^{8}$

We assume a time-varying inflation target as to capture the behavior of the inflation target in Brazil, which varied from 1999 to 2005, and has been kept constant since then at $4.5 \%$ per year. For the purposes of estimation and simulation, we assume that the CPI inflation target is conveniently described by an $\operatorname{AR}(1)$ with a potentially high degree of persistence:

$$
\left(\bar{\Pi}_{t, t+4}^{C}\right)^{\frac{1}{4}}=\left(\bar{\Pi}^{C}\right)^{1-\rho_{\bar{\Pi}} C}\left(\left(\bar{\Pi}_{t-1, t+3}^{C}\right)^{\frac{1}{4}}\right)^{\rho_{\bar{\Pi}^{C}}} \exp \left\{\varepsilon_{t}^{\bar{\Pi}^{C}}\right\} .
$$

\subsubsection{Fiscal Policy}

The current fiscal regime in Brazil has been in place since 1999. The fiscal authority announces annual targets for the nonfinancial public sector primary surplus as a proportion of GDP. The government's ultimate goal is to stabilize (or even reduce) the public sector net debt-to-GDP ratio. So the primary surplus is an intermediate target.

Thus, we set up an equation where the actual primary surplus responds to the announced targets, with a smoothing component, ${ }^{9}$ as follows:

$$
S_{t}^{y}=\bar{S}^{y}+\phi_{S}\left(S_{t-1}^{y}-\bar{S}^{y}\right)+\phi_{\bar{S}}\left(\bar{S}_{t}^{y}-\bar{S}^{y}\right)-s_{G} z_{t}^{G},
$$

where $\phi_{S} \in[0,1), \phi_{\bar{S}}>0, S_{t}^{y}$ is the (actual) primary surplus-to-GDP ratio $\left(S_{t}^{n} / P_{t}^{Y} Y_{t}\right), S_{t}^{n}$ is the nominal primary surplus, $\bar{S}_{t}^{y}$ is the target for the primary

\footnotetext{
${ }^{8}$ It differs from the output gap defined as deviations from the long-run output that would prevail under full price/wage flexibility and no markup distortions (model-consistent output gap), as in Smets and Wouters $(2003,2007)$, and WOODFORD (2003). The advantages of our output gap measure are that is does not require the computation of the flexible price/wage equilibrium, seems to be preferred by the data, at least when estimating DSGE closed economy models for the US (DEL NEGRO et al., 2007), and is closer to the usual definition of output gap used by policymakers.

${ }^{9}$ We also allowed a specification that included a countercyclical component in the rule. However, we have not found robust results in the estimation. Note that, in the case of the countercyclical fiscal policy launched in the end of 2008 and 2009 to respond to the global crisis, the primary surplus target was reduced.
} 
surplus-to-GDP ratio, $\bar{S}^{y}$ is its long-run value, $z_{t}^{G}$ is a shock to the primary surplus, and $s_{G}=\left(Q^{G} \tilde{G}\right) /\left(Q^{Y} \tilde{Y}\right)$ is the steady-state share of government consumption in GDP $\left(Q^{G}=P^{G} / P^{C}\right.$ and $Q^{Y}=P^{Y} / P^{C}$ are the corresponding relative price deflators, and $\tilde{G}$ and $\tilde{Y}$ are the stationary steady-state values of government consumption and real GDP). ${ }^{10}$

As we will see shortly, since the tax rate is exogenous, the fiscal instrument implied by the rule is government consumption. In other words, deviations of the primary surplus from the target are corrected endogenously by changes in government spending. Thus we interpret $z_{t}^{G}$ as unexpected shifts in government spending. Scaling the shock by $s_{G}$ is just a matter of convenience. An exogenous change in government consumption by one percent will shift the primary surplusto-GDP ratio by $s_{G}$. In other words, in order to reduce the primary surplus-toGDP ratio by one unit, government consumption should rise by $1 / s_{G}$ percent.

Since the primary surplus target in Brazil has been, in general, set to stabilize the public sector net debt-to-GDP ratio, we assume that the primary surplus target evolves according to the following rule:

$$
\bar{S}_{t}^{y}=\bar{S}^{y}+\rho_{\bar{S}}\left(\bar{S}_{t-1}^{y}-\bar{S}^{y}\right)+\phi_{B}\left(B_{t}^{y}-B^{y}\right)+\varepsilon_{t}^{\bar{S}},
$$

where $\rho_{\bar{S}} \in[0,1), \phi_{B}>0, B_{t}^{y} \equiv B_{t} / P_{t-1}^{Y} Y_{t-1}$ is government debt as a proportion of $\mathrm{GDP}^{11}, B^{y}$ is its long-run value, and $\varepsilon_{t}^{\bar{S}}$ is a shock to the primary surplus target. Technically, this equation also guarantees that the government debt-to-GDP ratio is stationary.

The nominal primary surplus is defined as the difference between non-interest government revenues and expenses, which in the model is given by the difference between nominal net tax revenues and nominal government consumption:

$$
S_{t}^{n}=T A X_{t}^{n}-P_{t}^{G} G_{t},
$$

where $T A X_{t}^{n}$ is aggregate nominal tax revenues in net terms:

$$
T A X_{t}^{n}=\varpi_{R T} T_{t}^{R T} W_{t}^{n} N_{t}+\left(1-\varpi_{R T}\right) T_{t}^{O, n}-T_{t}^{D, n} .
$$

For simplicity, we follow MEDINA and SOTO (2007) and assume that total taxes are a time-varying proportion of nominal GDP:

$$
T A X_{t}^{n}=T_{t}\left(P_{t}^{Y} Y_{t}\right)
$$

where $T_{t}$ is the average tax rate, which we assume is exogenously determined:

$$
T_{t}=T+\rho_{T}\left(T_{t}-T\right)+\varepsilon_{t}^{T},
$$

\footnotetext{
${ }^{10}$ VALLI and CARVALHO (2010) also model fiscal policy in Brazil using a rule based on the primary surplus.
}

${ }^{11}$ Remember that $B_{t}$ is a pre-determined variable in period $t$, i.e., decided in $t-1$. 
where $T$ is the steady-state average tax rate, and $\varepsilon_{t}^{T}$ is a shock to the average tax rate.

We further assume that the tax rate faced by rule-of-thumb households, $T_{t}^{R T}$, is equal to the average tax rate of the economy, $T_{t}$. Notice that because $T_{t}^{D}=W_{t}^{n} \bar{N}$, the lump-sum tax levied on optimizing household must adjust as to ensure that condition (60) is satisfied in each period. In other words, from the government's point of view, $\left(1-\varpi_{R T}\right) T_{t}^{O, n}$ is a residual taxation given by $T_{t}\left(P_{t}^{Y} Y_{t}-\varpi_{R T} W_{t} N_{t}\right)$ $+W_{t}^{n} \bar{N}$. Alternatively, we could have assumed in the model the presence of distortionary taxes rates on several margins (consumption, labor income, capital income, profits, etc.). However, since our focus is on the business cycle effects of government spending and not on the effects of different tax structures, we decided to have a simpler formulation for aggregate taxes.

Using equations (59) and (61), the primary surplus-to-GDP ratio can be written as $T_{t}-\left(P_{t}^{G} G_{t}\right) /\left(P_{t}^{Y} Y_{t}\right)$, which can be rearranged to express the behavior of government consumption consistent with the primary surplus rule:

$$
G_{t}=\frac{P_{t}^{Y} Y_{t}}{P_{t}^{G}}\left(T_{t}-S_{t}^{y}\right)
$$

As mentioned before, for a given exogenous tax rate, changes in the primary surplus are obtained through changes in government consumption. In the case of Brazil, adjustments in spending tend to take place faster than changes in tax rates. For instance, large part of the taxes are not allowed to be changed during the fiscal year. The equation also implies that, given government goods relative price and the tax rate, changes in output require proportional changes in government consumption in order to keep the primary surplus constant. Thus, in this setup, fiscal policy is not countercyclical.

Now we derive the law of motion of the government debt. In each period $t$, the government receives a flow of tax revenues and issues one-period non-contingent bonds at the interest rate $R_{t}$. The government uses these proceeds to pay for its expenditures and for the outstanding debt. Therefore, the flow budget constraint for the government is given by:

$$
P_{t}^{G} G_{t}+B_{t}=\frac{B_{t+1}}{R_{t}}+T_{t}\left(P_{t}^{Y} Y_{t}\right)
$$

Dividing both sides by current nominal GDP and using identity (63), we obtain the expression for the law of motion of government debt:

$$
B_{t+1}^{y}=R_{t}\left(\frac{B_{t}^{y}}{\Pi_{t}^{Y}} \frac{Y_{t-1}}{Y_{t}}-S_{t}^{y}\right),
$$

where $\Pi_{t}^{Y}=P_{t}^{Y} / P_{t-1}^{Y}$ is the gross GDP deflator inflation. Note that a rise in the interest rate set by the monetary authority raises the government debt, which by 
equation (58) increases the primary surplus target, and consequently by equations (57) and (63) leads to a reduction in government consumption. Therefore, the model allows for direct effects of monetary policy on fiscal policy.

\subsection{Rest of the World}

We do not model the rest-of-the-world economy, but instead assume that foreign variables follow $\mathrm{AR}(1)$ processes, describing the dynamics of detrended world income $\tilde{Y}_{t}^{*}$, foreign inflation $\Pi_{t}^{C^{*}}$, foreign investors' risk aversion $V_{t}^{*}$, interest rate $R_{t}^{*}$, and relative price of imports in foreign currency $Q_{t}^{M^{*}} \equiv P_{t}^{M^{*}} / P_{t}^{C^{*}}$.

\subsection{Shocks}

The remaining variables affecting the domestic economy are the shock processes, which are also modeled as AR(1) processes. They are the shocks to household preference $\left(Z_{t}^{C}\right)$, country risk premium $\left(Z_{t}^{B^{*}}\right)$, transitory technology $\left(Z_{t}^{D}\right)$, permanent technology (trend growth rate) $\left(Z_{t}^{Z}\right)$, investment technology $\left(Z_{t}^{I}\right)$, import demand $\left(Z_{t}^{M}=Z_{H, t}^{M}, H=C, I, X\right)$, export demand $\left(Z_{t}^{M^{*}}\right)$, productivity differential $\left(z_{t}^{*}\right)$, price markup $\left(\varepsilon_{H, t}^{P}, H=C, G, I, X\right)$, wage markup $\left(\varepsilon_{t}^{W}\right)$, administered prices $\left(Z_{t}^{A}\right)$, monetary policy $\left(Z_{t}^{R}\right)$, and fiscal policy (government consumption) $\left(z_{t}^{G}\right)$. Note that we assumed that the shock to import demand $Z_{H, t}^{M}$ is the same across sectors. Additionally, because the UIP condition is known to have a very poor fit to the data, we add the ad hoc shock $z_{t}^{Q}$ to its log-linear version.

\subsection{Aggregation, Market Clearing and Balanced Growth Path}

In the model, the aggregation of quantities of differentiated goods goes through the Dixit-Stiglitz aggregator ("weighted" average), and the simple aggregation is basically an "unweighted" average. The difference between the two values arises from price or wage distortions, which, because of full indexation, vanishes both in the steady state and when we take first-order approximations around the steady state.

The law of motion of net foreign assets as a proportion of GDP is given by:

$$
\frac{B_{t+1}^{* y}}{R_{t}^{*} S_{t}^{B^{*}}}=\left(\frac{Y_{t-1}}{\Pi_{t}^{Y} Y_{t}} \frac{Q_{t}}{Q_{t-1}} \frac{\Pi_{t}^{C}}{\Pi_{t}^{C^{*}}}\right) B_{t}^{* y}+N X_{t}^{y}-L_{t}^{* y},
$$

where $B_{t+1}^{* y} \equiv S_{t} B_{t+1}^{*} / P_{t}^{Y} Y_{t}, N X_{t}^{y}$ is the net exports-to-GDP ratio (or trade balance-to-GDP ratio), given by

$$
N X_{t}^{y}=\frac{S_{t} P_{t}^{X} X_{t}}{P_{t}^{Y} Y_{t}}-\left(\frac{\hat{P}_{t}^{M}}{P_{t}^{M}}\right)^{-\epsilon_{M}} \frac{S_{t} P_{t}^{M^{*}} M_{t}}{P_{t}^{Y} Y_{t}}
$$

\footnotetext{
${ }^{12}$ More details on these topics are recorded in the working paper version of this paper.
} 
and $L_{t}^{* y}$ is defined as total payments of interests on external borrowing by firms as a proportion of GDP:

$$
L_{t}^{* y}=\sum_{H} \iota_{H}\left(R_{t}^{*} S_{t}^{B^{*}}-1\right) \frac{P_{t}^{M} M_{t}^{H}}{P_{t}^{Y} Y_{t}}
$$

Note that $\left(Q_{t} \Pi_{t}^{C}\right) /\left(Q_{t-1} \Pi_{t}^{C^{*}}\right)=S_{t} / S_{t-1}$. Therefore, the evolution of net foreign assets-to-GDP depends on the trade balance, income account (interest on loans and bonds) and "accounting terms", given by GDP growth and the difference between GDP deflator inflation and nominal exchange rate change.

In terms of market clearing conditions, we start by the final goods sectors. In equilibrium, the aggregate supply of sectoral good $H$ is equal to the aggregate demand for that good: $Y_{t}^{C}=C_{t} ; Y_{t}^{I}=I_{t} ; Y_{t}^{G}=G_{t} ; Y_{t}^{X}=X_{t}$. In the inputs market, the market clearing condition for the domestic input is $Y_{t}^{D}=Y_{C, t}^{D}+$ $Y_{I, t}^{D}+Y_{G, t}^{D}+Y_{X, t}^{D}$, where $Y_{t}^{D}$ is the aggregate supply, and the right-hand side terms are the sectoral demands, obtained by aggregating equation (37) and taking into account the relationship between "weighted" and "unweighted" averages. By the same token, the market clearing condition for the imported input is $M_{t}=$ $M_{t}^{C}+M_{t}^{I}+M_{t}^{X}$, where $M_{t}$ is the aggregate supply, and the right-hand side terms are the sectoral demands, obtained by aggregating equation (38) and taking into consideration the relationship between "weighted" and "unweighted" averages. In the case of stock variables, the aggregate demand for $K_{t}, B_{t}$, and $B_{t}^{*}$, obtained by simple aggregation across all optimizing households, should be equal to the corresponding aggregate supply.

Since we express real GDP as $Y_{t}$ and GDP deflator as $P_{t}^{Y}$, nominal GDP is given by $P_{t}^{Y} Y_{t}$, which is defined as the difference between total nominal values of domestic production and imports:

$$
P_{t}^{Y} Y_{t}=P_{t}^{C} C_{t}+P_{t}^{I} I_{t}+P_{t}^{G} G_{t}+S_{t} P_{t}^{X} X_{t}-S_{t} P_{t}^{M^{*}}\left(\frac{\hat{P}_{t}^{M}}{P_{t}^{M}}\right)^{-\epsilon_{M}} M_{t}
$$

Therefore, the definition is consistent with the nominal value-added concept used in National Accounts. Note that we have to include the import price distortion term since we aggregate over imported differentiated goods.

Because we do not have an equilibrium condition that pins down either real GDP or the GDP deflator, we need an additional equation to determine one of these variables. We model the GDP deflator in such a way that changes in relative prices (price of goods in equation (69) relative to the GDP deflator) play no role in the real GDP dynamics. In other words, in the linear version of the model, changes in the real GDP will depend only on changes in the volumes of the aggregate demand variables and not directly on changes in the relative prices of the corresponding goods. This means that, in the model, changes in the real GDP are computed at constant weights. 
This is equivalent to say that the level of the GDP deflator is given by:

$$
P_{t}^{Y}=\left(P_{t}^{C}\right)^{s_{C}}\left(P_{t}^{G}\right)^{s_{G}}\left(P_{t}^{I}\right)^{s_{I}}\left(S_{t} P_{t}^{X}\right)^{s_{X}}\left[S_{t} P_{t}^{M^{*}}\left(\frac{\hat{P}_{t}^{M}}{P_{t}^{M}}\right)^{-\epsilon_{M}}\right]^{-s_{M}}
$$

where $s_{j}$ is the share of component $j$ in nominal GDP so that $s_{j}=\frac{P^{j} \tilde{Y}^{H}}{P^{Y} \tilde{Y}}, j=$ $C, G, I, s_{X}=\frac{S P^{X} \tilde{Y}^{X}}{P^{Y} \tilde{Y}}, s_{M}=\frac{S P^{M^{*}} \tilde{M}}{P^{Y} \tilde{Y}}$, and $\sum_{j} s_{j}=1$.

The next step of model derivation is to put the model into the stationary form. For that purpose, we divide all real variables by the level of technology $Z_{t}$. Similarly, we make all nominal variables stationary by dividing their corresponding levels by the numéraire $P_{t}^{C}$. As for nominal wages, we divide them by both $Z_{t}$ and $P_{t}^{C}$. Some variables, including labor, ratios to GDP and financial variables, such as interest rates and foreign investors' risk aversion, are already stationary. Finally, as in CHRISTOFFEL et al. (2008), we detrend foreign output by the level of technology prevailing abroad, $Z_{t}^{*}$.

Next, we derive the deterministic steady state of the stationary model, and then log-linearize the BGP equilibrium conditions around the deterministic steady state. ${ }^{13}$ The resulting linear equations are used in the estimation stage.

\section{Estimation}

The model was estimated using Bayesian methods. ${ }^{14}$ This procedure allows the use of available information, in the form of prior distributions, and the use of observed data to update these priors, providing the calculation of the posterior distributions of the estimated parameters. Technically, it also helps shaping the likelihood function, which is particularly important for the estimation of large DSGE models. In the case of Brazil, the estimation of such models by classical full information methods (e.g., maximum likelihood and GMM) is even more difficult because the data sample span is very short. In practice, the Bayesian approach is a bridge between calibration and classical estimation. Calibration methods do not incorporate information from the likelihood, but likelihood estimation is not technically possible. The Bayesian estimation makes possible to estimate otherwise weakly identified parameters by incorporating prior knowledge or judgment.

Our model encompasses a total of 118 parameters, of which 37 are calibrated and 81 are estimated (33 are structural and 48 are shock-related parameters). In the next subsections, we describe the data set and the variable transformation used in the estimation, the calibration procedure, the setting of the prior distributions of the estimated parameters, and the estimation results.

\footnotetext{
${ }^{13}$ Details can be found in the working version of this paper.

${ }^{14}$ See, for instance, CANOVA (2007).
} 


\subsection{Data and Shocks}

We estimated the model using quarterly data spanning from 1999Q3 to 2010Q2 (44 data points). We use 23 model variables as observables - 18 domestic and five foreign variables. Table 1 provides the list of the observable variables, the symbol of the correspondent model variables, and the source and treatment of each series.

We have chosen this set of observables taking into account data availability, their relevance for policymarkers' decisions, and their role in explaining the variables of higher interest. Furthermore, a large set of observables reduces the problem of identification.

To prepare the data for the model estimation, we detrended non stationary series, and demeaned the stationary ones. Figure 1 provides the graphs of the series after being transformed. For the series corresponding to the variables $Y_{t}, C_{t}, I_{t}$, $G_{t}, X_{t}, M_{t}, N_{t}, W_{t}$ and $Y_{t}^{*}$, we applied first log-difference. We then demeaned the transformed series to eliminate differences in the trends across growing variables. Regarding $S_{t}^{B^{*}}, S_{t}^{y}, \bar{S}_{t}^{y}, \Pi_{t}^{X}, \Pi_{t}^{*}, V_{t}^{*}$ and $R_{t}^{*}$, we subtract the sample mean from their corresponding levels. In the case of the real effective exchange rate, $Q_{t}$, we use percent difference from the sample mean. Since the price of imports relative to world prices, $Q_{t}^{M^{*}}$, has a trend over the sample period, we make it stationary using a linear trend procedure.

For the CPI-related inflation rates $-\Pi_{t}^{C}, \Pi_{t}^{F}$ and $\Pi_{t}^{A}-$ we subtract the inflation target from these series, but using the target value in place since 2005, $4.5 \%$. The target values for the previous period are considered as transitional values (the targets were set to $8.0 \%$ and $6.0 \%$ for 1999 and 2000, respectively). In fact, the economic period starting in 2005 is more stable than the previous one. In particular, on average, inflation has been close to the target since 2005 up to the end of the sample, whereas the inflation average in the previous years was much higher. From 1999 to 2004, the economy experienced the impact of the exchange rate crisis in 1999, the challenges of implementing inflation targeting and a new fiscal regime, and the confidence crisis with the presidential elections in

2002. Similarly, we subtract $4.5 \%$ from the inflation target series, $\bar{\Pi}_{t}^{C}$. Since the targets are set for calendar years, we smoothed the target trajectory using linear interpolation. In order to be consistent with the procedure used for the inflation rates, we demean the domestic interest rate, $R_{t}$, using the sample mean for the period 2005Q1-2010Q2.

We add measurement errors in the equations for GDP growth and CPI inflation. In the estimated linear model, CPI inflation is assumed to be a fixed weighted average between free and administered prices, and the weights of GDP aggregate components are assumed to be constant as well. The measurement errors capture the effect of changes of the actual weights overtime (CPI weights change every month, and, in the case of GDP, the actual weights are fixed only for each calendar year). 
Table 1. Description of the data series used in the estimation

\begin{tabular}{|c|c|c|c|}
\hline \multicolumn{2}{|c|}{ Description } & Source $^{a}$ & Treatment $^{b}$ \\
\hline \multicolumn{4}{|c|}{ Domestic Observable Variables } \\
\hline$Y_{t}$ & GDP - volume (seasonally adjusted - s.a.) & IBGE & fld \\
\hline$C_{t}$ & Households' consumption - volume (s.a.) & IBGE & fld \\
\hline$I_{t}$ & Investment: Gross formation of fixed capital - vol. (s.a.) & IBGE & fld \\
\hline$G_{t}$ & Government consumption - volume (s.a) & IBGE & fld \\
\hline$X_{t}$ & Exports of goods and services - volume (s.a.) & IBGE & fld \\
\hline$M_{t}$ & Imports of goods and services - volume (s.a.) & IBGE & fld \\
\hline$N_{t}$ & Number of employed people (s.a.) ${ }^{c}$ & IBGE & fld \\
\hline$W_{t}$ & Real wage ("usual compensation" - s.a.) ${ }^{c}$ & IBGE & fld \\
\hline$\Pi_{t}^{C}$ & CPI Inflation: IPCA (s.a. - \% per quarter) & IBGE & dam \\
\hline $\bar{\Pi}_{t}^{C}$ & CPI Inflation Target (\% per quarter) & $\mathrm{BCB}$ & dam \\
\hline$\Pi_{t}^{A}$ & Administered price inflation (s.a. - \% per quarter) & $\mathrm{BCB}$ & dam \\
\hline$\Pi_{t}^{F}$ & Free price inflation (s.a. - \% per quarter) & $\mathrm{BCB}$ & dam \\
\hline$\Pi_{t}^{X}$ & Export price inflation (s.a. - \% per quarter) & Funcex & $\mathrm{dm}$ \\
\hline$R_{t}$ & Nominal interest rate - Selic (\% per quarter) & $\mathrm{BCB}$ & dam \\
\hline$S_{t}^{y}$ & Primary surplus-to-GDP ratio - public sector (12 months) & $\mathrm{BCB}$ & $\mathrm{dm}$ \\
\hline $\bar{S}_{t}^{y}$ & Primary surplus target-to-GDP ratio - pub. sec. (12 mon.) & $\mathrm{BCB}$ & $\mathrm{dm}$ \\
\hline$Q_{t}$ & Real effective exchange rate & $\mathrm{BCB}$ & pd \\
\hline$S_{t}^{B^{*}}$ & Country risk premium: EMBI Brazil (\% per quarter) & J.P.Morgan & $\mathrm{dm}$ \\
\hline \multicolumn{4}{|c|}{ Foreign Observable Variables } \\
\hline$Y_{t}^{*}$ & World imports - volume (s.a.) & $\mathrm{CPB}$ & fld \\
\hline$Q_{t}^{M^{*}}$ & Relative price of imports (Brazil's import prices/US CPI) & Funcex & lt \\
\hline$\Pi_{t}^{*}$ & World inflation - US CPI AUCLS (\% per quarter) & Fed St. Louis & $\mathrm{dm}$ \\
\hline$V_{t}^{*}$ & Foreign investors' risk aversion - VIX & $\mathrm{CBOE}$ & $\mathrm{dm}$ \\
\hline$R_{t}^{*}$ & World nominal interest rate - Fed Funds rate (\% p.q.) & Fed St. Louis & $\mathrm{dm}$ \\
\hline
\end{tabular}

${ }^{a}$ Acronyms: IBGE - Brazilian Institute of Geography and Statistics; BCB - Central Bank of Brazil; CPB - CPB Netherlands Bureau for Economic Policy Analysis; Funcex: Trade Studies Center Foundation; CBOE - Chicago Board Options Exchange.

${ }^{b}$ Notation: fld: first log difference; dm: difference from the sample mean; dam: difference from the adjusted mean (sample from 2005 onwards); pd: percentage deviation from the mean; lt: linear trend

${ }^{c}$ Due to a methodology change in the employment and wage series in 2002, two time series were combined: the current one, which started in March 2002, and the one that was discontinued that time. We applied the growth rate of the discontinued series to obtain values for 1999Q32002Q1. 
Besides those 23 series, we also construct a proxy for the implied contribution of inventory investment to GDP growth, $I_{t}^{i n v}$. The Brazilian Institute of Geography and Statistics (IBGE) provides the calculation of the volume of gross formation of fixed capital, but not of inventory changes. When we calculate the actual weighted growth rate of the five modeled aggregate components, it does not correspond exactly to the actual GDP growth rate, whose calculation is based on the output method. In other words, there remains a wedge between the weighted growth of the five aggregate demand components and the GDP growth in the data. We treat this wedge as the implied contribution of inventory investment to the GDP growth, although it may also be capturing measurement errors of the other aggregate demand components. This term is added to the linear equation describing the market equilibrium condition in the final goods sector. ${ }^{15}$ If we did not take into account this wedge, we would have a larger estimated measurement error in the GDP growth equation - resulting not from the model, but from the actual data - and distortions in the output gap estimation.

The measurement equations for the non stationary variables are the following:

$$
\Delta y_{t}^{o b s}=y_{t}-y_{t-1}+z_{t}^{Z},
$$

where $\Delta y_{t}^{o b s}$ corresponds to the variables in first log-difference listed in Table 1, $y_{t}$ is the corresponding model variable in log-deviation from the steady state, and $z_{t}^{Z}$ is the permanent technology shock in the linear form. The latter only enters the measurement equations of variables that have real unit roots in the model.

The number of shocks is equal to the number of observables. We have a total of 23 shocks, plus the shock to inventory investment. The list of shocks can be found in Table 3 .

In the linear version of the model, we have added a shock to the UIP equation with the objective of capturing deviations from the UIP condition. Note that the risk premium in the UIP equation is usually treated as an unobservable in many DSGE models; so in these models the risk premium shock also captures deviations from the UIP condition. In contrast, in our model, we treat it as an observable, warranting the inclusion of the shock $\varepsilon_{t}^{Q} .{ }^{16}$

\subsection{Calibrated Parameters}

We calibrate 37 parameters - comprised of aggregate shares or ratios, steadystate values that appear as parameters in the linear model, and some weakly

\footnotetext{
${ }^{15}$ Since this term is already in first difference (weighted by its contribution to the GDP growth), we add a measurement equation for it, and the estimated deviation from the steady state enters the market equilibrium equation. Since it is a residual, we model it as an $\operatorname{AR}(1)$ process.

${ }^{16}$ The domestic risk premium is also an unobservable in the UIP equation, but it is subject to cross-equation restrictions coming from the equilibrium conditions for consumption and investment.
} 
identified parameters. Table 2 presents the list of the calibrated parameters and the corresponding values used in the estimation. We describe below the procedures used to find those values. In most cases, we match the parameter values with their sample means.

The shares of aggregate demand components in GDP $\left(s_{C}, s_{G}, s_{I}, s_{X}, s_{M}\right)$ are based on sample average calculated from the National Accounts. We match the tax rate $\tau$ with the sample mean of the government tax revenues-to-GDP ratio. The share of rule-of thumb households' consumption in total consumption, $\tilde{\varpi}_{C}$, is set to $0.40 .{ }^{17}$

We calibrate two preference parameters. The time discount factor, $\tilde{\beta} \equiv \beta$ $\left(Z^{Z}\right)^{1-\sigma}=0.989$, is calculated taking into account the average GDP growth rate, the average domestic interest rate (the policy Selic rate) over 2005Q1-2010Q2, and the $4.5 \%$ inflation target. The inverse of the elasticity of labor supply, $\eta$, was not possible to be identified in the estimation, and is set to 1 , which is in the range commonly found in the business cycle literature.

We calibrate twenty technology parameters. The gross growth rate, $Z^{Z}$, matches the sample average GDP growth rate of $0.9 \%$ per quarter. We follow the literature in the calibration of markups in inputs and goods markets. First, we set the elasticity of substitution between differentiated labor, $\epsilon_{W}$, to 3 , which implies a wage markup of $50 \%$. Second, the elasticity of substitution between differentiated intermediate goods in each sector, $\epsilon_{H}^{P}$, where $H=C, I, G, X$, and the elasticity of substitution between differentiated imported goods, $\epsilon_{M}$, are set to 11 , implying a $10 \%$ price markup in goods market.

The weight of capital in the domestic Cobb-Douglas production function, $\alpha$, matches the average capital income share in GDP (0.448). In turn, the share of production labor in total labor, $\alpha_{N}$, is set to 0.8 . The depreciation rate of capital, $\delta$, is calibrated to 0.015 , meaning $6 \%$ per year. ${ }^{18}$

We have four technology parameters describing the weights of imported inputs in sectoral production, $1-\varpi_{H}^{D}$, with $H=C, G, I, X$. First, we assume that government consumption goods are produced without using imported inputs, that is, $\varpi_{G}^{D}=1$. Second, we calculate the weights in the investment and exported goods using proxies for the share of imports in these sectors. The value of imports of capital goods from the Balance of Payments statistics are fully assigned to investment, and the value of imports of intermediate goods is distributed among investment and exports according to their shares in GDP. In the case of consumption goods, the weight was determined using the steady-state relationship, so that it absorbs all remaining imported goods.

\footnotetext{
${ }^{17} \mathrm{We}$ assumed that workers that receive up to 2.5 minimum wages in Brazil behave as ruleof-thumb consumers. We used data on income distribution from the National Household Sample Survey (PNAD).

${ }^{18}$ This value is between the available estimations for the Brazilian economy, including those of CARVALHO (1996) and BONELLI and FONSECA (1998), and those commonly used in the literature.
} 
Table 2. Calibrated parameters

\begin{tabular}{|c|c|c|}
\hline Symbol & Description & Value \\
\hline \multicolumn{3}{|l|}{ Shares } \\
\hline$s_{C}$ & Households' consumption-to-GDP ratio & 0.62 \\
\hline$s_{G}$ & Government consumption-to-GDP ratio & 0.20 \\
\hline$s_{I}$ & Investment-to-GDP ratio & 0.17 \\
\hline$s_{X}$ & Exports-to-GDP ratio & 0.13 \\
\hline$s_{M}$ & Imports-to-GDP ratio & 0.12 \\
\hline$\tau$ & Average aggregate tax rate & 0.35 \\
\hline$\tilde{\varpi}_{C}$ & Share of rule-of-thumb households in total consumption & 0.40 \\
\hline \multicolumn{3}{|c|}{ Preference and Technology Parameters } \\
\hline$\widetilde{\beta}$ & Time discount factor & 0.989 \\
\hline$\eta$ & Inverse of the elasticity of labor supply & 1.00 \\
\hline$Z^{Z}$ & Gross growth rate - BGP & 1.009 \\
\hline & Elasticity of substitution: differentiated labor & 3 \\
\hline$\epsilon_{C}^{P}, \epsilon_{I}^{P}, \epsilon_{G}^{P}, \epsilon_{X}^{P}$ & Elasticity of substitution: intermediate goods & 11 \\
\hline$\epsilon_{M}$ & EoS: intermediate goods - imported goods & 11 \\
\hline$\alpha$ & Cobb-Douglas production function - capital income share & 0.448 \\
\hline$\alpha_{N}$ & Share of production labor in total labor & 0.8 \\
\hline$\delta$ & Depreciation rate of capital & 0.015 \\
\hline$\varpi_{C}^{D}$ & Weight of dom. input in consumption goods marginal cost & 0.8418 \\
\hline$\varpi_{I}^{D}$ & Weight of dom. input in investment goods marginal cost & 0.79 \\
\hline$\varpi_{G}^{D}$ & Weight of dom. input in gov.cons. goods marginal cost & 1.00 \\
\hline$\varpi_{X}^{D}$ & Weight of dom. input in exported goods marginal cost & 0.9 \\
\hline \multicolumn{3}{|c|}{ Shares of Imports that are Externally Financed } \\
\hline$\iota_{C}, \iota_{I}, \iota_{X}$ & Consumption, Investment and Export goods sector & 0.5 \\
\hline \multicolumn{3}{|c|}{ Administered Prices } \\
\hline$\varpi_{A}$ & Weight of administered prices in CPI inflation & 0.3 \\
\hline$\chi_{A}$ & Adjustment factor of administered and free prices & 0.8 \\
\hline \multicolumn{3}{|c|}{ Steady-State Parameters in the Law of Motion of Government and External Debts } \\
\hline$B^{* y}$ & Net foreign assets-to-GDP ratio (quarterly GDP) & -0.68 \\
\hline$B^{y}$ & Net government debt-to-GDP ratio (quarterly GDP) & 2.00 \\
\hline$A F_{B}^{*}$ & Adjustment factor in the law of motion of external debt & 0.0397 \\
\hline$A F_{B}$ & Adjustment factor in the law of motion of domestic debt & 0.53 \\
\hline $\bar{\Pi}^{C}$ & Inflation target (quarterly gross rate) & 1.011 \\
\hline$R$ & Domestic nominal interest rate (quarterly gross rate) & 1.0314 \\
\hline$\Pi^{*}$ & World inflation (quarterly gross rate) & 1.0064 \\
\hline$R^{*}$ & World nominal interest rate (quarterly gross rate) & 1.0074 \\
\hline$S^{B *}$ & Country risk premium (quarterly gross rate) & 1.014 \\
\hline
\end{tabular}


Finally, using several calibrated parameters listed in Table 2 and steady-state relations, we find the share of each sector in total demand for domestic inputs $\left(s_{C}^{D}\right.$, $\left.s_{I}^{D}, s_{G}^{D}, s_{X}^{D}\right)$ and in total demand for imported inputs $\left(s_{C}^{M}, s_{I}^{M}, s_{X}^{M}\right)$, as well as the shares of sectoral imports in GDP $\left(s_{M, C}, s_{M, I}, s_{M, X}\right)$.

We calibrate the sectoral working capital constraints, $\iota_{H}$, for $H=C, I, X$, using data on the value of imports that are funded by external financing. Since data does not allow us to distinguish between sectors, we assume $\iota_{H}=0.5$ for all sectors.

We have two calibrated parameters related to administered prices. The weight of administered price inflation in overall CPI inflation, $\varpi_{A}=0.3$, is set to the corresponding sample average. The parameter governing the convergence of administered prices, $\chi_{A}$, is set to 0.8 , so in each quarter 0.2 of the relative price change is corrected.

Finally, we set the steady-state values affecting the law of motion of government and external debt in the linear form. The net foreign assets-to-GDP ratio and the net government debt-to-GDP ratio $\left(B^{* y}, B^{y}\right)$ correspond to the sample average of the net foreign debt and net debt of nonfinancial public sector, as a proportion of quarterly GDP. We also make interest rate payments in the model consistent with debt maturity. ${ }^{19}$

The steady-state gross inflation target, $\bar{\Pi}^{C}$, matches the annual inflation rate of $4.5 \%$, in accordance with the target since 2005 . The gross nominal interest rate, $R$, also matches the sample average over 2005Q1-2010Q2. For the world gross inflation rate, $\Pi^{C^{*}}$, we consider the average US CPI inflation, and for the world gross nominal interest rate, $R^{*}$, we use the average Fed funds rate. The gross country risk premium, $S^{B^{*}}$, matches the average spread of Brazilian bonds over US treasury bonds of equivalent maturities, and is measured by the Emerging Markets Bond Index (EMBI) for Brazil.

\subsection{Prior Distributions}

Setting the priors for the estimated parameters involves choosing the type of the distribution, its mean and variance. The type of the distribution was chosen to place theoretical or convenient restrictions over the support of the parameters. For instance, beta distributions are used for parameters restricted to be in the interval [0,1], and gamma and inverse gamma for those restricted to be positive. Their variances were chosen according to our beliefs regarding the probability mass that

\footnotetext{
${ }^{19}$ Since the model has only one-period bonds, changes in the interest rate affect immediately the cost of the whole outstanding debt. However, the average maturity in the data is higher than one quarter, so shifts in interest rates affect only partially the interest rate payments in the current quarter. Thus, in order to prevent the model from overestimating the impact of interest rate changes on the outstanding debt, we scale down the interest rate payments implied by the law of motion of both debts. These scale or adjustment factors of external and domestic debts are denoted by $A F_{B}^{*}$ and $A F_{B}$, respectively. We calibrate their values taking into account the debt maturity and the share of debt that is indexed to the interest rate.
} 
should be around the prior mean. In general, prior information or judgment is surrounded by a large degree of uncertainty, so we avoided using tight priors.

We estimated a total of 81 parameters, divided into two major groups: parameters related to the endogenous transmission mechanism - preference, real frictions, nominal rigidities and policy parameters - interpreted as structural parameters, and those related to the shocks and $\operatorname{AR}(1)$ processes. We have used several procedures for setting the priors: studies based on micro data, evidence for other countries, training sample, and specialists' knowledge. Table 3 provides a list of the prior distribution used for each parameter, and Figure 2 shows the shapes of the priors of the structural parameters and the corresponding posterior distributions.

Four preference parameters were estimated. The prior of the inverse of intertemporal elasticity of substitution, $\sigma$, is normal with mean equals to 1.3 , consistent with the evidence that this parameter is equal to or larger than 1.0. The habit persistence parameter, $\tilde{\kappa}$, has a beta distribution with a 0.85 mean, based on international evidence on the observed response of domestic consumption to monetary policy shocks. Note that it implies a coefficient of 0.46 in the lagged consumption term in the linear Euler equation for consumption $(\tilde{\kappa} /(1+\tilde{\kappa}))$. The priors for the elasticities of the country risk premium with respect to foreign investors' risk aversion, $\varphi_{V^{*}}$, and net foreign assets, $\varphi_{B^{*}}$, are inverse gamma whose mean are based on regressions using data before the adoption of inflation targeting regime.

We have estimated nine technology parameters. We use gamma distributions with a mean of 1.0 for the priors of the elasticity of substitution between domestic and imported inputs $\left(\epsilon_{C}, \epsilon_{I}, \epsilon_{X}, \epsilon^{*}\right)$, which imply Cobb-Douglas technologies. For the adjustment cost parameters $\left(\vartheta_{I}, \vartheta_{C}^{M}, \vartheta_{I}^{M}, \vartheta_{X}^{M}, \vartheta^{M^{*}}\right)$, we set diffuse gamma distributions because of the uncertainty regarding their magnitude.

Regarding the priors for the twelve parameters governing nominal rigidity, we assume beta distributions with a mean of 0.65 for the Calvo parameters $\left(\theta_{F}, \theta_{I}\right.$, $\left.\theta_{G}, \theta_{X}, \theta_{M}\right)$, implying that prices are optimally adjusted on average every three quarters. ${ }^{20}$ We also set beta distributions centered at 0.65 for the price indexation parameters $\left(\omega_{F}, \omega_{I}, \omega_{G}, \omega_{X}, \omega_{M}\right)$. They are relatively large because we believe there are important inertial mechanisms in the Brazilian economy, although we use loose priors for this set of parameters.

\footnotetext{
${ }^{20}$ Using Brazilian CPI micro data, GOUVÊA (2007) found a frequency of price adjustment of 1.3 quarter. However, the mapping from the results from micro studies to the parameters in macro models is not one-to-one. This occurs for several reasons. The theory of cross-sectional aggregation of dynamic processes shows that slow macroeconomic adjustments maybe consistent with much faster average speed of adjustments at the micro level (ALTISSIMO et al., 2007). Also, when calculating frequency of price adjustments using micro data, all price changes are considered (optimal changes and indexation-based changes); therefore, a direct mapping to the value of parameter $\theta_{F}$ is not adequate. Furthermore, the parameter is somehow model dependent. For instance, a model with firm-specific capital generates different values for this parameter.
} 
Turning to wage dynamics, we believe nominal wages are more rigid than prices in Brazil. Wage negotiations in each workers category usually take place once a year. The minimum wage, which is earned by a large number of workers, is also adjusted annually. Additionally, the international evidence that wages are more rigid than prices is quite robust. ${ }^{21}$ Thus, we assume prior beta distributions with mean of 0.75 for the Calvo parameter $\theta_{W}$, implying optimal wage adjustment every three quarters. For the wage indexation parameter, we use a beta distribution with mean 0.65 , but slightly tighter than that for price indexation, because we believe more firmly in the presence of (informal) indexation mechanisms for wages.

The priors for the parameters in the administered price rule $\left(v_{A}^{1}\right.$ and $\left.v_{A}^{2}\right)$ are based on the information about the contracts governing electricity and telephone rates. The impact of changes in the real exchange rate and real marginal cost is lower than that of the CPI inflation.

Concerning the parameters of the Taylor rule, we chose relatively loose priors. We assume beta prior distribution for the interest-rate smoothing parameter, $\gamma_{R}$, with mean of 0.6 and standard deviation of 0.15 , and normal distribution for the coefficient on expected inflation, $\gamma_{\Pi}$, centered at 2.0 , with a 0.35 standard deviation. For the coefficient on the output gap, $\gamma_{Y}$, we use a relatively diffuse gamma distribution with mean equal to 0.25 and standard deviation of 0.1 .

The priors for the fiscal rule parameters $\left(\phi_{S}, \phi_{\bar{S}}\right)$ were set considering that government expenditure do react to primary surplus deviations from the target, but not as to meet the target promptly. So, we use priors with mean at 0.4 and 0.35 , respectively. The prior distribution for the coefficient governing the reaction of the primary surplus target to debt deviations, $\phi_{B}$, was set taking account the fact that the coefficient has to be positive, but at the same time should not provoke unduly volatility in the primary surplus target.

The parameters related to shocks and variables modeled as $\operatorname{AR}(1)$ processes are estimated using diffuse priors. We use beta distributions for the autoregressive coefficients, except for that in the inventory investment equation, with mean 0.5 and standard deviation 0.25 . The priors for the standard deviations of the 24 innovations are inverse gamma with mean equal to 1.0. We also use diffuse priors for the standard deviations of the two measurement errors.

${ }^{21}$ See, for instance, ERCEG et al. (2009). 
Table 3. Estimated parameters

\begin{tabular}{|c|c|c|c|c|c|c|c|}
\hline \multirow{2}{*}{\multicolumn{2}{|c|}{ Description }} & \multicolumn{3}{|c|}{ Prior Distribution } & \multicolumn{3}{|c|}{ Posterior Distribution } \\
\hline & & \multirow[t]{2}{*}{ Distribution } & \multirow[t]{2}{*}{ Mean } & \multirow[t]{2}{*}{ SD } & \multirow[t]{2}{*}{ Mean } & \multicolumn{2}{|c|}{ Cred. Interval } \\
\hline \multicolumn{4}{|c|}{ Preference Parameters } & & & & \\
\hline$\widetilde{\kappa}$ & Habit persistence & beta & 0.85 & 0.05 & 0.74 & 0.65 & 0.84 \\
\hline$\sigma$ & Inverse of intertemporal EoS & Normal & 1.30 & 0.05 & 1.30 & 1.22 & 1.38 \\
\hline$\varphi_{V}^{*}$ & Risk premium: investors' aversion coef. & Inv-gamma & 0.05 & 0.15 & 0.03 & 0.02 & 0.04 \\
\hline$\varphi_{B}^{*}$ & Risk premium: NFA coef. & Inv-gamma & 0.05 & 0.15 & 0.02 & 0.01 & 0.03 \\
\hline \multicolumn{8}{|c|}{ Technology Parameters } \\
\hline$\epsilon_{C}$ & EoS domestic imported inputs - cons. & Gamma & 1.0 & 0.5 & 1.09 & 0.64 & 1.55 \\
\hline$\epsilon_{I}$ & EoS domestic imported inputs - invest. & Gamma & 1.0 & 0.5 & 0.83 & 0.18 & 1.47 \\
\hline$\epsilon_{X}$ & EoS domestic imported inputs - exports & Gamma & 1.0 & 0.5 & 0.95 & 0.23 & 1.63 \\
\hline$\epsilon^{*}$ & EoS Brazil's exports - ROW inputs & Gamma & 1.0 & 0.5 & 0.66 & 0.36 & 0.95 \\
\hline$\vartheta^{M^{*}}$ & Adjustment cost in foreign imports & Gamma & 4.0 & 1.5 & 1.99 & 0.83 & 3.13 \\
\hline$\vartheta_{I}$ & Adjustment cost of investment & Gamma & 4.0 & 1.5 & 3.42 & 1.30 & 5.38 \\
\hline$\vartheta_{C}^{M}$ & Imports adjust. cost - consumption & Gamma & 4.0 & 1.5 & 0.76 & 0.44 & 1.09 \\
\hline$\vartheta_{I}^{M}$ & Imports adjust. cost - investment & Gamma & 4.0 & 1.5 & 1.97 & 0.86 & 3.07 \\
\hline$\vartheta_{X}^{M}$ & Imports adjust. cost - exports & Gamma & 4.0 & 1.5 & 3.12 & 128 & 4.88 \\
\hline \multicolumn{8}{|c|}{ Nominal Rigidity Parameters } \\
\hline$\theta_{F}$ & Calvo - freely-set price & Beta & 0.65 & 0.1 & 0.74 & 0.68 & 0.81 \\
\hline$\theta_{G}$ & Calvo - government goods price & Beta & 0.65 & 0.1 & 0.47 & 0.32 & 0.62 \\
\hline$\theta_{I}$ & Calvo - investment goods price & Beta & 0.65 & 0.1 & 0.65 & 0.48 & 0.83 \\
\hline$\theta_{X}$ & Calvo - exports price & Beta & 0.65 & 0.1 & 0.77 & 0.68 & 0.86 \\
\hline$\theta_{M}$ & Calvo - imports price & Beta & 0.65 & 0.1 & 0.64 & 0.52 & 0.75 \\
\hline$\theta_{W}$ & Calvo parameter for wages & Beta & 0.75 & 0.1 & 0.75 & 0.66 & 0.84 \\
\hline$\omega_{F}$ & Freely-set price indexation & Beta & 0.65 & 0.2 & 0.33 & 0.08 & 0.57 \\
\hline$\omega_{G}$ & Government goods indexation & Beta & 0.65 & 0.2 & 0.49 & 0.14 & 0.82 \\
\hline$\omega_{M}$ & Import price indexation & Beta & 0.65 & 0.2 & 0.65 & 0.35 & 0.97 \\
\hline$\omega_{I}$ & Investment price indexation & Beta & 0.65 & 0.2 & 0.55 & 0.22 & 0.90 \\
\hline$\omega_{X}$ & Export price indexation & Beta & 0.65 & 0.2 & 0.35 & 0.08 & 0.60 \\
\hline$\omega_{W}$ & Wage indexation & Beta & 0.65 & 0.15 & 0.49 & 0.31 & 0.69 \\
\hline
\end{tabular}


Table 3. Estimated parameters (cont.)

\begin{tabular}{|c|c|c|c|c|c|c|c|}
\hline \multirow{2}{*}{\multicolumn{2}{|c|}{ Description }} & \multicolumn{3}{|c|}{ Prior Distribution } & \multicolumn{3}{|c|}{ Posterior Distribution } \\
\hline & & \multirow{2}{*}{ Distribution } & \multirow[t]{2}{*}{ Mean } & \multirow[t]{2}{*}{$\mathrm{SD}$} & \multirow[t]{2}{*}{ Mean } & \multirow{2}{*}{\multicolumn{2}{|c|}{ Cred. Interval }} \\
\hline Admin & ered Price Rule Parameters & & & & & & \\
\hline$v_{A}^{1}$ & Exchange rate coefficient & Beta & 0.05 & 0.03 & 0.05 & 0.01 & 0.09 \\
\hline$v_{A}^{2}$ & Marginal cost coefficient & Beta & 0.2 & 0.05 & 0.20 & 0.12 & 0.27 \\
\hline \multicolumn{8}{|c|}{ Policy Parameters - Taylor rule } \\
\hline$\gamma_{R}$ & Interest rate smoothing & Beta & 0.60 & 0.15 & 0.79 & 0.74 & 0.85 \\
\hline$\gamma_{\Pi}$ & Inflation coefficient & Normal & 2.0 & 0.35 & 2.43 & 1.98 & 2.89 \\
\hline$\gamma_{Y}$ & Output gap coefficient & Gamma & 0.25 & 0.1 & 0.16 & 0.06 & 0.25 \\
\hline \multicolumn{8}{|c|}{ Policy Parameters - Fiscal rule } \\
\hline$\phi_{S}$ & Primary surplus reaction coef. & Beta & 0.4 & 0.05 & 0.49 & 0.42 & 0.56 \\
\hline$\phi_{\bar{S}}$ & Primary surplus target coefficient & Normal & 0.35 & 0.05 & 0.41 & 0.34 & 0.49 \\
\hline$\phi_{B}$ & Government debt coefficient & Inv-Gamma & 0.05 & 0.15 & 0.02 & 0.01 & 0.02 \\
\hline \multicolumn{8}{|c|}{ Autoregressive Shocks } \\
\hline$\rho_{B}$ & Domestic risk premium & Beta & 0.5 & 0.25 & 0.85 & 0.75 & 0.99 \\
\hline$\rho_{I}$ & Investment adjustment cost & Beta & 0.5 & 0.25 & 0.33 & 0.05 & 0.56 \\
\hline$\rho_{C}$ & Household preference & Beta & 0.5 & 0.25 & 0.13 & 0.00 & 0.27 \\
\hline$\rho_{M}$ & Import adjustment cost & Beta & 0.5 & 0.25 & 0.60 & 0.44 & 0.76 \\
\hline$\rho_{A}$ & Administered prices & Beta & 0.5 & 0.25 & 0.37 & 0.19 & 0.56 \\
\hline$\rho_{P}$ & Price markup & Beta & 0.5 & 0.25 & 0.17 & 0.00 & 0.32 \\
\hline$\rho \overline{\bar{\Pi}}_{C}$ & Inflation target & Beta & 0.5 & 0.25 & 0.84 & 0.70 & 0.99 \\
\hline$\rho_{W}$ & Wage markup & Beta & 0.5 & 0.25 & 0.09 & 0.00 & 0.18 \\
\hline$\rho_{D}$ & Transitory technology & Beta & 0.5 & 0.25 & 0.91 & 0.84 & 0.99 \\
\hline$\rho_{Z}$ & Permanent technology & Beta & 0.5 & 0.25 & 0.25 & 0.01 & 0.46 \\
\hline$\rho_{Q}$ & UIP & Beta & 0.5 & 0.25 & 0.94 & 0.89 & 0.99 \\
\hline$\rho_{B^{*}}$ & Country risk premium & Beta & 0.5 & 0.25 & 0.73 & 0.56 & 0.91 \\
\hline$\rho_{T}$ & Tax rate & Beta & 0.5 & 0.25 & 0.80 & 0.65 & 0.96 \\
\hline$\rho_{\bar{S}}$ & Primary surplus & Beta & 0.5 & 0.25 & 0.76 & 0.66 & 0.87 \\
\hline$\rho_{P^{*}}$ & Foreign price markup & Beta & 0.5 & 0.25 & 0.30 & 0.02 & 0.55 \\
\hline$\rho_{\Pi^{*}}$ & Foreign inflation & Beta & 0.5 & 0.25 & 0.13 & 0.00 & 0.25 \\
\hline$\rho_{R^{*}}$ & World nominal interest rate & Beta & 0.5 & 0.25 & 0.90 & 0.84 & 0.96 \\
\hline$\rho_{Y^{*}}$ & World demand & Beta & 0.5 & 0.25 & 0.93 & 0.86 & 0.99 \\
\hline$\rho_{Q^{M^{*}}}$ & Import relative price & Beta & 0.5 & 0.25 & 0.88 & 0.80 & 0.97 \\
\hline$\rho_{V^{*}}$ & Foreign investors's risk aversion & Beta & 0.5 & 0.25 & 0.79 & 0.60 & 1.0 \\
\hline$\rho_{M^{*}}$ & World import demand & Beta & 0.5 & 0.25 & 0.13 & 0.00 & 0.25 \\
\hline$\rho_{\text {Iest }}$ & Inventory changes & Normal & 0.0 & 0.2 & 0.38 & 0.18 & 0.58 \\
\hline
\end{tabular}


Table 3. Estimated parameters (cont.)

\begin{tabular}{|c|c|c|c|c|c|c|c|}
\hline \multirow{2}{*}{\multicolumn{2}{|c|}{ Description }} & \multicolumn{3}{|c|}{ Prior Distribution } & \multicolumn{3}{|c|}{ Posterior Distribution } \\
\hline & & \multirow{2}{*}{ Distribution } & \multirow[t]{2}{*}{ Mean } & \multirow[t]{2}{*}{$\mathrm{SD}$} & \multirow[t]{2}{*}{ Mean } & \multicolumn{2}{|c|}{ Cred. Interval } \\
\hline \multicolumn{4}{|c|}{ Exogenous Shocks } & & & & \\
\hline$\varepsilon_{B}$ & Domestic risk premium shock & Inv-gamma & 1.0 & $\inf$ & 0.57 & 0.29 & 0.85 \\
\hline$\varepsilon_{I}$ & Investment adjustment shock & Inv-gamma & 1.0 & $\inf$ & 3.54 & 1.81 & 5.30 \\
\hline$\varepsilon_{C}$ & Household preference shock & Inv-gamma & 1.0 & $\inf$ & 8.80 & 4.76 & 12.80 \\
\hline$\varepsilon_{M}$ & Import adjustment cost shock & Inv-gamma & 1.0 & $\inf$ & 9.01 & 6.54 & 11.32 \\
\hline$\varepsilon_{A}$ & Administered shock & Inv-gamma & 1.0 & $\inf$ & 1.40 & 1.15 & 1.64 \\
\hline$\varepsilon_{P}$ & Price markup shock & Inv-gamma & 1.0 & $\inf$ & 0.79 & 0.57 & 1.00 \\
\hline$\varepsilon_{\bar{\Pi}_{C}}$ & Inflation target shock & Inv-gamma & 1.0 & $\inf$ & 0.14 & 0.12 & 0.16 \\
\hline$\varepsilon_{W}$ & Wage markup shock & Inv-gamma & 1.0 & $\inf$ & 1.38 & 1.09 & 1.68 \\
\hline$\varepsilon_{D}$ & Transitory technology shock & Inv-gamma & 1.0 & $\inf$ & 1.13 & 0.93 & 1.33 \\
\hline$\varepsilon_{Z}$ & Permanent technology shock & Inv-gamma & 1.0 & inf & 0.17 & 0.14 & 0.20 \\
\hline$\varepsilon_{Q}$ & UIP shock & Inv-gamma & 1.0 & $\inf$ & 0.80 & 0.41 & 1.18 \\
\hline$\varepsilon_{B^{*}}$ & Country risk premium shock & Inv-gamma & 1.0 & $\inf$ & 0.38 & 0.31 & 0.45 \\
\hline$\varepsilon_{G}$ & Government consumption shock & Inv-gamma & 1.0 & $\inf$ & 1.73 & 1.41 & 2.03 \\
\hline$\varepsilon_{T}$ & Tax rate shock & Inv-gamma & 1.0 & $\inf$ & 0.48 & 0.40 & 0.56 \\
\hline$\varepsilon \bar{S}$ & Primary surplus target shock & Inv-gamma & 1.0 & $\inf$ & 0.29 & 0.24 & 0.34 \\
\hline$\varepsilon_{R}$ & Monetary policy shock & Inv-gamma & 1.0 & $\inf$ & 0.32 & 0.25 & 0.38 \\
\hline$\varepsilon_{P^{*}}$ & Foreign price markup shock & Inv-gamma & 1.0 & $\inf$ & 3.89 & 2.67 & 5,08 \\
\hline$\varepsilon_{\Pi *}$ & Foreign inflation shock & Inv-gamma & 1.0 & $\inf$ & 0.85 & 0.70 & 1.00 \\
\hline$\varepsilon_{R^{*}}$ & Foreign interest rate shock & Inv-gamma & 1.0 & $\inf$ & 0.19 & 0.15 & 0.22 \\
\hline$\varepsilon_{Y^{*}}$ & World demand shock & Inv-gamma & 1.0 & $\inf$ & 2.87 & 2.38 & 3.35 \\
\hline$\varepsilon_{Q^{M *}}$ & Imports relative price shock & Inv-gamma & 1.0 & $\inf$ & 1.85 & 1.53 & 2.16 \\
\hline$\varepsilon_{V^{*}}$ & Foreign investors's risk aversion shock & Inv-gamma & 1.0 & inf & 6.54 & 5.43 & 7.62 \\
\hline$\varepsilon_{M^{*}}$ & World import demand shock & Inv-gamma & 1.0 & $\inf$ & 18.73 & 11.19 & 26.29 \\
\hline$\varepsilon_{\text {Iest }}$ & Inventories changes shock & Inv-gamma & 1.0 & $\inf$ & 0.69 & 0.57 & 0.81 \\
\hline \multicolumn{8}{|c|}{ Measurement Errors } \\
\hline$\varepsilon_{m e}^{Y}$ & GDP growth & Inv-gamma & 0.25 & $\inf$ & 0.08 & 0.06 & 0.11 \\
\hline$\varepsilon_{m e}^{\pi_{C}}$ & CPI Inflation & Inv-gamma & 0.25 & $\inf$ & 0.12 & 0.10 & 0.14 \\
\hline
\end{tabular}




\subsection{Estimation Results}

We used the Dynare program for estimation (STÉPHANE et al., 2011). Posterior distributions for the parameters were computed using the Metropolis-Hastings algorithm, which relies on the Monte Carlo Markov Chain (MCMC) procedure. ${ }^{22}$ Table 3 presents the mean and the credible interval ( $5^{\text {th }}$ and $95^{\text {th }}$ percentiles) for the estimated parameters. As mentioned before, Figure 2 provides the graphs of the priors and posteriors of the structural parameters.

Observed data played an important role in determining the estimates for large part of the parameters. In other words, the data was informative in the estimation process. Many posteriors are tighter than their corresponding priors or are centered on different points of the support. We can observe these patterns in most of the parameters related to rigidity and indexation of price and wages, real frictions, and monetary and fiscal policies. The same occurs for parameters of the $\operatorname{AR}(1)$ processes and innovations. The main exceptions are the inverse of intertemporal elasticity of substitution, $\sigma$ - usually of difficult identification - the elasticity of substitution between imported and domestic inputs in some sectors, and the administered price rule parameters.

Some results emerge from the posteriors for which data was more informative. The posterior mean for the habit persistent parameter $(\tilde{\kappa})$ was smaller than that in the prior, implying, for $\tilde{\kappa} /(1+\tilde{\kappa})$, a mean of 0.43 , instead of 0.46 . The estimated sensitivity of the country risk premium to net foreign assets $\left(\varphi_{B}^{*}\right)$ and foreign investors' risk aversion $\left(\varphi_{V}^{*}\right)$ is lower too.

In the consumption goods sector, the rigidity of freely-set prices is higher than the embedded in the prior. As a matter of fact, the mean of the posterior of $\theta_{F}$ is 0.74 , which implies that, in the model, prices would be adjusted optimally every four quarters instead of three. The estimation was rather informative - the $90 \%$ credible interval goes from 0.68 to 0.81 . On the other hand, the posterior mean of the indexation parameter for those prices was lower than the prior mean $(0.33$ against 0.65 ). Note that its complement, 0.67 , does not mean that prices are not indexed, but they are so to the inflation target instead of the past inflation. Concerning wages, the estimation confirmed the degree of wage rigidity, but indicated a lower degree of indexation to the past inflation than the embedded in the priors. On the other hand, the likelihood was not informative about the parameters governing the prices of investment goods and imported inputs in domestic currency, which is related to the fact that those variables are non observables in the estimation.

Regarding monetary policy parameters, the estimations indicate relatively high degree of interest-rate smoothing (mean of $\gamma_{R}$ equal to 0.79) and response to inflation (mean of $\gamma_{\Pi}$ equal to 2.43), and a response to the output gap lower than

\footnotetext{
${ }^{22}$ We ran two blocks, with one million draws each. The resulting acceptance rates were 0.2366 and 0.2310 . We disregarded the first $50 \%$ of the draws. The multivariate diagnosis indicates that the estimation converged.
} 
the one set in the prior (mean of $\gamma_{Y}$ equal to 0.15 , which, for an annualized interest rate, corresponds to 0.60). ${ }^{23}$ For fiscal policy, the means of the posteriors of $\phi_{S}$ and $\phi_{\bar{S}}$ were a little higher than those in the priors, but with a lower response of the targets to the debt level (parameter $\phi_{B}$ ).

In terms of autoregressive parameters, we stress the high degree of persistence in the cases of temporary shocks to technology and shocks to the domestic risk premium and exchange rate. Concerning the standard deviation of the innovations, we should be careful about the interpretation because, in some cases, the shock enters equilibrium conditions in the model variables through a constant lower than one, implying in practice a lower volatility for the variable.

\section{Model Properties}

In this section, we assess the empirical performance of the model. We report the impulse response functions and evaluate how the transmission mechanisms of different shocks are reproduced by the model. We also compare the sample moments with the model-implied moments, and calculate the variance error decomposition. Finally, we show forecasting exercises.

\subsection{Impulse Response Functions}

We estimate impulse response functions for all shocks. In general, the responses are well behaved, with the expected signs and hump-shaped paths. For the sake of parsimony, we assess the responses to an interest rate shock, wage markup shock, investment shock, exchange rate shock, fiscal shock, and permanent technology shock. Therefore, we are evaluating the results of shocks of different nature shocks to policy, aggregate supply, and aggregate demand. Figures 3 to 8 present those responses. ${ }^{24}$ We record the path of the main macroeconomic variables plus the shock of interest. The solid line is the mean and the shaded area represents the $90 \%$ credible interval, implied by the posterior distributions of the parameters. We present the responses up to 12 quarters in order to focus on a more relevant horizon for monetary policy, but they converge back to the steady state.

\subsubsection{Interest Rate Shock}

The economy is hit by an interest rate shock of 100 basis points $(0.25 \%$ in quarterly terms) (Figure 3). Household consumption and investment decrease, leading to a fall in output. The presence of habit persistence in consumption and adjustment costs in investment makes their responses hump-shaped, and so is the

\footnotetext{
${ }^{23}$ The parameter means are higher than those found by MINELLA and SOUZA-SOBRINHO (2013), which used a single-equation estimation of the Taylor rule for Brazil, without including an output gap term. Their point estimates for the interest-rate smoothing component and for the coefficient on expected inflation are 0.62 and 1.57 , respectively.

${ }^{24}$ See the working paper version for the impulse response functions to all remaining shocks.
} 
output response. Note that the response of investment is stronger than that of consumption.

Due to the UIP condition, the higher domestic interest rate results in an appreciation of the domestic currency (a drop in the exchange rate measured as units of domestic currency per foreign currency). As a consequence, exports decline as expenditure-switching effects push away the international demand from domestic goods towards foreign produced goods. Since we assume pricing-to-market and price rigidity, the reduction in exports is not pronounced though. In the case of imports, however, there are two transmission channels acting in opposite directions. Due to the domestic currency appreciation, import prices fall, putting an upward pressure on imports. On the other hand, the fall in output pushes imports down. The income effect prevails, resulting in a negative net effect on imports. Furthermore, the reduction in imports is higher than that in exports, so net exports become positive. In other words, the contractionary effect of a monetary policy shock improves the trade balance, which is consistent with the empirical evidence for Brazil. ${ }^{25}$

The downturn in output leads to a reduction in tax revenues. In order to meet the target for the primary surplus, government lowers its consumption. Moreover, since the lower output and the higher interest payments make the government debt-to-GDP ratio to deviate from its steady-state level, government also raises the primary surplus target to bring debt back to its long-run level. As a consequence, in the fourth quarter, the fall in government consumption surpasses the output contraction. Therefore, fiscal policy behaves in a procyclical way.

Because of the output downturn, demand for labor goes down, leading to a reduction in nominal wages (not shown). The response of real wages is smoother and delayed due to the initial drop in inflation. The lower demand for capital also reduces the rental rate of capital (not shown). The combination of lower economic activity and exchange rate appreciation — both pushing marginal costs downwards - drives inflation below the target. Notice that inflation also displays a humpshaped response. Moreover, the response of administered prices is slower and less strong than that of freely-set prices, but at the same time is more persistent. The trough of the four-quarter inflation of administered prices occurs in the sixth quarter and is 0.20 percentage points (p.p.), whereas that of freely-set prices takes place in the fourth quarter and is 0.31 p.p. This delayed and more persistent response is due to the backward indexation rule assumed for administered prices and helps to account for the observed persistence of the overall CPI inflation in Brazil.

In terms of timing, most variables are nearly back to the steady state in two years. The largest drop in the four-quarter CPI inflation occurs in the fourth quarter, and is around 0.25 p.p. Note that, since the monetary authority reacts to

\footnotetext{
${ }^{25}$ Similar result is found by MINELLA and SOUZA-SOBRINHO (2013), who estimated a semi-structural model for Brazil, using similar sample period.
} 
its own shock through the Taylor rule, the interest rate in the first quarter is lower than 100 basis points and, more importantly, is already close to zero in the fourth quarter. Keeping the interest rate fixed for one year would generate a larger fall in inflation.

\subsubsection{Wage Markup Shock}

In this subsection we analyze here a domestic cost-push shock, which also has direct demand implications. A positive shock to wage markup immediately raises real labor income and consequently the marginal cost of consumption goods and, therefore, CPI inflation (Figure 4). Rule-of-thumb households spend their additional labor income on consumption goods, which boosts private consumption. The monetary authority responds to the inflationary pressures by raising the interest rate, which reduces investment and the consumption of optimizing households. The reduction in optimizers' consumption, however, is smaller than the increase in the consumption of rule-of-thumb households in the first year; so aggregate household consumption goes up.

As the interest rate rises the domestic currency appreciates, exerting an upward pressure on imports and lowering exports, which results in a trade deficit. Exports also go down because the higher production costs make them less competitive in world markets. Imports are also boosted by the substitution between domestic and imported inputs arising from the more expensive labor. The relative price of government consumption goods rises as the relative contribution of wages to their production costs is higher than for the other goods. As a result, the primary surplus-to-GDP ratio falls, triggering a reduction in government consumption. Thus, government consumption, which in general tends to follow output, drops more quickly, amplifying the contraction in aggregate demand.

In spite of the boost in private consumption, the reduction in investment, exports and government consumption, together with the increase in imports, prevails, resulting in a hump-shaped fall in output. In turn, the contraction in economic activity and the wage rise push labor demand down, which also displays a humpshaped path. The fall in employment lowers the consumption of rule-of-thumb households, and aggregate private consumption becomes negative in the second year.

Although the markup wage shock lasts basically only one period, the fourquarter CPI inflation peaks in the fourth quarter. Note that, as before, the response of administered prices is more delayed and persistent than that of freely-set prices. Thus, the wage also exerts a persistent effect on relative prices and inflation.

In a nutshell, a cost-push shock originated in the labor market increases inflation, private consumption and imports, and depresses investment, exports, government consumption, output and employment. Even though the positive effect 
on private consumption is short-lived, the shock has relatively persistent effects on output, employment and inflation. Note that this persistent effect does not arise from the estimated persistence of the shock itself, which is close to zero $\left(\rho_{W}=0.09\right)$, but results from the propagation mechanisms of the model.

\subsubsection{Investment Technology Shock}

A positive shock to investment technology (reduction in the adjustment cost) boosts the demand for investment (Figure 5). It raises employment and consequently the consumption of rule-of-thumb households. Following the fiscal rule, government consumption is also expansionary. As a result, output rises as well.

The surge in demand for labor and capital increases nominal wages and the rental rate of capital, putting upward pressures on production costs and inflation. The monetary authority then reacts by raising the interest rate in order to cool down domestic demand and inflation.

Imports increase more than output, in spite of the real exchange rate depreciation. The reason is that the share of imports used in the production of investment goods is higher than in the other sectors. Thus the model implies that investment booms are accompanied by higher imports and deterioration of the trade balance. This result is line with the evidence for Brazil that large part of fluctuations in imports are associated with investment fluctuations.

As the shock dies out and monetary contraction becomes more effective, output gap returns to zero and inflation goes back to target. However, the reduction of net foreign assets due to the trade deficit leads to a relatively persistent depreciation of the real exchange rate, which later will have a positive effect on exports.

Therefore, a positive innovation to investment technology boosts aggregate demand and output, and puts upward pressure on inflation. It also leads to shortlived deficits in the trade balance.

\subsubsection{Exchange Rate Shock}

An unexpected depreciation of the real exchange rate boosts exports and depresses imports (Figure 6), generating a significant positive trade balance. Note that the $1 \%$ innovation to the UIP condition increases the real exchange rate by about $9 \%$. The rise in import prices increases the marginal costs of consumption goods, pushing inflation upwards. The monetary authority then reacts by raising the interest rate, which reduces the consumption of optimizing households and depresses investment. Investment is also negatively affected by the increase in the relative price of investment goods (more intensive in imports than consumption goods). ${ }^{26}$ The higher inflation lowers real wages, and thus the consumption of ruleof-thumb households. Both consumption and investment display a hump-shaped

${ }^{26}$ For this effect in the Brazilian economy, see da SILVA FILHO (2007). 
response.

In the first year, the positive response of net exports offsets the contraction of the domestic private components of aggregate expenditure so that output is relatively stable. In the second year, however, the contractionary effect on domestic demand starts prevailing for the output path.

The shock is very persistent and the deviation of the real exchange rate from its equilibrium value approaches zero only at the end of the third year. The effects on the CPI inflation are even more persistent. The four-quarter CPI inflation peaks in the fifth quarter. The pass-through of the exchange rate to CPI inflation is around $7 \%$ in the first year and $14 \%$ in two years (calculated as the ratio of total CPI increase to the rise in the exchange rate in the first period).

In summary, positive innovations to the exchange rate are associated with higher inflation and exports, and lower consumption, investment, imports, and real wages. The initial effect on output is around zero, but becomes significantly negative in the second year.

\subsubsection{Fiscal Policy Shock}

Here, we define the fiscal policy shock as a shock to government consumption, whose response functions are shown in Figure 7. The positive innovation to government expenditure increases GDP and the demand for labor and imports. The rise in employment, in turn, boosts the consumption of rule-of-thumb households. As a result, aggregate private consumption goes up in the first quarters.

The higher demand for production factors raises the marginal cost of consumption goods, pushing inflation upwards. Monetary authority reacts by raising the interest rate. Consequently, investment and the consumption of optimizing households both drop below their long-run values in a hump-shaped manner. The trade balance initially deteriorates but the ensuing depreciation of the real exchange rate tends to restore the equilibrium in external accounts.

In the first quarters, the net effects on both private consumption and output are positive, whose paths closely follow that of government consumption. This result is in line with the empirical evidence on the effects of fiscal policy shocks. ${ }^{27}$ In terms of magnitude, a $1.0 \%$ shock in government expenditure raises output by $0.3 \%$ on impact, and by $0.1 \%$ on average over the first year. Given that the share of government consumption in GDP is 0.20 and the fact that government consumption actually rises by $1.3 \%$ in the first period, the model implies a government spending multiplier on output of 1.3 on impact (the multiplier says how many units of output an increase of one unit in the government consumption generates). Taking into account the total increase in output and government consumption in the first year, the multiplier is 1.1 . On impact, the multiplier on private consumption is 0.5. Note, however, that the monetary authority reacted in a counter-cyclical way,

\footnotetext{
${ }^{27}$ See, for instance, GALÍ et al. (2007). 
reducing the value of the multiplier. The latter would be higher if monetary policy was rather accommodative.

Therefore, the model suggests that a fiscal expansion leads to an increase in both output and inflation, and negative results in the trade balance in the short run. Although the values of fiscal multipliers vary across models and empirical studies for other countries, the values found in this paper are in line with the range found in both approaches. ${ }^{28}$

\subsubsection{Permanent Technology Shock}

A permanent technology shock affects positively all aggregate demand components and real wage, permanently shifting their levels. In order to capture this feature, Figure 8 displays, for those variables, the deviation from the balanced growth path that would prevail in the absence of the permanent shock to technology. In other words, it records the permanent change in levels plus temporary deviations.

Initially, the strongest responses are those of investment and exports. Capital becomes more productive, encouraging capital accumulation. Exports are benefited by the fall in marginal costs, which increases their competitiveness and generates a mild trade surplus on impact. Also in the first quarter, the demand for labor drops as it is possible to produce the same amount of goods with less inputs. Nevertheless, as aggregate demand rises in the following quarters, more labor is required in the production process.

The higher productivity is translated into higher real wages and, in the short run, into lower marginal costs. Later on, however, the increase in the return to capital raises production costs and pushes inflation up. The monetary authority then responds by raising the interest rate, which appreciates the domestic currency and boosts imports even further.

In the long run, inflation goes back to the target, but the levels of all variables containing a real unit root remain permanently higher, in the new balanced-growth path.

\subsection{Moment Conditions and Variance Error Decomposition}

We simulate the model to generate second order moments, and compare them to those from the data (Table 4). The results are mixed, as the model matches some empirical moments but tends to overestimate others.

Regarding real variables, the model replicates fairly well the standard deviation of the quarterly growth rates of investment, exports and imports. In contrast, the volatility generated by the model for the growth rates of consumption, government consumption, employment and GDP is higher than those from the data. The

\footnotetext{
${ }^{28}$ For a comparison of the fiscal multiplier accross different structural models, see COENEN et al. (2010).
} 
results in terms of relative volatility are better. In accordance with the data, investment, exports and imports are substantially more volatile than output, and consumption volatility is similar to that of output.

Concerning nominal and financial variables, the results are mixed as well. The implied volatility for real wage change, real exchange rate, and administered prices are relatively close to the empirical moments. However, for CPI inflation, freelyset prices, and nominal interest rate, the model generates higher second order moments.

We also calculate the variance forecast error decomposition for the main variables. Table 5 presents the results for quarter-on-quarter GDP growth and quarterly CPI inflation, over several horizons: one, four and eight quarters, as well as asymptotically.

For GDP growth, in the short run, the bulk of the variance of forecast errors is related to shocks to aggregate demand components - basically household preference shock, export demand shock, and import demand shock, and to a less extent to investment shock and fiscal policy shocks (government consumption and tax rate). At longer horizons, shocks to transitory technology and domestic risk premium also gain relevance. In contrast, monetary policy shocks were not important for the forecast errors. Note that we are referring to the role played by the shock and not to the systematic component of the rule.

In the case of CPI inflation, the forecast error variance is dominated by price shocks, although their importance diminishes at longer horizons. Shocks to price markup, administered prices and wage markup account for $76 \%$ of the forecast error variance over one-quarter horizon. In the eight-quarter horizon, they respond for $47 \%$. At longer horizons, the shocks to domestic risk premium, transitory technology and exchange rate gain relevance too.

\subsection{Forecasting Exercises}

In this subsection, we assess the forecasting performance of the model and analyze the forecasts in two specific moments. We estimate the root-mean-squared errors (RMSE) of the forecasts using SAMBA, and compare them to usual benchmarks, where the forecast is given by the following: i) the last observed value; ii) the sample average; and iii) a Bayesian vector autoregressive (BVAR) model. When available, we also compare the model forecasts to those from a survey conducted by the BCB among professional forecasters. 
Table 4. Moment conditions

\begin{tabular}{|c|c|c|c|}
\hline \multirow{2}{*}{\multicolumn{2}{|c|}{ Variable }} & \multicolumn{2}{|c|}{$\begin{array}{l}\text { Standard } \\
\text { Deviation }\end{array}$} \\
\hline & & Empirical & $\begin{array}{l}\text { Model- } \\
\text { Implied }\end{array}$ \\
\hline \multicolumn{4}{|c|}{ Domestic Observable Variables } \\
\hline$\Delta y_{t}^{o b s}$ & GDP (quarter-on-quarter growth) & 1.1914 & 2.8305 \\
\hline$\Delta c_{t}^{o b s}$ & Households' consumption (q-o-q growth) & 1.1931 & 2.5244 \\
\hline$\Delta i_{t}^{o b s}$ & Investment (q-o-q growth) & 4.2804 & 4.3137 \\
\hline$\Delta g_{t}^{o b s}$ & Government consumption (q-o-q growth) & 1.4773 & 5.1032 \\
\hline$\Delta x_{t}^{o b s}$ & Exports of goods and services (q-o-q growth) & 6.3540 & 6.9336 \\
\hline$\Delta m_{t}^{o b s}$ & Imports of goods and services (q-o-q growth) & 5.7670 & 5.6441 \\
\hline$\Delta n_{t}^{o b s}$ & Number of employed people (q-o-q growth) & 0.6323 & 4.4378 \\
\hline$\Delta w_{t}^{o b s}$ & Real wage (q-o-q growth) & 1.7699 & 1.9060 \\
\hline$\Pi_{t}^{C}$ & CPI inflation (\% per quarter) & 1.0037 & 1.3403 \\
\hline $\bar{\Pi}_{t}^{C}$ & CPI inflation target. (\% per quarter) & 0.1428 & 0.2560 \\
\hline$\Pi_{t}^{A}$ & Administered price inflation ( $\%$ per quarter) & 1.6328 & 1.8093 \\
\hline$\Pi_{t}^{F}$ & Free price inflation (\% per quarter) & 0.9783 & 1.5016 \\
\hline$\Pi_{t}^{X}$ & Export price inflation (\% per quarter) & 4.4661 & 5.099 \\
\hline$R_{t}$ & Nominal interest rate - Selic (\% per quarter) & 1.0659 & 1.2992 \\
\hline$S_{t}^{y}$ & Primary surplus-to-GDP ratio (quarterly GDP) & 0.7917 & 1.0817 \\
\hline $\bar{S}_{t}^{y}$ & Primary surplus target-to-GDP ratio (quarterly GDP) & 0.6055 & 1.2647 \\
\hline$Q_{t}$ & Real effective exchange rate (\% per quarter) & 19.9655 & 19.2850 \\
\hline$S_{t}^{B^{*}}$ & Country risk premium: EMBI Brazil (\% per quarter) & 1.0026 & 1.0515 \\
\hline$I_{\text {est }}$ & Inventory investment (implied contribution to GDP) & 0.7746 & 0.7499 \\
\hline \multicolumn{4}{|c|}{ Foreign Observable Variables } \\
\hline$\Delta y_{t}^{*^{o b s}}$ & World imports (q-o-q growth) & 3.0082 & 2.9332 \\
\hline$Q_{t}^{M^{*}}$ & Relative price of imports & 4.3027 & 3.8927 \\
\hline$\Pi_{t}^{*}$ & World inflation - US (\% per quarter) & 0.8361 & 0.8612 \\
\hline$V_{t}^{*}$ & Foreign investors' risk aversion - VIX & 9.0339 & 10.5997 \\
\hline$R_{t}^{*}$ & World nominal interest rate - Fed Funds (\% per quarter) & 0.5180 & 0.4284 \\
\hline
\end{tabular}


Table 5. Forecast Error Variance Decomposition

\begin{tabular}{|c|c|c|c|c|c|c|c|c|}
\hline \multirow[b]{3}{*}{ Shock } & \multicolumn{4}{|c|}{ Real GDP Growth } & \multicolumn{4}{|c|}{ CPI Inflation } \\
\hline & \multicolumn{8}{|c|}{ Forecast Horizon } \\
\hline & $1 \mathrm{qtr}$ & $4 \mathrm{qtr}$ & $8 \mathrm{qtr}$ & Asympt & $1 \mathrm{qtr}$ & $4 \mathrm{qtr}$ & $8 \mathrm{qtr}$ & Asympt \\
\hline Administered prices & 0.39 & 1.61 & 0.96 & 1.06 & 23.58 & 17.56 & 12.22 & 11.18 \\
\hline Domestic risk premium & 4.60 & 13.06 & 8.94 & 9.78 & 4.52 & 11.63 & 17.19 & 16.79 \\
\hline Country risk premium & 0.01 & 0.03 & 0.05 & 0.07 & 0.06 & 0.17 & 0.20 & 0.18 \\
\hline Household preference & 17.29 & 11.52 & 12.93 & 11.85 & 1.50 & 1.97 & 1.64 & 1.53 \\
\hline Transitory technology & 0.22 & 10.47 & 9.92 & 10.55 & 9.87 & 14.92 & 16.14 & 17.73 \\
\hline Gov. consumption & 7.87 & 3.87 & 4.37 & 3.98 & 0.18 & 0.14 & 0.09 & 0.08 \\
\hline Investment & 7.75 & 9.85 & 7.02 & 6.67 & 0.54 & 0.74 & 0.58 & 0.63 \\
\hline Import demand & 15.29 & 9.47 & 15.09 & 14.33 & 3.98 & 4.37 & 3.03 & 2.73 \\
\hline Export demand & 26.12 & 15.34 & 16.23 & 14.78 & 0.59 & 0.36 & 0.24 & 0.31 \\
\hline Price markup & 0.85 & 0.61 & 0.63 & 0.60 & 37.99 & 14.54 & 8.44 & 7.33 \\
\hline Export price markup & 0.01 & 0.40 & 0.49 & 0.66 & 0.04 & 0.15 & 0.24 & 0.35 \\
\hline Real exchange rate & 0.27 & 0.34 & 0.97 & 2.26 & 1.19 & 5.01 & 9.63 & 12.38 \\
\hline Monetary policy & 1.06 & 2.85 & 1.88 & 1.94 & 0.72 & 1.74 & 2.27 & 2.07 \\
\hline Wage markup & 0.38 & 6.58 & 8.22 & 9.90 & 14.54 & 25.75 & 26.09 & 23.30 \\
\hline Permanent technology & 0.06 & 0.60 & 0.39 & 0.37 & 0.00 & 0.00 & 0.02 & 0.07 \\
\hline Tax rate & 9.98 & 6.40 & 6.24 & 5.75 & 0.36 & 0.36 & 0.26 & 0.25 \\
\hline Primary surplus target & 0.64 & 0.80 & 0.82 & 0.80 & 0.07 & 0.12 & 0.12 & 0.12 \\
\hline Inflation target & 0.20 & 0.70 & 0.61 & 0.72 & 0.03 & 0.03 & 0.75 & 1.50 \\
\hline Foreign inflation & 0.00 & 0.01 & 0.01 & 0.01 & 0.00 & 0.00 & 0.01 & 0.03 \\
\hline Import price in USD & 0.17 & 0.13 & 0.10 & 0.13 & 0.03 & 0.13 & 0.26 & 0.34 \\
\hline Foreign interest rate & 0.00 & 0.00 & 0.03 & 0.07 & 0.06 & 0.20 & 0.34 & 0.36 \\
\hline World income & 6.83 & 5.36 & 4.05 & 3.70 & 0.11 & 0.03 & 0.11 & 0.63 \\
\hline $\begin{array}{l}\text { Foreign investor risk } \\
\text { aversion }\end{array}$ & 0.00 & 0.01 & 0.02 & 0.02 & 0.02 & 0.07 & 0.10 & 0.09 \\
\hline
\end{tabular}


For this forecasting exercise, we used the following procedures. We assess forecasts for one to eight quarters ahead. The first forecast is made with data up to 2004Q4, and then we update actual data sequentially until 2008Q4. Note that our sample size goes from 1999Q3 to 2010Q2, which implies that the number of periods for the estimation of the RMSE is relatively low — only 16 data points. ${ }^{29}$ Thus, we should consider the results with some caution. Due to the short size of the sample, the estimated parameters are based on information for the entire sample period. Ideally, we should reestimate the parameters using only the information up to the last quarter before the forecasting period. However, we did not pursue this avenue as we would be using only 22 data points for estimating the parameters to be used in the forecasting cycle starting in 2004Q4. On the other hand, we estimate all 58 non-observable variables using the information available only up to that data point. In other words, in each forecasting cycle, we reestimate the non-observables. Furthermore, for that estimation, we remove the average from the series based on the values up to that data point, and add this average when making the forecast. Thus, we do not use the averages over the whole sample. Moreover, we conduct only unconditional forecasting. This means that, even for foreign variables, their forecasted trajectories are given by the $\mathrm{AR}(1)$ processes built in the model. The same is applied for domestic variables modeled as $\operatorname{AR}(1)$ processes.

The BVAR was estimated using four variables, which are also used as observables in the estimation of SAMBA: GDP growth rate, CPI inflation, real effective exchange rate, and Selic interest rate. As in SAMBA, we used quarterly data, starting in 1999Q3. In the case of the BVAR, we reestimate the model every forecasting cycle.

We evaluate the forecasting performance for four-quarter CPI inflation (price level in quarter $i$ compared to price level in quarter $i-4)$, year-on-year GDP growth rate (GDP volume in quarter $i$ compared to the GDP volume in quarter $i-4$ ), and the Selic rate (measured as \% per quarter). Figure 9 illustrates the results. In the case of the CPI inflation, SAMBA forecasting performance is superior to those of the mean procedures at all horizons and of the last observation at fiveto eight-quarter horizons. However, when compared to BVAR performance, the results are mixed. Up to five quarters, the point estimates of RMSE generated by the BVAR are lower than those arising from SAMBA, but are higher for six- to eight-quarter horizons. Considering the four-, six- and eight-quarter horizons, the RMSEs for SAMBA are 1.74, 1.67 and 1.63, respectively, whereas for the BVAR are $1.34,1.75$ and 1.79 , respectively. Note that those forecasts are made in a mechanical way.

For the year-on-year GDP growth rate, the results are less promising. The RMSE is large for all models. Similarly to inflation, in terms of point values,

\footnotetext{
${ }^{29}$ If we consider periods without any overlap, it is only five data points in the case of fourquarter horizon.
} 
SAMBA provides worse results than the BVAR for horizons up to five quarters and better ones for longer horizons. Finally, in terms of forecasting for the Selic rate, SAMBA provides better performance than the other models for most of horizons. On the other hand, the RMSE seems large for all methods.

Finally, we conduct two exercises in order to have a better sense of SAMBA projections. We present the projections in two specific dates: 2004Q4, when most of the effects of the 2002-2003 confidence crisis had faded away, and 2008Q4, when GDP had plummeted as a result of the global crisis. Figure 10 shows the forecasts and corresponding actual values for four-quarter CPI inflation, year-on-year GDP growth, and Selic rate level (\% per year). The shaded areas represent 40\%, 60\% and $80 \%$ confidence intervals. They were estimated based on both the variances of the shocks and parameter uncertainty.

In general, the forecasts are in line with the actual values, mainly for inflation and GDP growth. In 2004Q4, the model predicted the fall in inflation and the increase in the GDP growth in the medium run, although it did not anticipate the rise in the interest rate. For the forecasts made in 2008Q4, the model predicted the fall in inflation, a further decrease in the y-o-y GDP growth and its resumption later on. In this exercise, the model overpredicted the Selic rate.

As mentioned earlier, all these exercises were unconditional ones and made in a mechanical way. Other countries' experience indicate that the combination of a DSGE model with specialists' forecasts - for some domestic variables for the very short run and for foreign variables at all horizons - can significantly improve the forecasting performance of the model.

\section{Conclusions}

We developed and estimated a DSGE model for the Brazilian economy. The model embeds features commonly found in standard DSGE models and aspects that are relevant for the Brazilian economy. In particular, SAMBA incorporates the presence of administered prices, an explicit target for the primary surplus, external finance of imports, and imports used as inputs in the production function.

The model has reasonable properties. The impulse response functions are well behaved and consistent with available evidence. This performance allows the use of the model as a tool for building up scenarios and assessing the impact of different shocks. The forecasting exercises are also encouraging, enabling the use of the model as part of a well-defined forecasting framework, which involves the use of experts' forecasts for domestic variables in the very short run and for external variables at all horizons. We should stress the role played by structural models in attaching economic interpretation, in a coherent way, to economic developments, scenario analysis and forecasting. In contrast with purely statistical models, structural models like SAMBA can be successfully used as a story-telling device in the policymaking process.

SAMBA is part of a broader research effort at the BCB to develop DSGE 
models for the Brazilian economy, which involves adding other important features to the models, such as financial intermediation and macroprudential policies. Until recently, the literature that incorporated financial frictions was still at its early stages. $^{30}$ As GERTLER and KIYOTAKI (2010) pointed out, large part of the earlier macroeconomics literature on financial frictions emphasized credit market constrains on nonfinancial borrowers and treated financial intermediaries largely as a veil, whereas the global crisis featured a disruption of financial intermediation.

\section{References}

ADOLFSON, M., LASÉEN, S., LINDÉ, J., \& VILLANI, M. (2007). Bayesian estimation of an open economy DSGE model with incomplete pass-through. Journal of International Economics, 72:481-511.

ADOLFSON, M., LASÉEN, S., LINDÉ, J., \& VILLANI, M. (2008). Evaluating an estimated new keynesian small open economy model. Journal of Economic Dynamics \& Control, 32:2690-2721.

AGÉNOR, P., ALPER, K., \& PEREIRA da SILVA, L. (2011a). Capital regulation, monetary policy and financial stability. Working Paper Series 237, Banco Central do Brasil.

AGÉNOR, P., ALPER, K., \& PEREIRA da SILVA, L. (2011b). Capital requirements and business cycles with credit market imperfections. Working Paper Series 231, Banco Central do Brasil.

ALtissimo, F., MOJON, B., \& ZAFFARONI, P. (2007). Fast micro and slow macro. Can aggregation explain persistence of infation? ECB Working Paper Series 729, ECB.

BAYOUMI, T., LAXTON, D., \& PESENTI, P. (2004). Benefits and spillovers of greater competition in Europe: A macroeconomic assessment. ECB Working Paper Series 341, ECB.

BONELLI, R. \& FONSECA, R. (1998). Ganhos de produtividade e de eficiência: Novos resultados para a economia brasileira. Pesquisa e Planejamento Econômico, 28.

CALVO, G. A. (1983). Staggered prices in a utility-maximizing framework. Journal of Monetary Economics, 12:383-398.

CANOVA, F. (2007). Methods for Applied Macroeconomic Research. Princeton University, Princeton.

\footnotetext{
${ }^{30}$ For initial efforts in this direction, see, for example, CHRISTIANO et al. (2007), and also AGÉNOR et al. (2011b,a) for calibrated DSGE models that include the financial system and deal with regulatory and macroprudential issues.
} 
CARVALHO, J. C. (1996). Estimativas do produto potencial, relação capital/produto e depreciação do estoque de capital. Textos Para Discussão 44, BNDES.

CHRISTIANO, L., EICHENBAUM, M., \& EVANS, C. (2005). Nominal rigidities and the dynamics effects of a shock to monetary policy. Journal of Political Economy, 113:1-45.

CHRISTIANO, L., TRABANDT, M., \& WALENTIN, K. (2007). Introducing financial frictions and unemployment into a small open economy model. Working Paper Series 214, Sveriges Riksbank.

CHRISTOFFEL, K., COENEN, G., \& WARNE, A. (2008). The new area wide model of the Euro area: A micro-founded open economy model for forecasting and policy analysis. ECB Working Paper Series 944, ECB.

COEnEN, G., ERCEG, C., FREEDMAN, C., FURCERI, D., KUMHOF, M., LALONDE, R., LAXTON, D., LINDÉ, J., MOUROUGANE, A., MUIR, D., MURSUlA, S., de RESENDE, C., ROBERTS, J., ROEGER, W., SNUDDEN, S., TRABANDT, M., \& in 't VELD, J. (2010). Effects of fiscal stimulus in structural models. Working Paper 10/73, IMF.

da SILVA FILHO, T. N. T. (2007). Is the investment-uncertainty link really elusive? The harmful effects of inflation uncertainty in Brazil. Working Paper Series 157, Banco Central do Brasil.

DEL NEGRO, M., SCHORFHEIDE, F., SMETS, F., \& R., W. (2007). On the fit of new keynesian models. Journal of Business and Economic Statistics, 25:123143.

ERCEG, C., GUERRIERI, L., \& GUST, C. (2006). SIGMA: A New Open Economy Model for Policy Analysis. International Journal of Central Banking, 2:550.

ERCEG, C. J., HENDERSON, D. W., \& LEVIN, A. T. (2000). Optimal monetary policy with staggered wage and price contracts. Journal of Monetary Economics, 46:281-313.

ERCEG, C. J., HENDERSON, D. W., \& LEVIN, A. T. (2009). Optimal monetary policy with staggered wage and price contracts. Working Paper 1084, Journal of Monetary Economics.

FREITAS, P. S. \& BUGARIN, M. (2007). A study of administered prices and optimal monetary policy: The Brazilian case. In 22nd Congress of the European Economic Association, Budapest. 
GALÍ, J., LÓPEZ-SALIDO, J. D., \& VALLÉS, J. (2007). Understanding the effects of government spending on consumption. Journal of the European Economic Association, 5:227-270.

GERTLER, M. \& KIYOTAKI, N. (2010). Financial intermediation and credit policy in business cycle analysis. Mimeo. NYU and Princeton.

GOUVÊA, S. (2007). Price rigidity in Brazil: Evidence from CPI micro data. Working Paper Series 143, Banco Central do Brasil.

McCALLUM, B. T. \& NELSON, E. (2000). Monetary policy for an open economy: An alternative framework with optimizing agents and sticky prices. Oxford Review of Economic Policy, 16:74-91.

MEDINA, J. P. \& SOTO, C. (2007). The Chilean business cycles through the lens of a stochastic general equilibrium model. Working Paper Series 457, Central Bank of Chile.

Minella, A., FREITAS, P. S., GOLDFAJN, I., \& MUINHOS, M. K. (2003). Inflation target in Brazil: Constructing credibility under exchange rate volatility. Journal of International Money and Finance, 22:1015-1040.

MINELLA, A. \& SOUZA-SOBRINHO, N. F. (2013). Monetary channels in Brazil through the lens of a semi-structural model. Economic Modelling, 30:405-419.

MURCHISON, S. \& RENNISON, A. (2006). ToTEM: The Bank of Canada's new quarterly projection model. Technical Report 97, Bank of Canada.

SMETS, F. \& WOUTERS, R. (2003). An estimated dynamic stochastic general equilibrium model of the Euro area. Journal of the European Economic Association, 1:1123-1175.

SMETS, F. \& WOUTERS, R. (2007). Shocks and frictions in US business cycles: A bayesian DSGE approach. American Economic Review, 97:586-606.

STÉPHANE, A., BASTANI, H., JUILlARD, M., MiHOUBI, F., PERENDIA, G., RATTO, M., \& VILLEMOT, S. (2011). Dynare: Reference manual, version 4. Dynare Working Papers 1, CEPREMAP.

VALLI, M. \& CARVALHO, F. A. (2010). Fiscal and monetary policy interaction: A simulation based analysis of a two-country new keynesian DSGE model with heterogeneous households. Working Paper Series 204, Banco Central do Brasil.

WOODFORD, M. (2003). Interest and Prices: Foundations of a Theory of Monetary Policy. Princeton University Press. 
Figure 1. Data series (after transformation)

GDP

(growth rate $-\%$ p.q.)

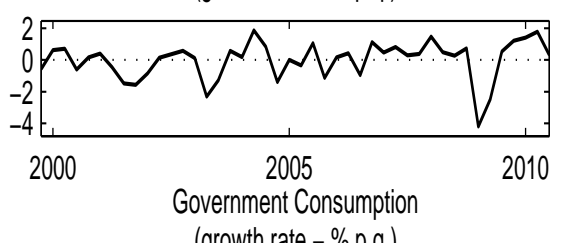

(growth rate - \% p.q.)

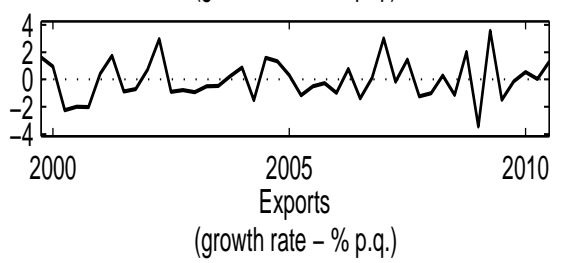

(growth rate $-\%$ p.q.)

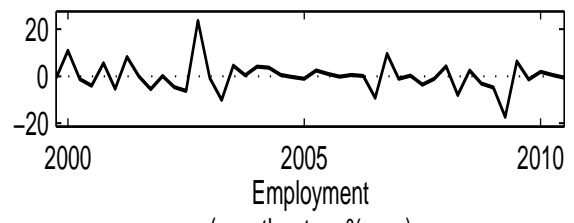

(growth rate - \% p.q.)

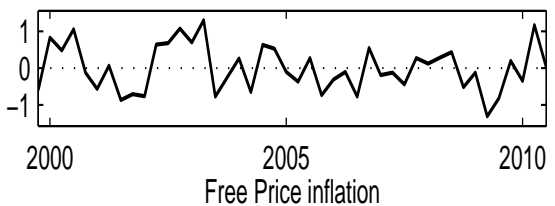

(\% p.q.)

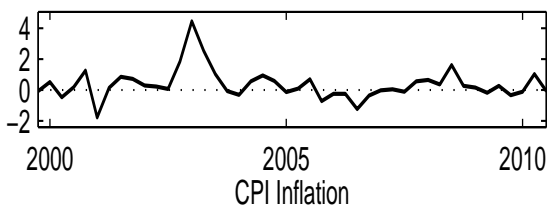

(\% p.q.)

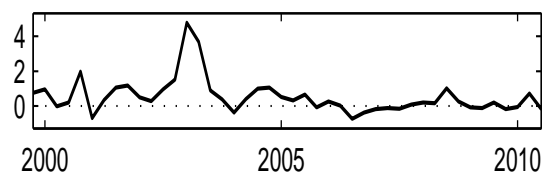

Private Consumption

(growth rate - \% p.q.
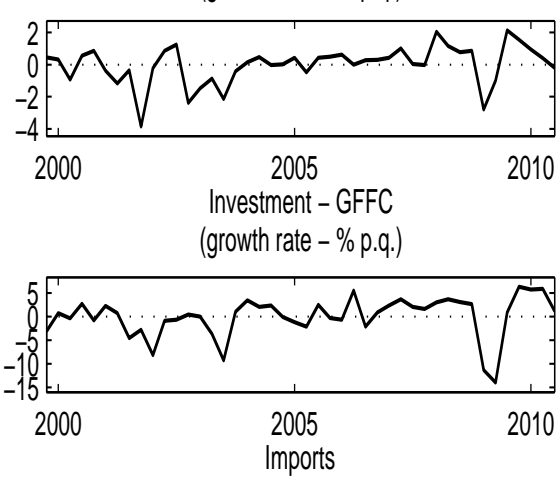

(growth rate - \% p.q.)

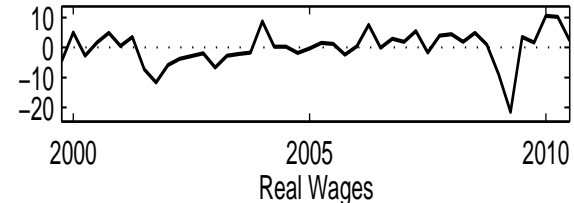

(growth rate $-\%$ p.q.)

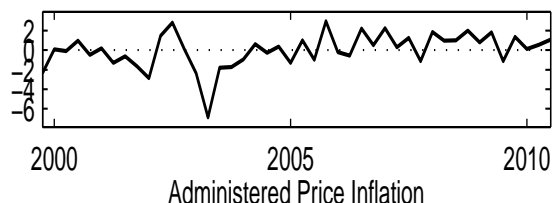
(\% p.q.)

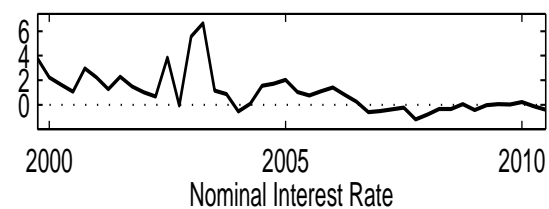

$(\%$ p.q.)

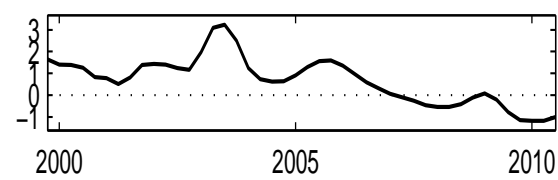


Figure 1. Data series (after transformation) (cont.)
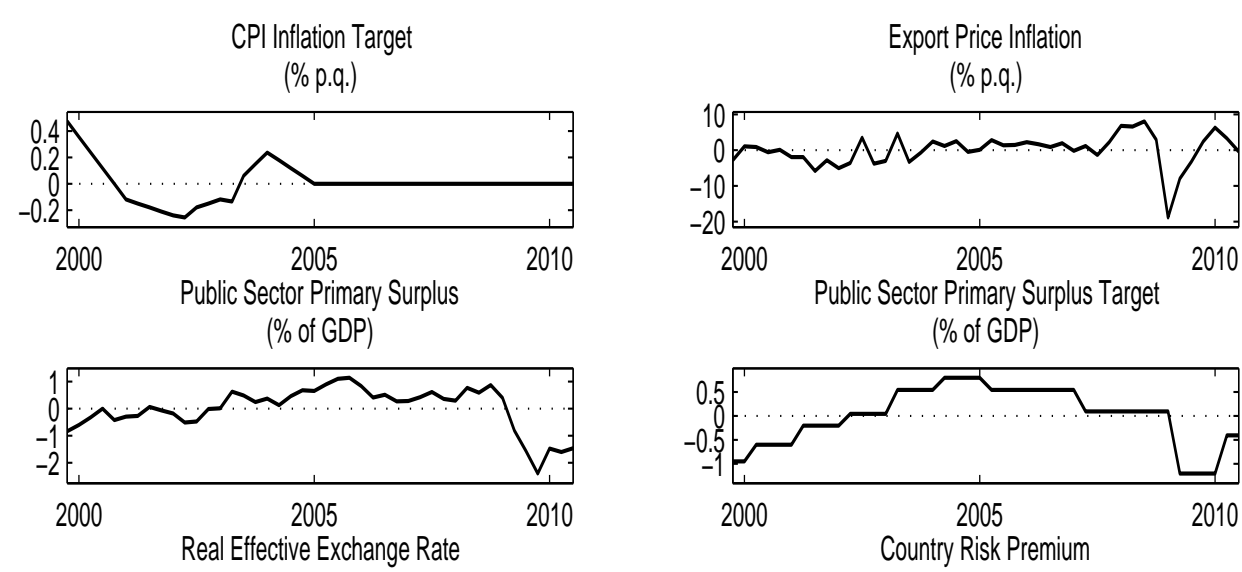
(\% of GDP)

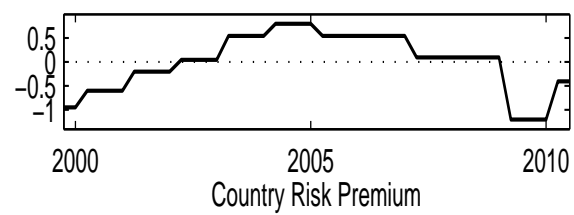

(\% deviation)

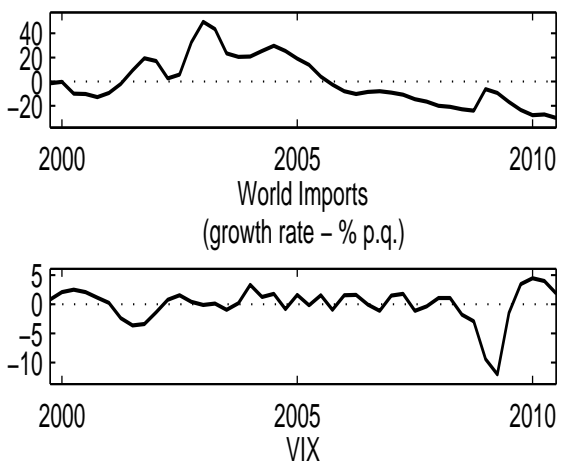

(p.p.)
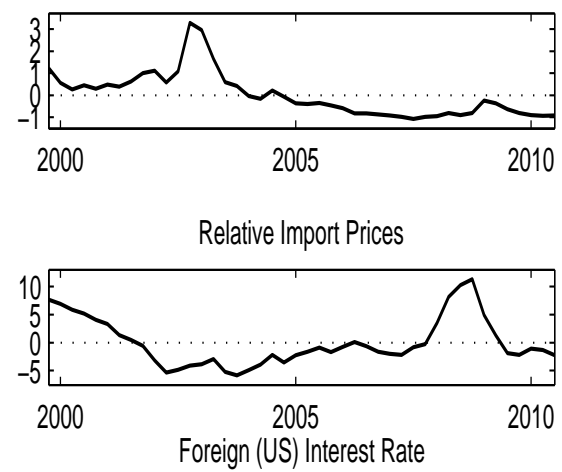

(p.p.)

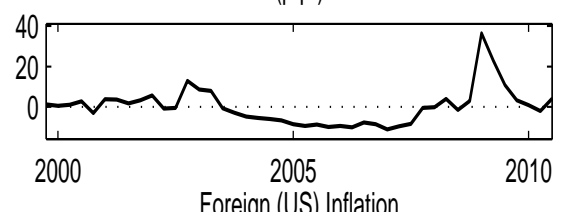

(\% p.q.)
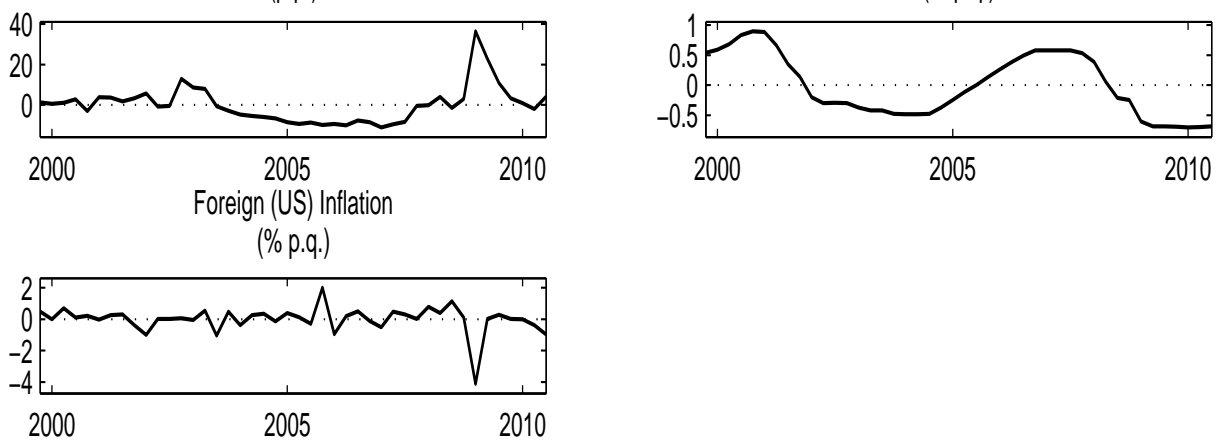
Figure 2. Priors and posteriors of the parameters
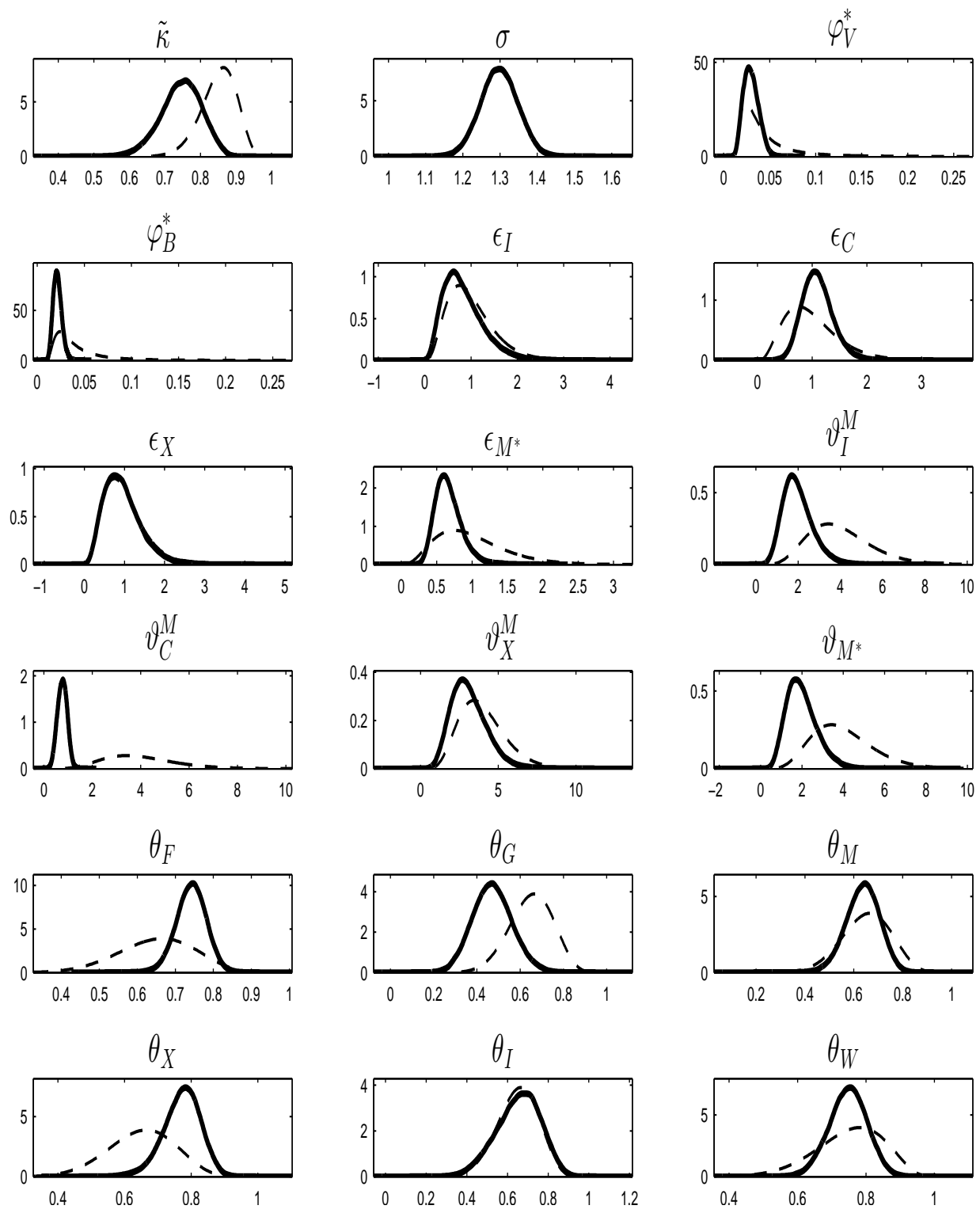

solid line $=$ posterior $;$ dashed line $=$ prior 
Figure 2. Priors and posteriors of the parameters (cont.)
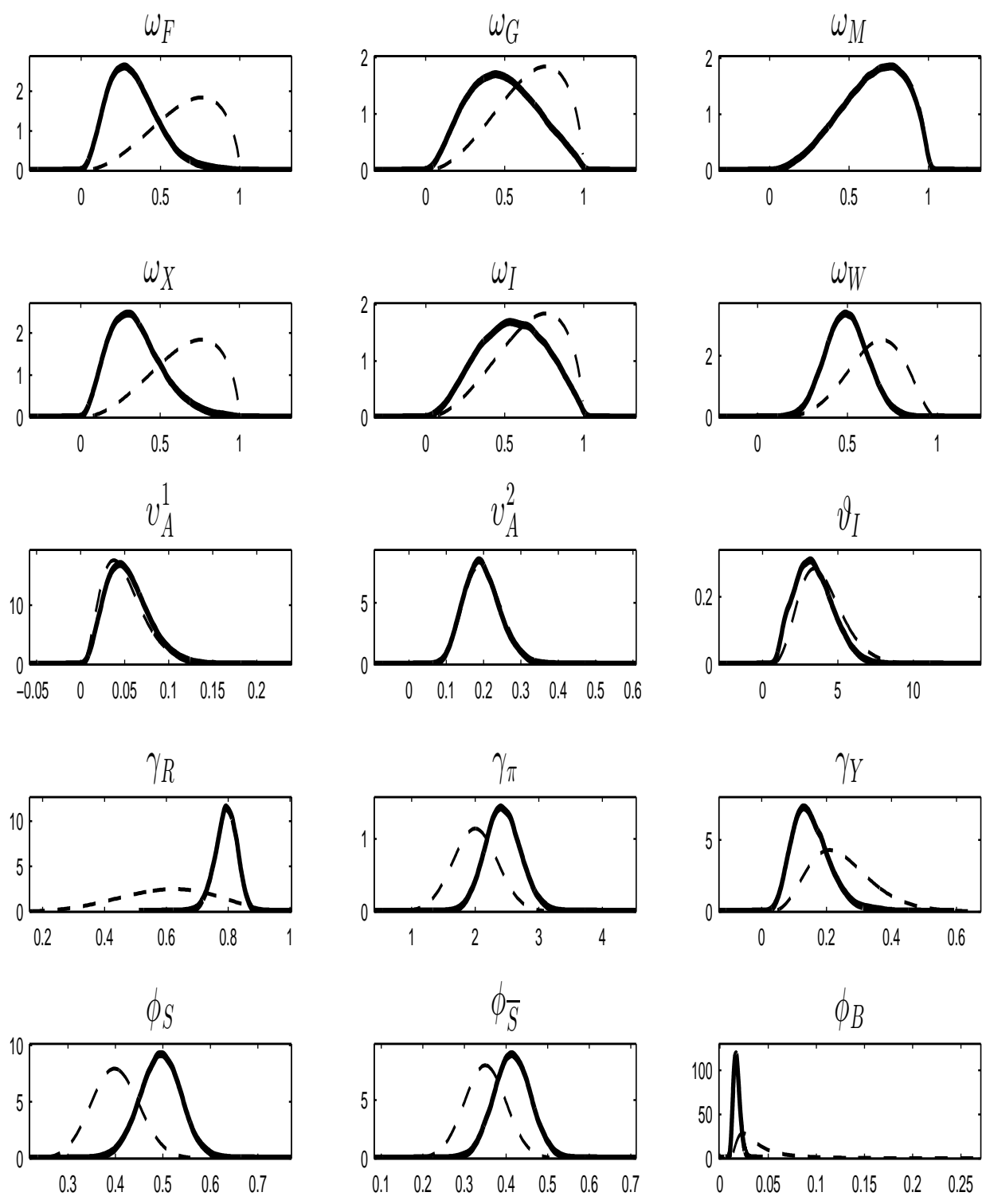

solid line $=$ posterior; dashed line $=$ prior 
Figure 3. Impulse Responses to a Monetary Policy Shock
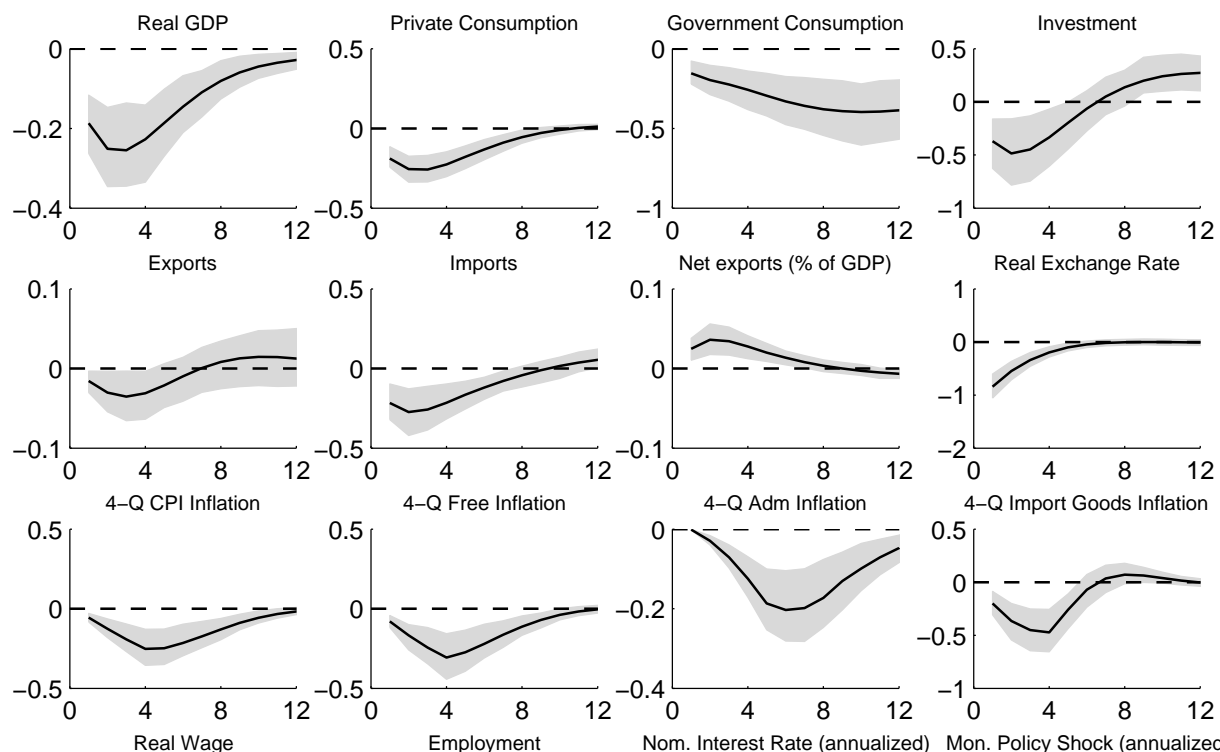

4-Q Import Goods Inflation
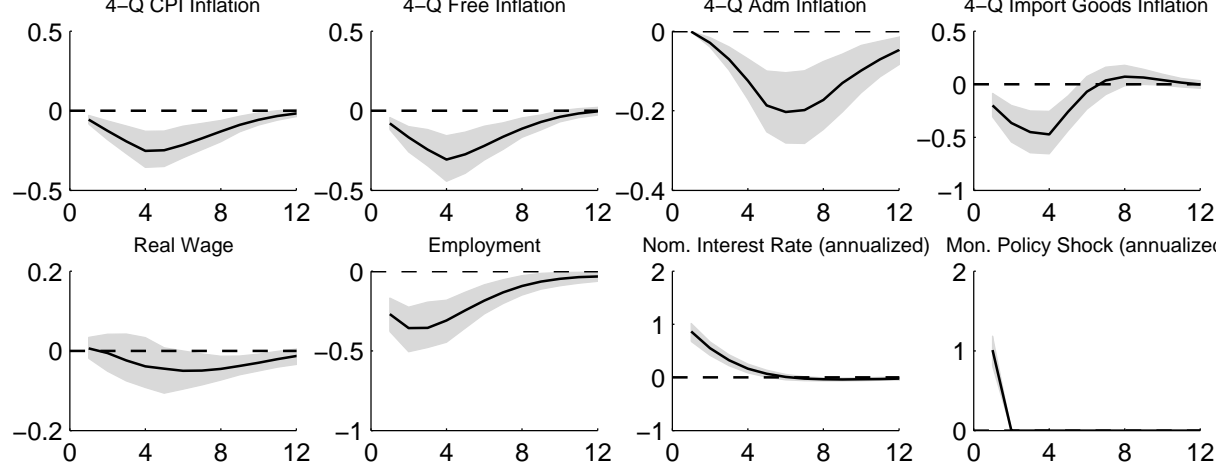
Figure 4. Impulse Responses to a Wage Markup Shock
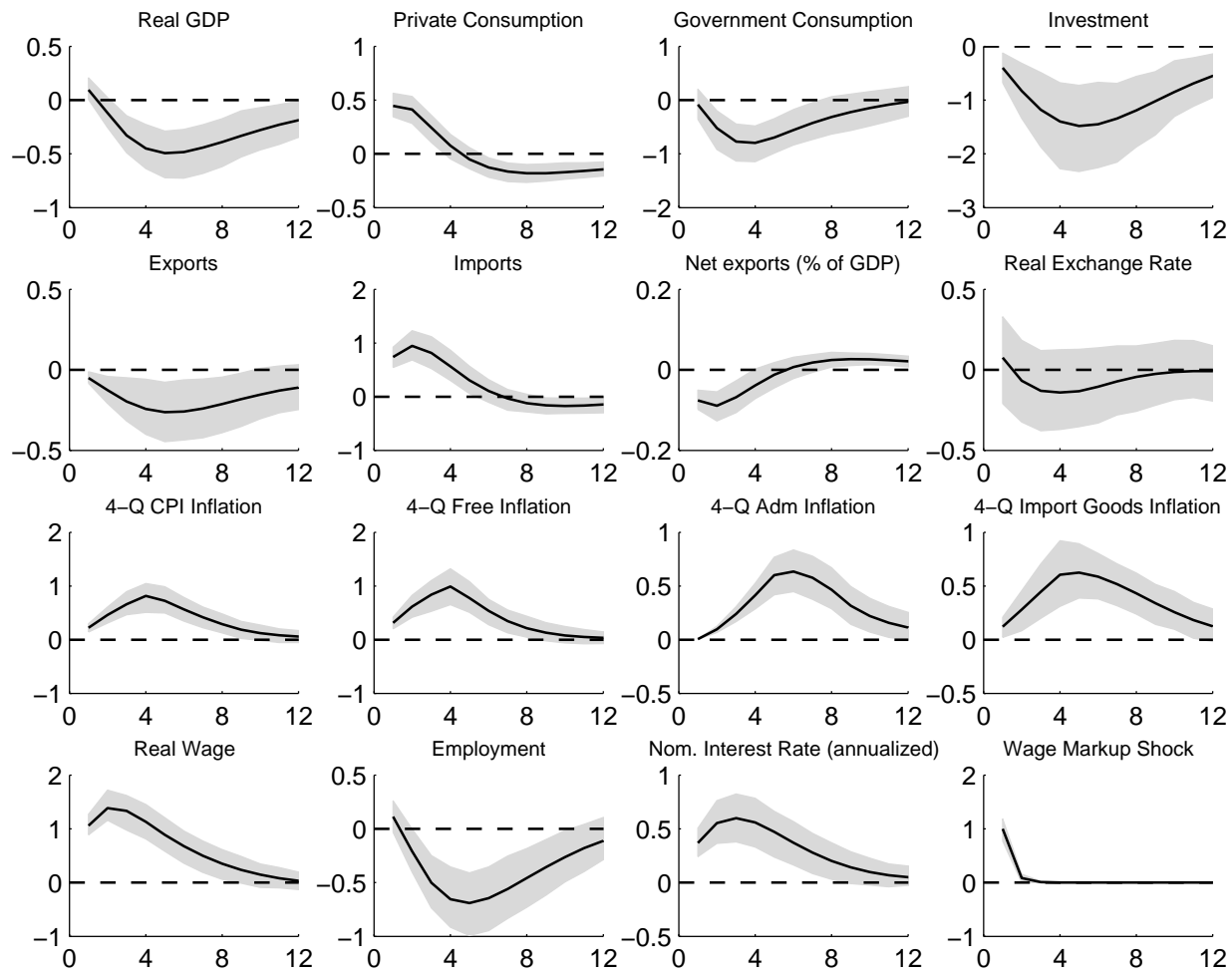
Figure 5. Impulse Responses to an Investment Shock
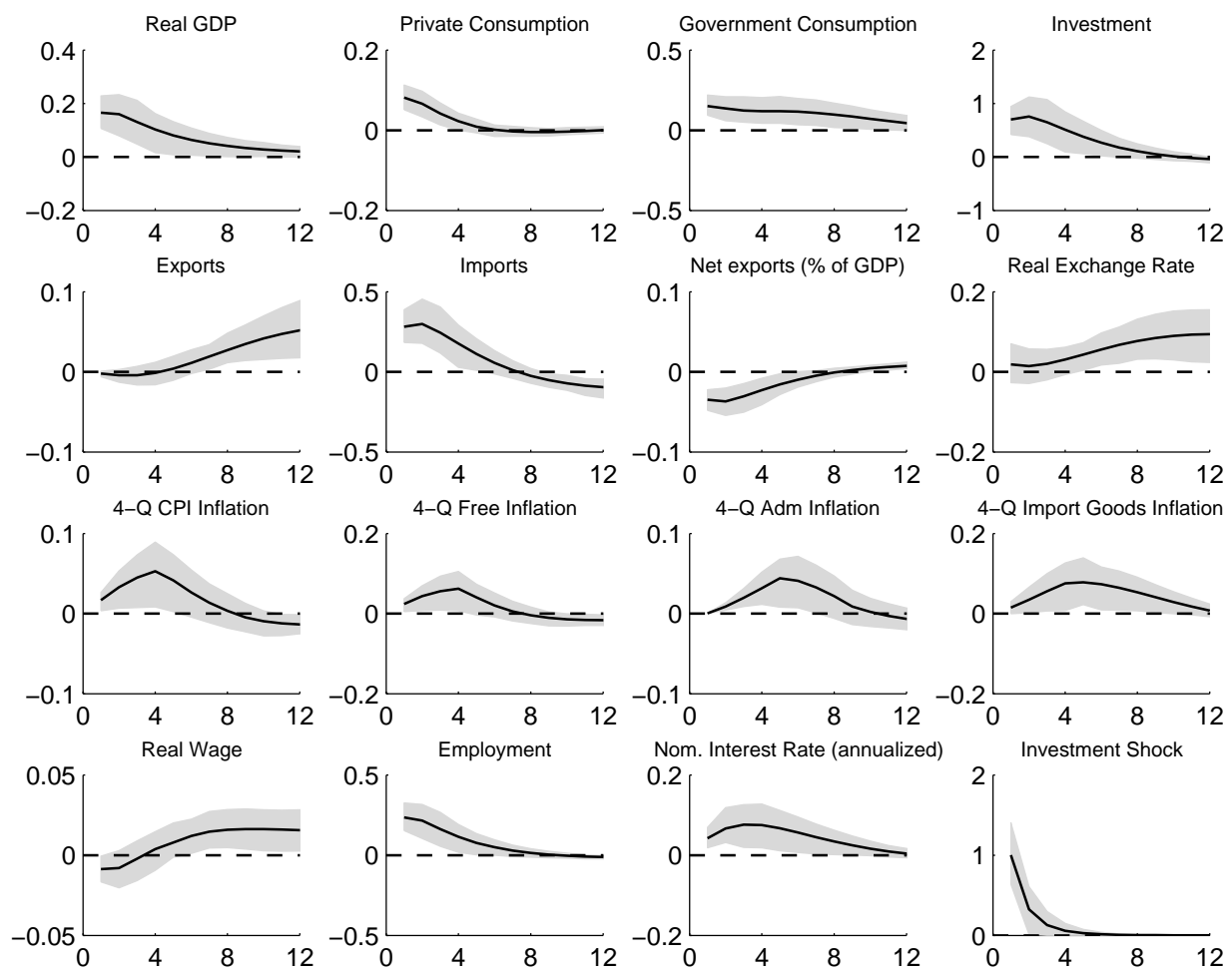
Figure 6: Impulse Responses to a Real Exchange Rate Shock
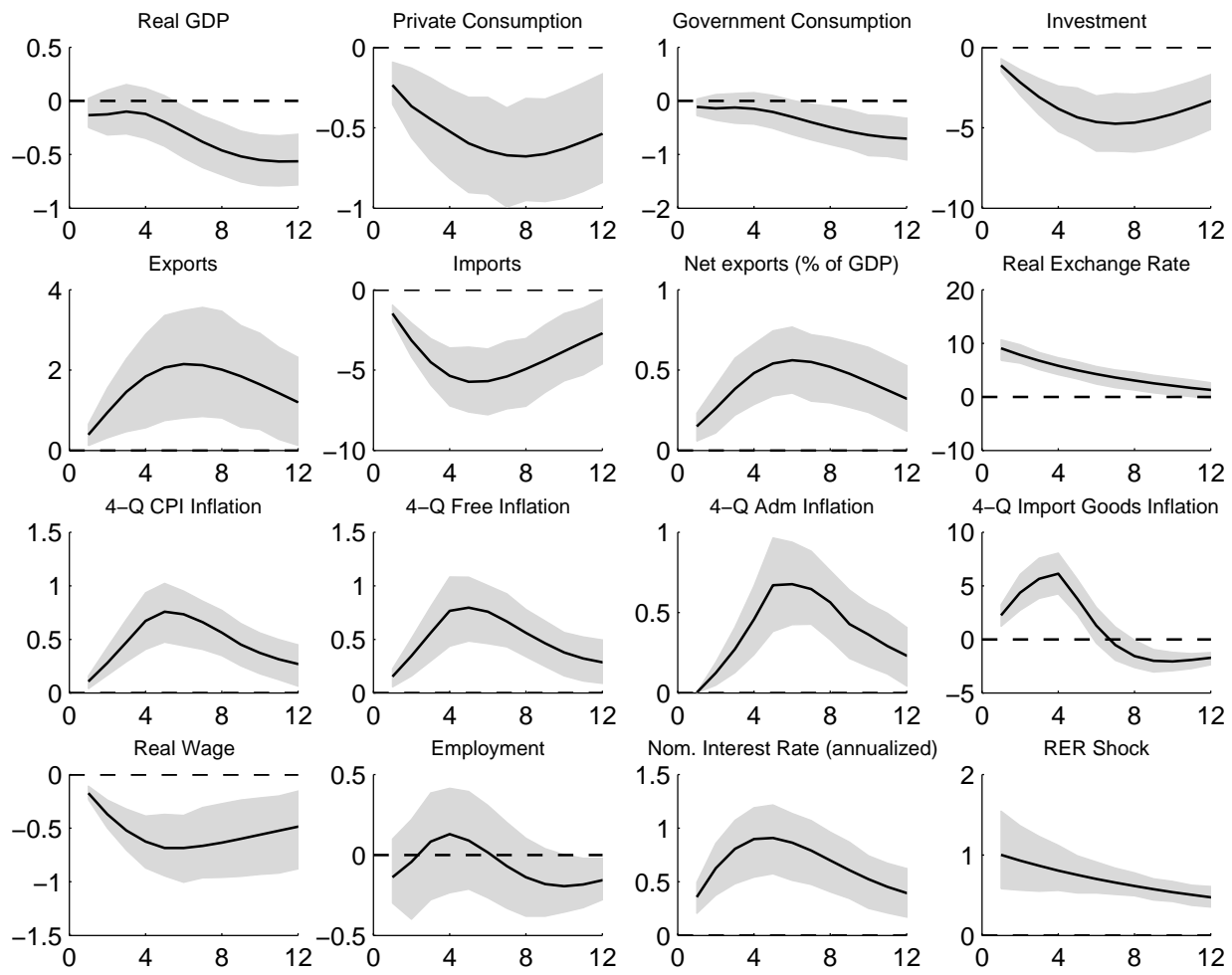
Figure 7: Impulse Responses to a Government Consumption Shock
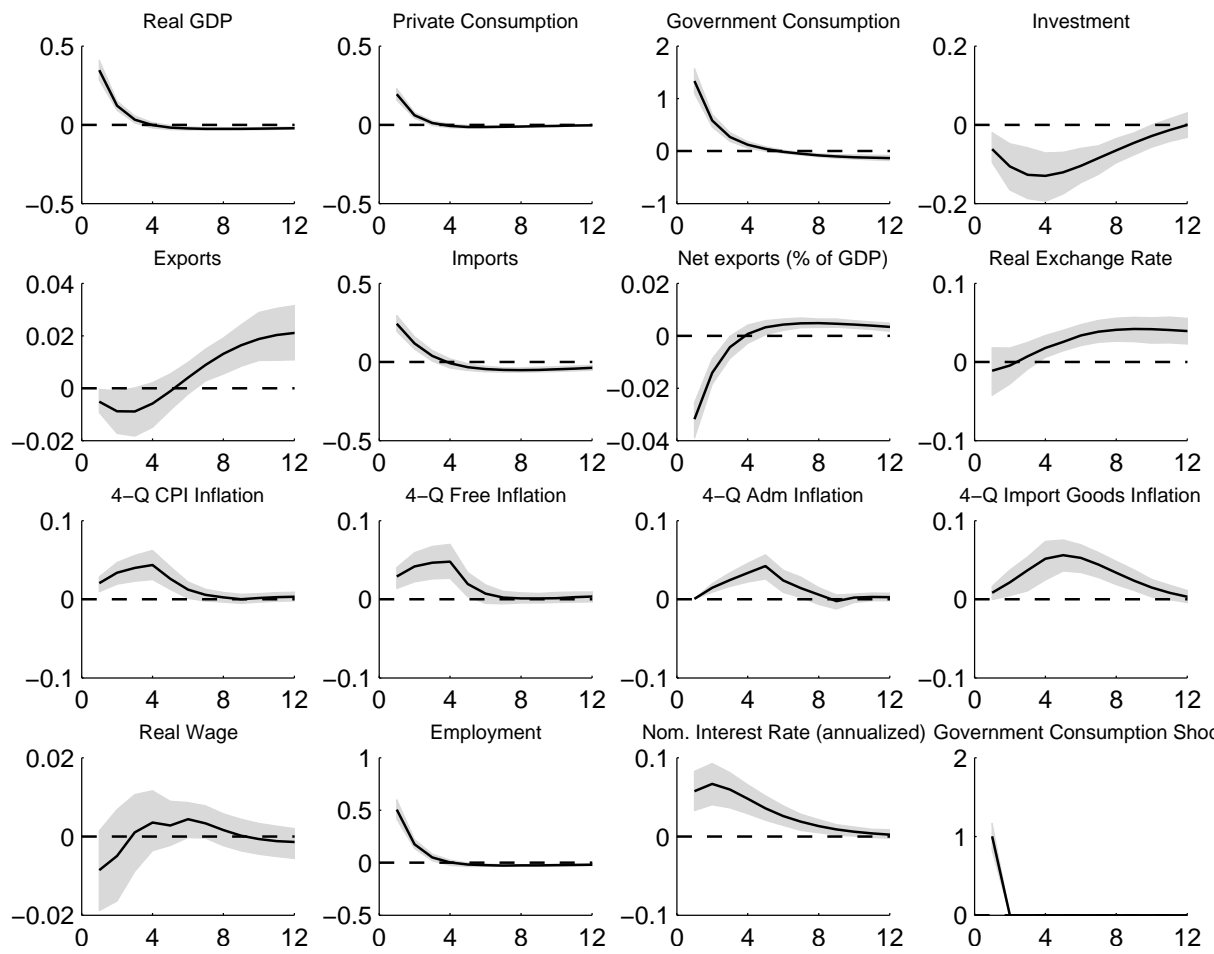
Figure 8. Impulse Responses to a Permanent Technology Shock
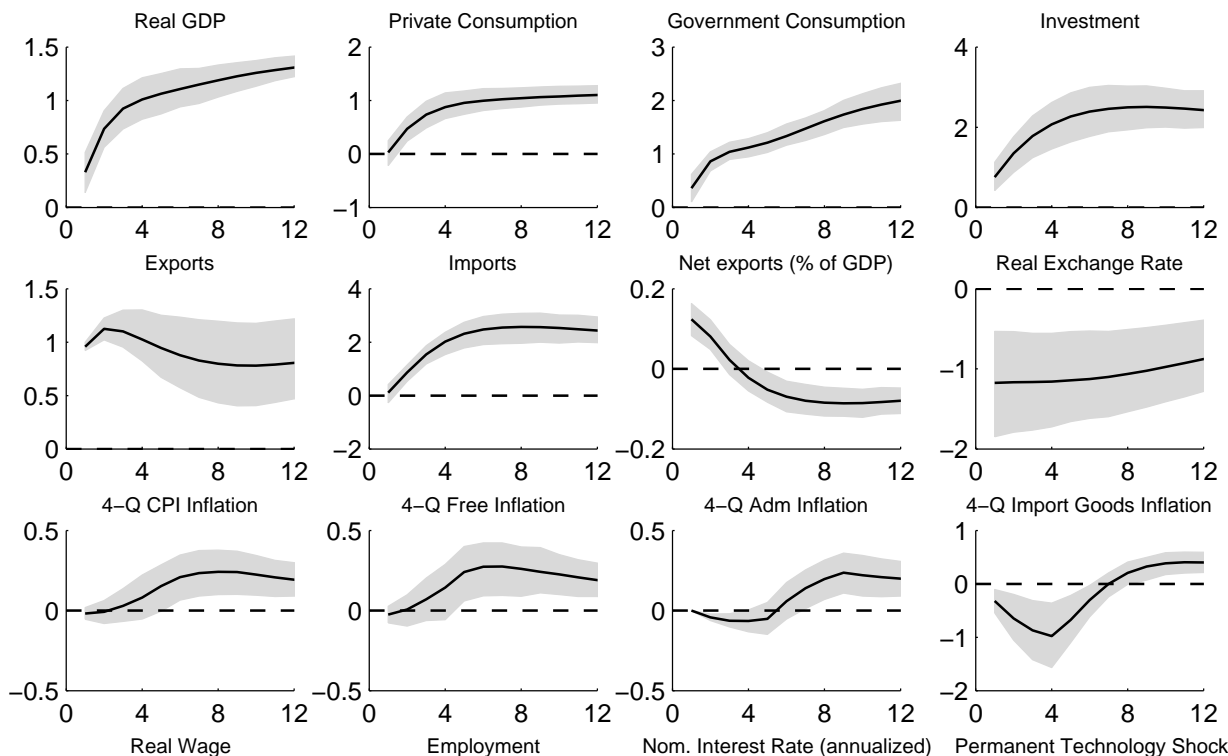

4-Q Import Goods Inflation
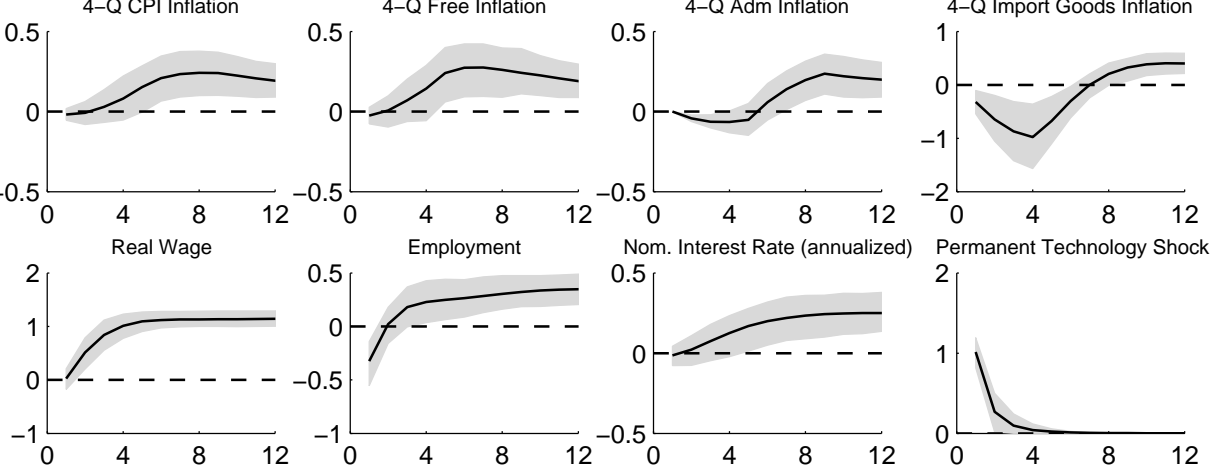
Figure 9. Root Mean Squared Errors of Forecasts

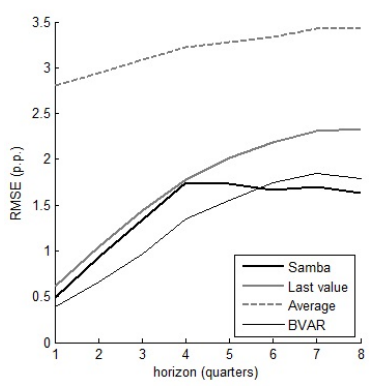

(a) CPI Inflation (four quarter)

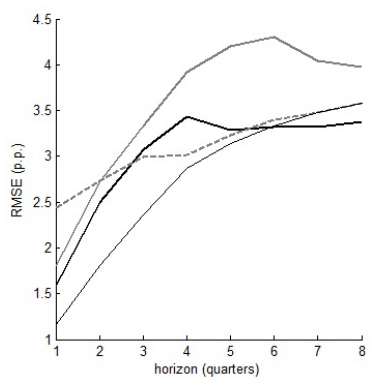

(b) Real GDP Growth (year-on-year)

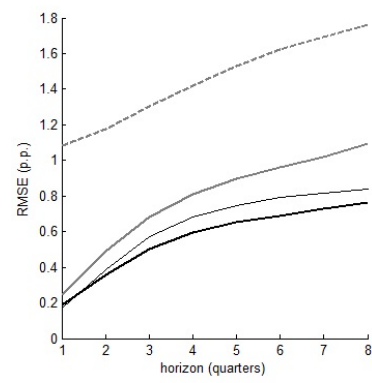

(c) Nominal Interest Rate (quarterly) 
Figure 10. Mean Forecast and Forecast Intervals for Two Episodes
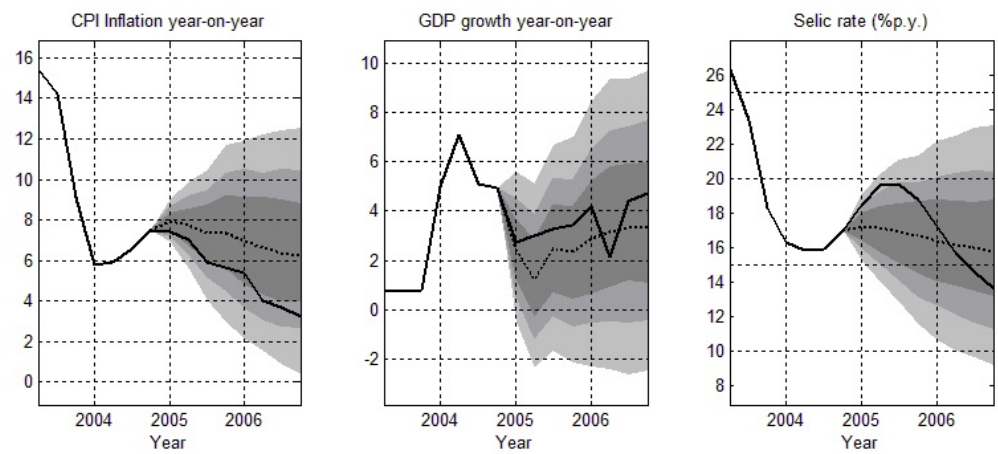

(a) Forecast with data up to 2004Q4
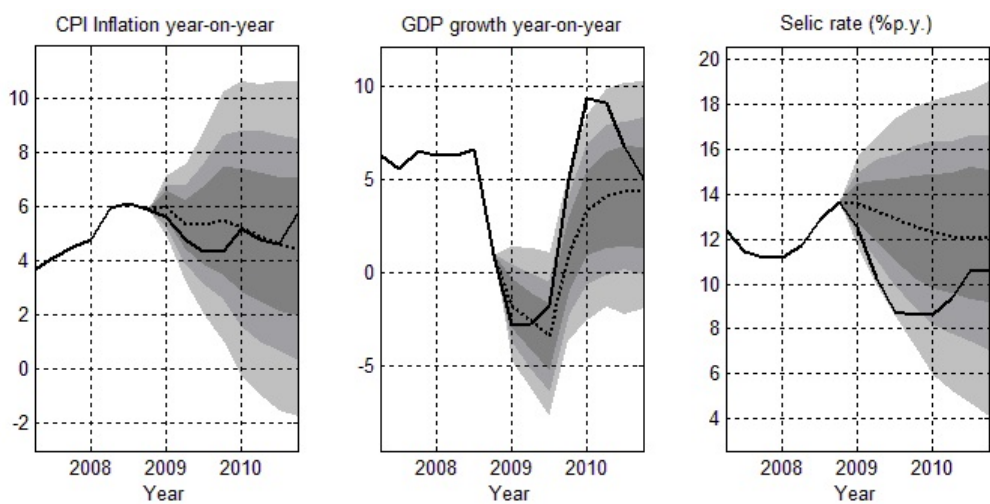

(b) Forecast with data up to 2008Q4 